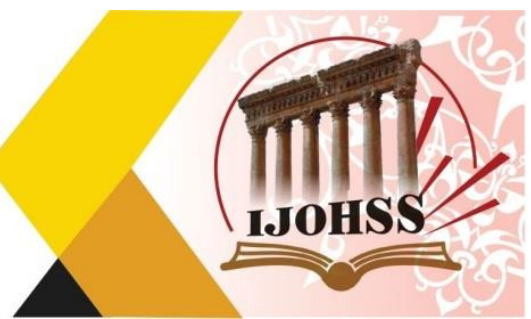

\title{
دعوى المدعى عليه في قانون المرافعات المدنية (دراسة تأصيلية تحليلية)
}

\author{
د. علي عبدالحسين منصور \\ محامي وخبير قضائي رسمي في رئاسة محكمة إستئناف البصرة البون الاتحادية

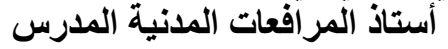 \\ كلية الكنوز الجامعة ـ العراق المعات العات \\ ali.abd@kunoozu.edu.iq
}

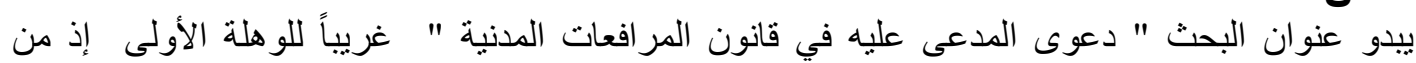

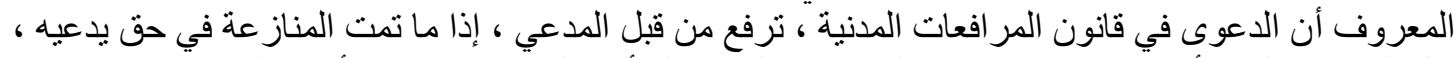

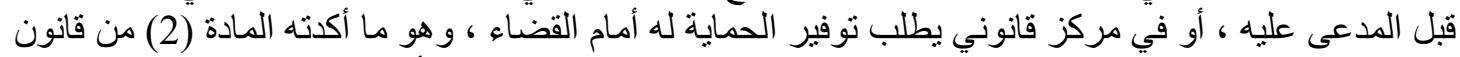

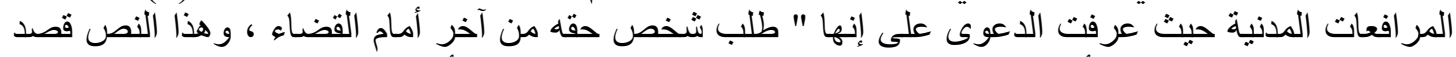

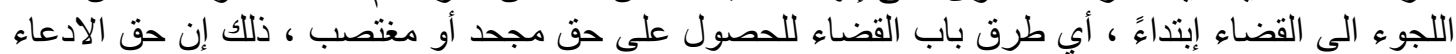

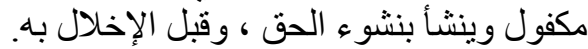

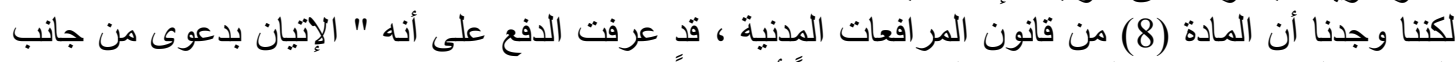

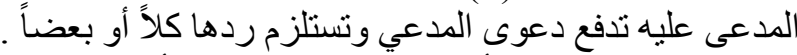

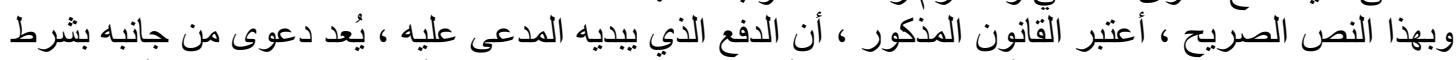

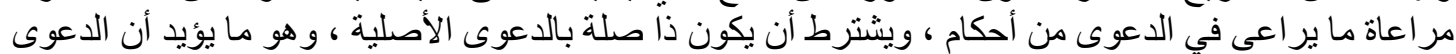

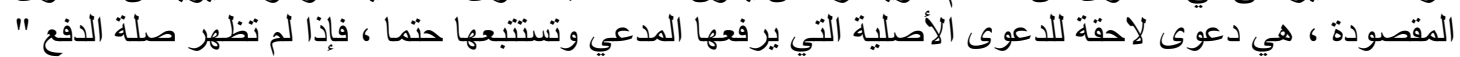

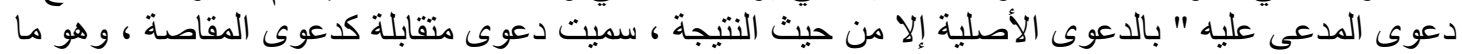

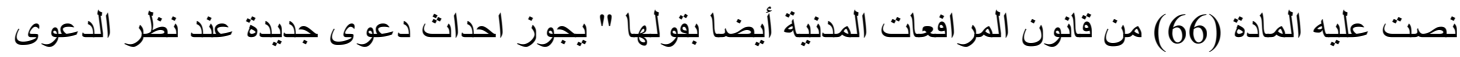

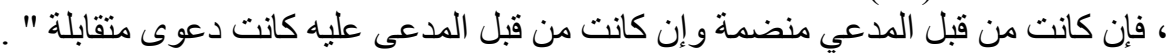

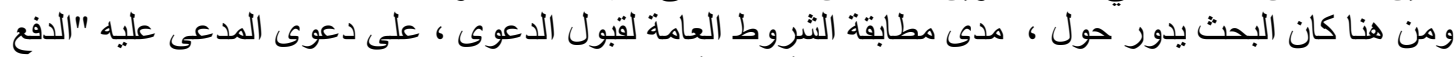

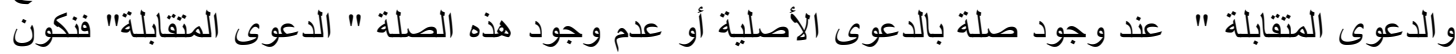
و الحالة هذه أمام دعوى لاحقة للاعوى الأصلية ، وهي دعوى الألية المدعى عليه.

الكلمات المفتاحية: المدعى عليه، المر افعات المدنية، قانون المر افعات. 


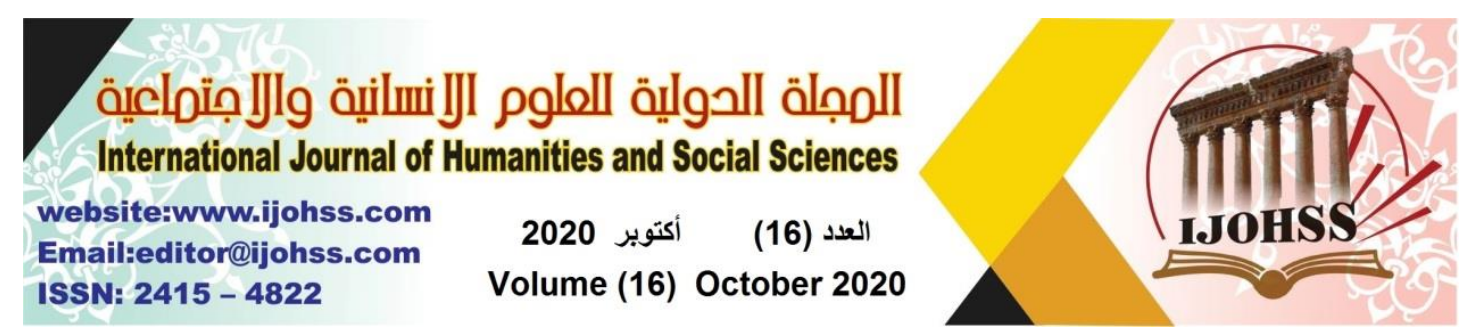

\title{
The defendant's lawsuit in the Civil Procedure Law (An analytical rooting study)
}

\author{
Dr. Ali Abdulhussein Mansoor \\ Lawyer and official judicial expert \\ Presidency of the Basra Federal Court of Appeal \\ Professor of civil defense teacher \\ AL-Kunooze University College - Iraq \\ ali.abd@kunoozu.edu.iq
}

\begin{abstract}
The title of the paper "Defendant's Case in the Civil Procedure Law" might seem strange at first glance, as it is known that the lawsuit in the Civil Procedure Law is filed by the plaintiff, if a dispute is made against his claim, before the defendant, or in a legal position requesting protection for him before the courts, this is confirmed by Article (2) of the Civil Procedure Law, where the lawsuit was defined as "a person's request for his right from another before the court , and this text is intended to resort to the judiciary in the first place, that is, to approach the door of the judiciary to obtain a right that is denied or usurped, because the right of claim is guaranteed and arises from the emergence of the right, and before breaching it .

However, we found that Article (8) of the Civil Procedure Law defines the defense as "bringing a lawsuit from the defendant to pay the plaintiff's lawsuit and necessitating its dismissal in whole or in part .

With this explicit text, consider the aforementioned law, that the defense presented by the defendant, is considered a case on his part, provided that the judgments taken into consideration in the case are taken into consideration, it is required that it be related to the original lawsuit, which confirms that the intended suit is a lawsuit subsequent to the original lawsuit filed by the plaintiff and it inevitably follows it, if the link of the "defendant's lawsuit" to the original lawsuit does not appear except in terms of the outcome, then a counterclaimed suit shall be called a set-off suit, , which is stipulated in Article (66) of the Civil Procedure Law also by stating, "A new lawsuit may be brought up when the lawsuit is heard. If the plaintiff was joined by the plaintiff, and if it was by the defendant, it was a cross case ".

Hence, the research revolved around the extent to which the general conditions for accepting the lawsuit were met by the defendant's lawsuit "the payment and the opposing lawsuit" when there is a link to the original lawsuit or the absence of this link with the "counter-suit", so we are and this case is before a lawsuit subsequent to the original lawsuit, which is the defendant's suit .
\end{abstract}

Keywords: Defendant, civil procedure, case law. 
مقدمة

بعد الحمد و الثكر لله سبحانه وتعالى و الثناء عليه لفضله ونعمه التي لا تحصى سوف نقسم هذه المقدمة الى

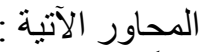

\section{أولاً : مدخل تعريفي بموضوع : البأية البحث}

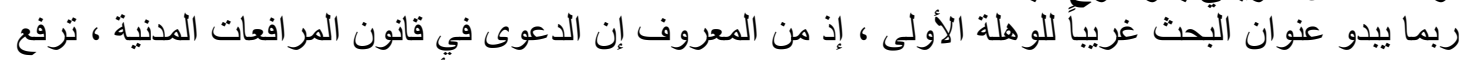

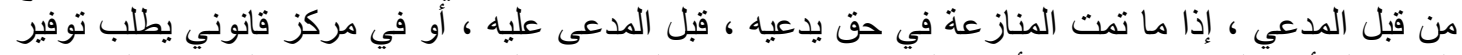

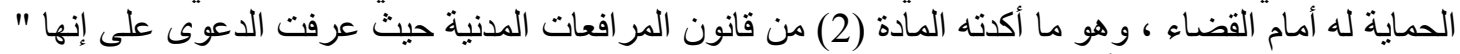

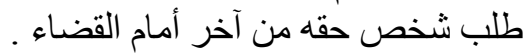

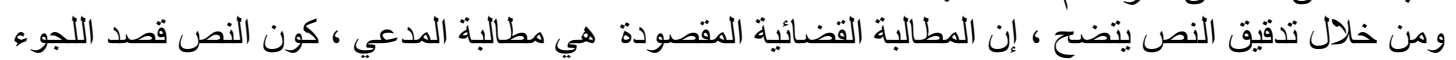

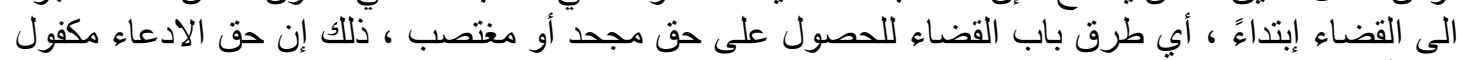

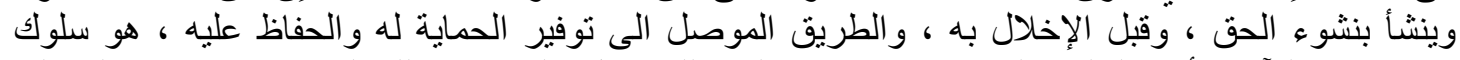

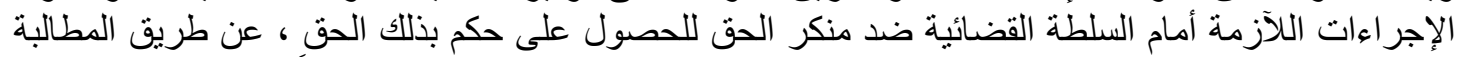

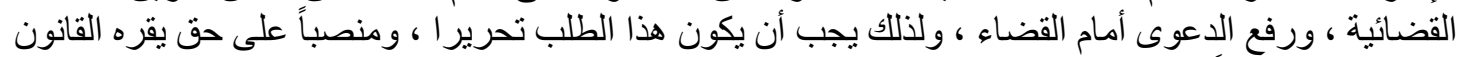

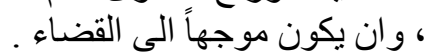

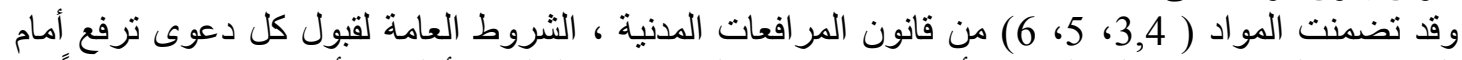

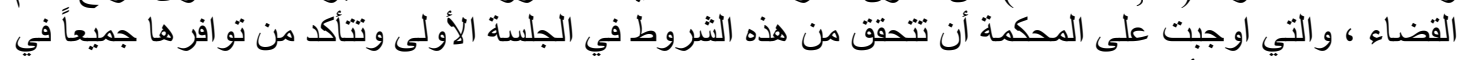

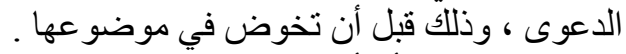

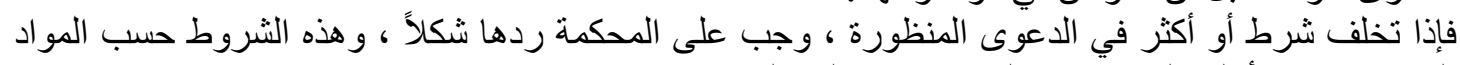

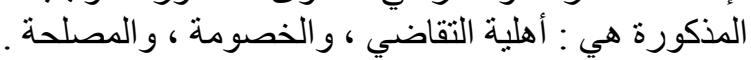

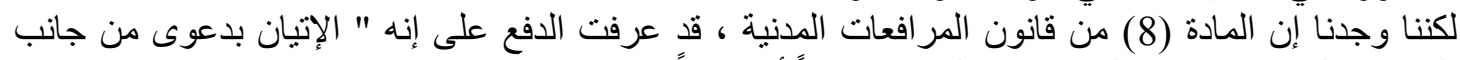

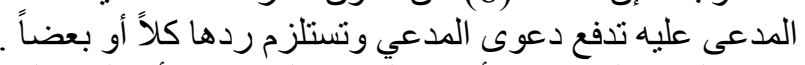

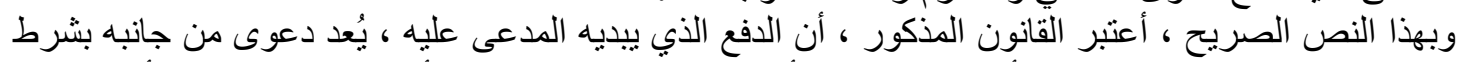

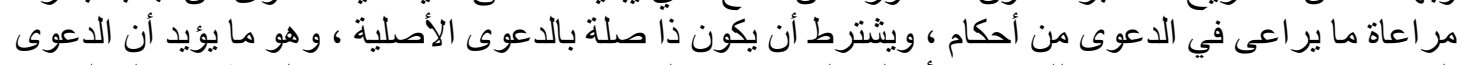

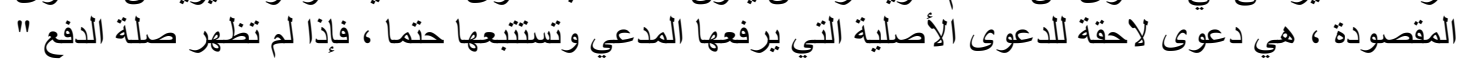

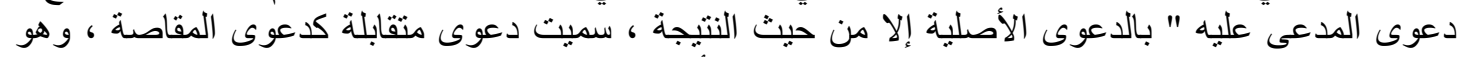

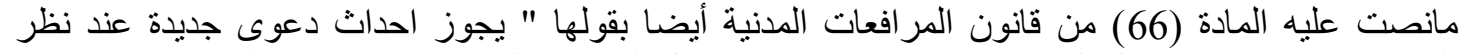

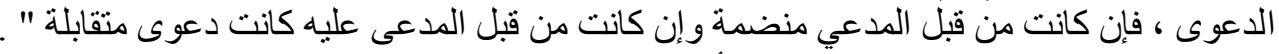

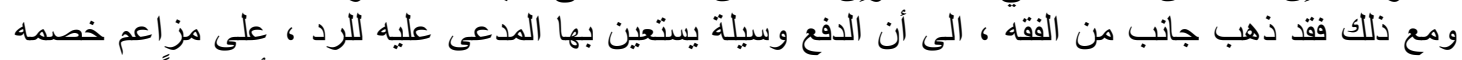

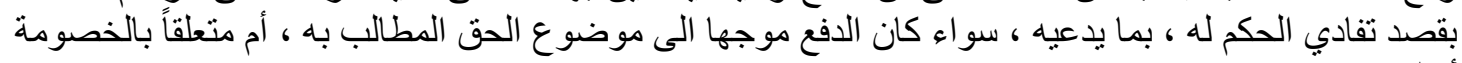

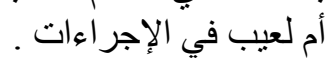

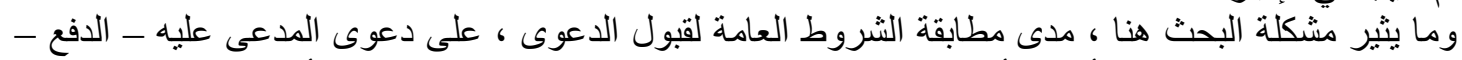

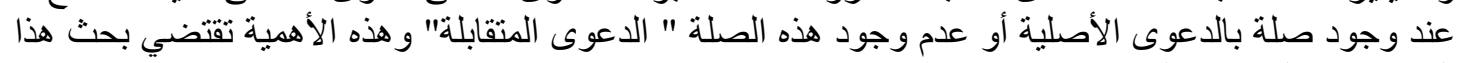

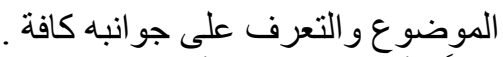
ثانياً : أهداف البحث وأهرف على أهيته

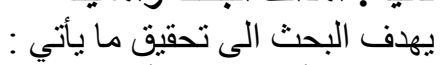

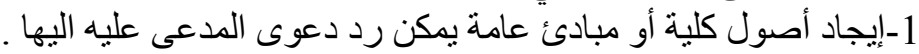

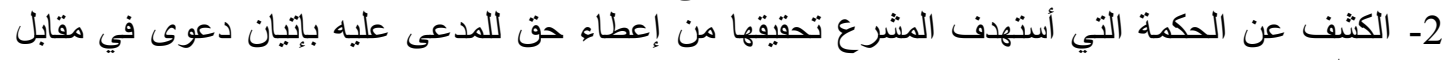

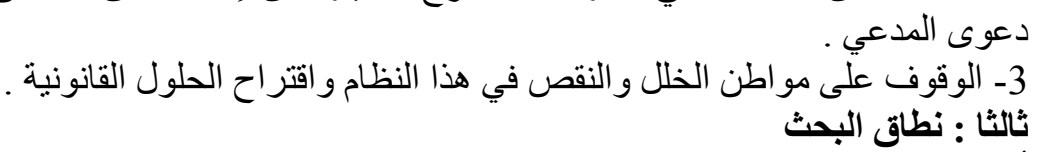

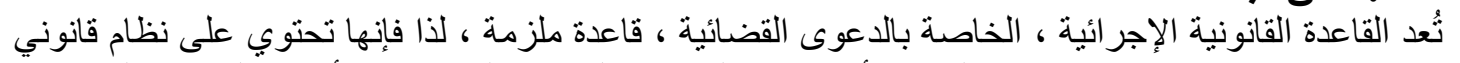

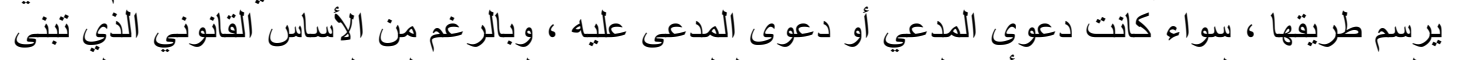

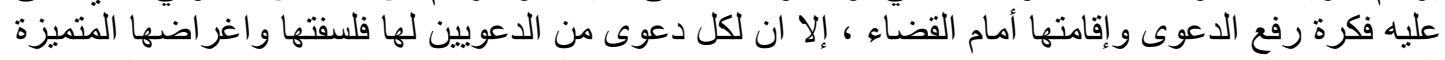

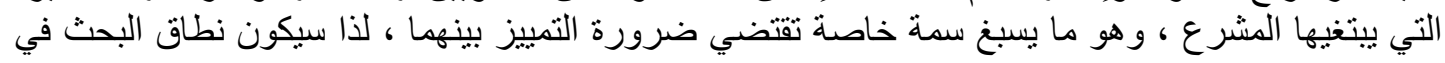


العدد (16)

Volume (16) October 2020

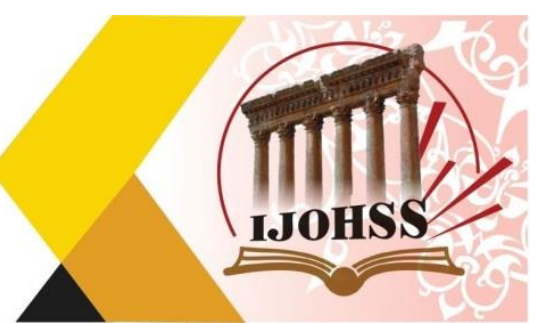

أطار دعوى المدعى عليه في قانون المرافعات الددنية ، مع الإشارة الى القوانين الأخرى بطريقة تتفق مع ما

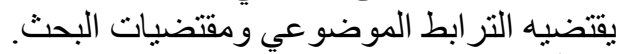

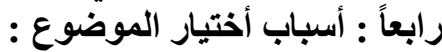

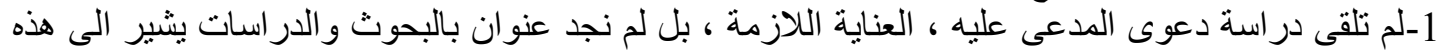

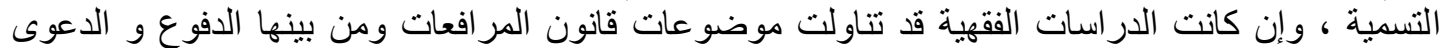
المتقابلة . 2-جاء تنظيم المشرع العر اقي بالنسبة لدعوى المدعى عليه دقيقا في بعض جو انبه ، إلا أن جو انبه الأخرى تخلو

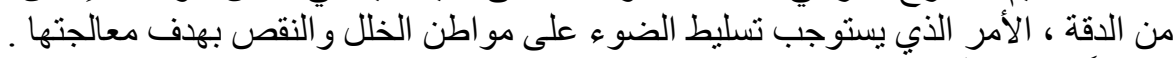

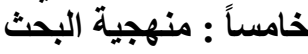

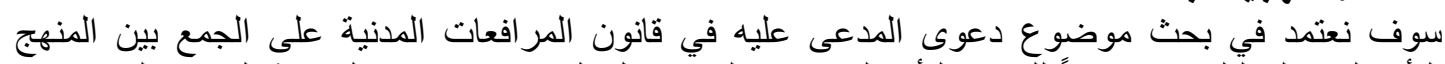

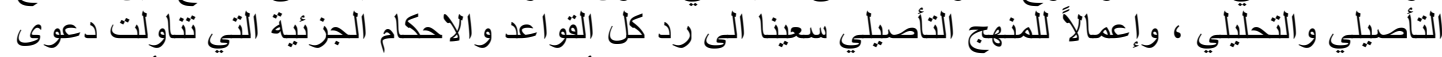

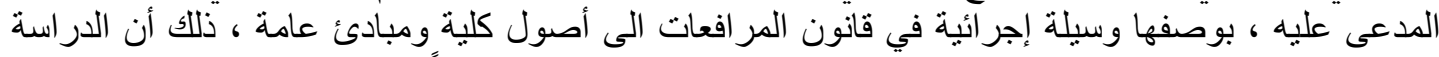

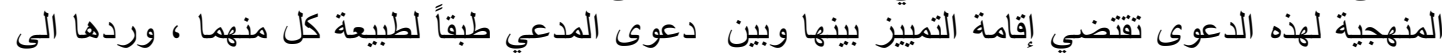

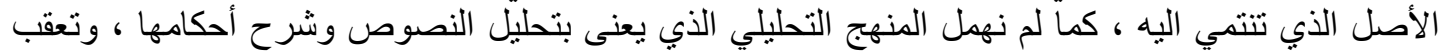
جزئياتها وتحديد آثار ها اليها

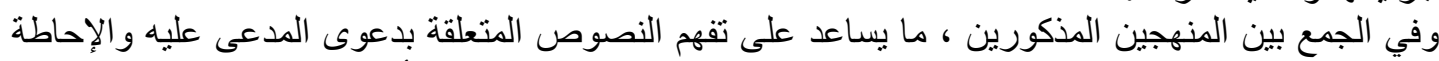

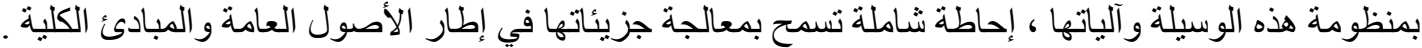
سادسا : هيكلية البحث البك

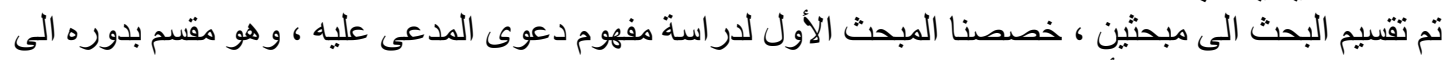

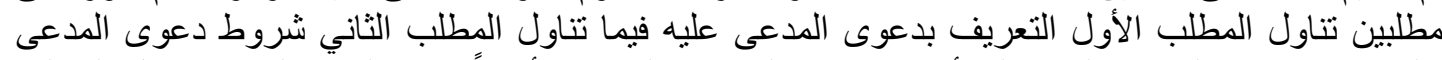

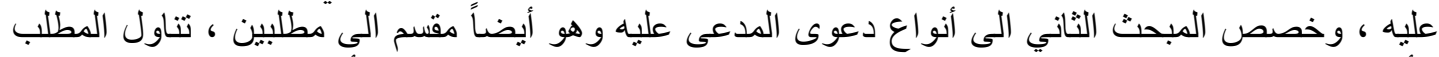

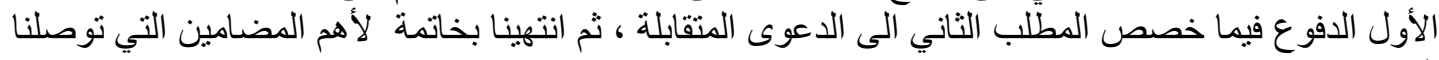

\section{المبحث الأول \\ مفهوم دعوى المدعى عليه في قانون المرل المرافعات المدنية}

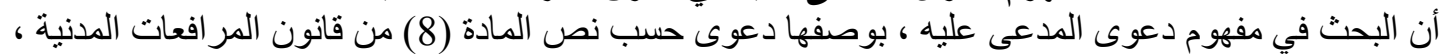

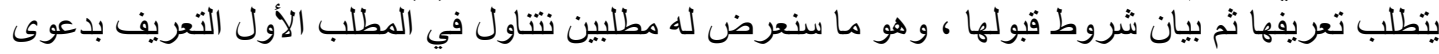

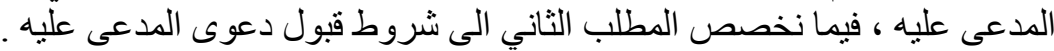

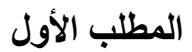

التعريف بدعوى المدعى عليه

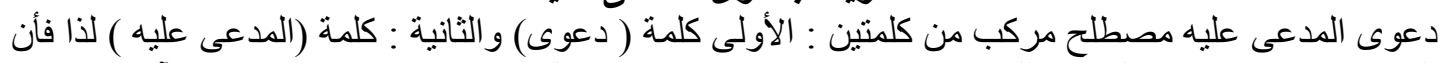

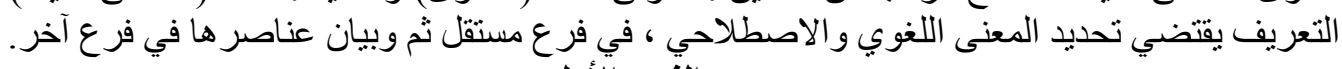

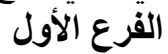

\section{التعريف اللغوي والاصطلاحي}

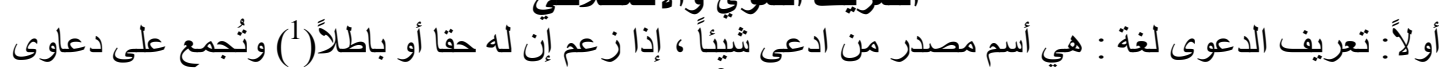

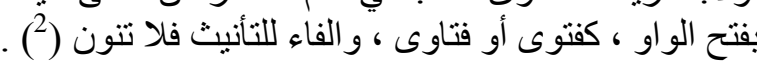

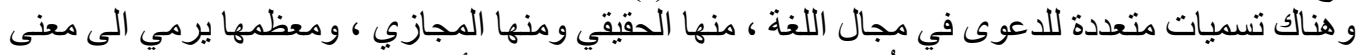

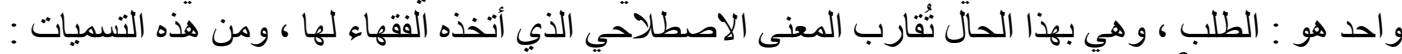

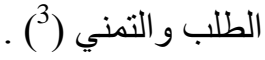

1'-أنظر: جمال الدين محمد مكرم أبن منظور الافريقي المصري ، لسان العرب ، ج5،ط6، دار صادر، بيروت ، لبنان ،

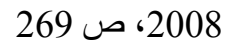
2 2 ـأنظر العلامة الثيخ سليمان بن محمد بن عمر، حاثنية اليجيري على شرح منهج الطلاب للإمام زكريا بن محمد أحمد

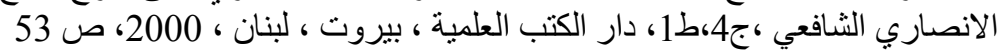




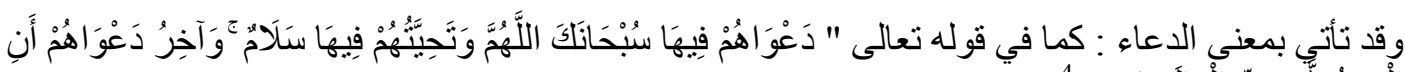

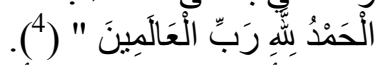

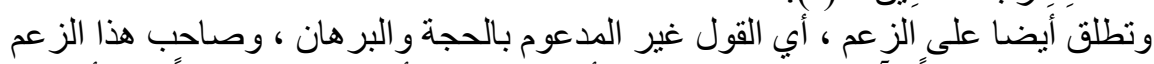

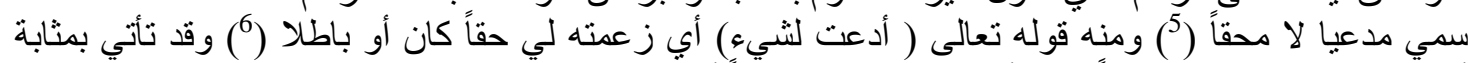

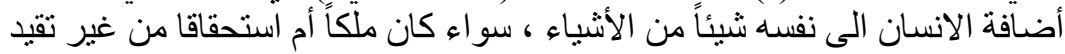

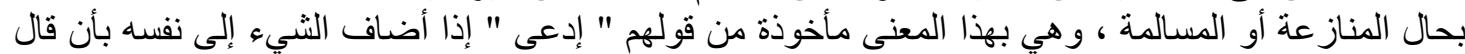

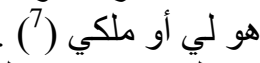
و هناك من يذهب ألى ملى ألى ألى الدعوى في اللغة " قول يقصد به الانسان إيجاب حق على غير نفسه " أما بالنسبة

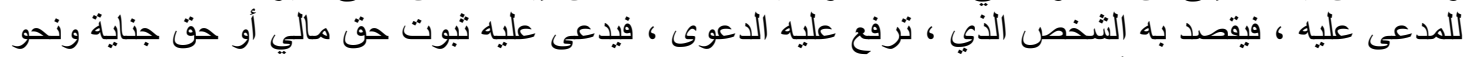

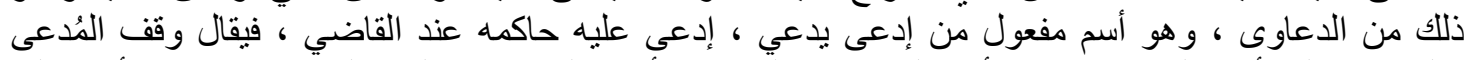

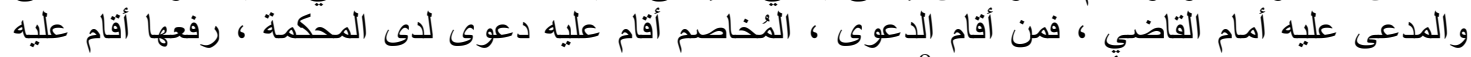

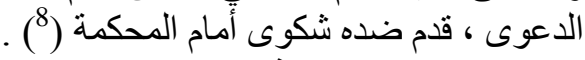

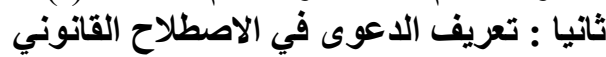

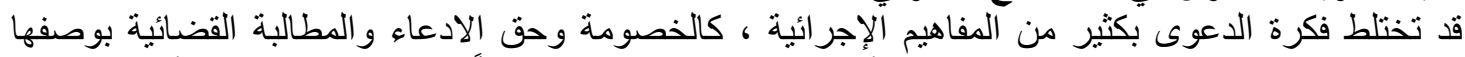

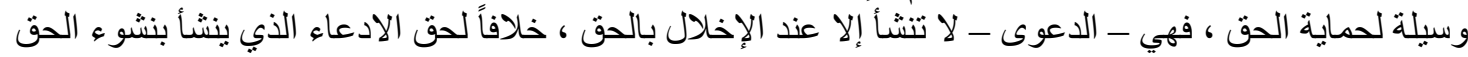

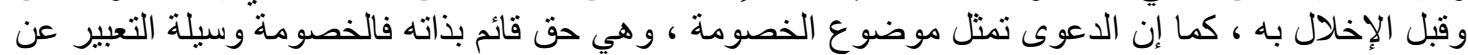

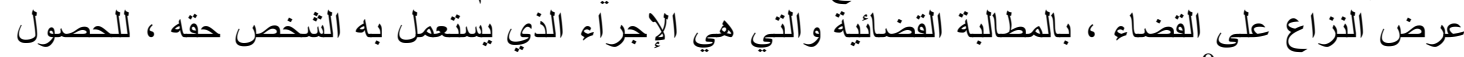

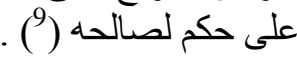

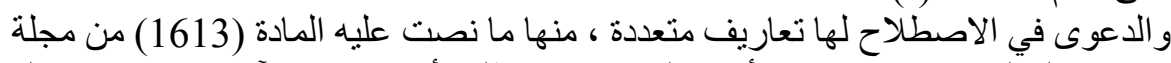

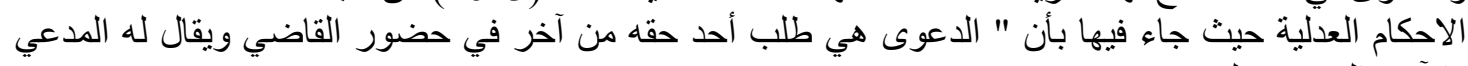

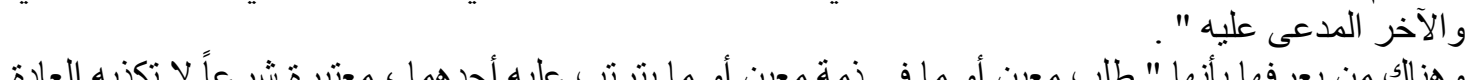

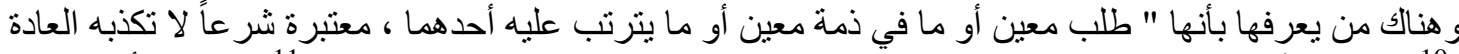

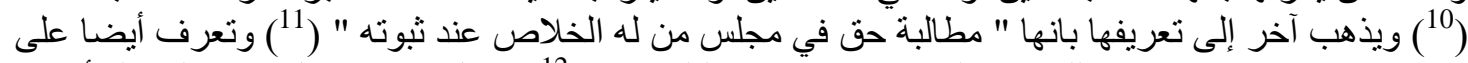

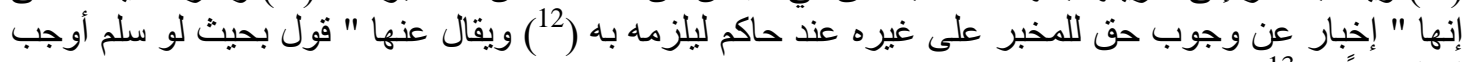

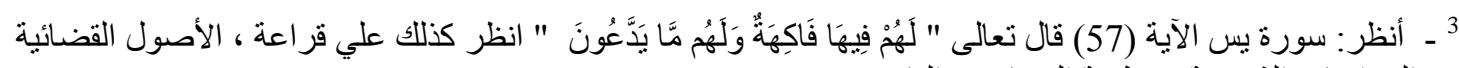

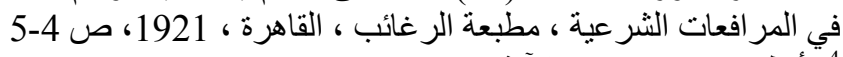

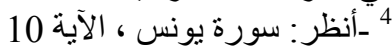

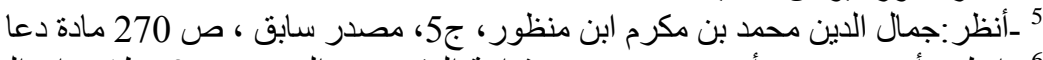

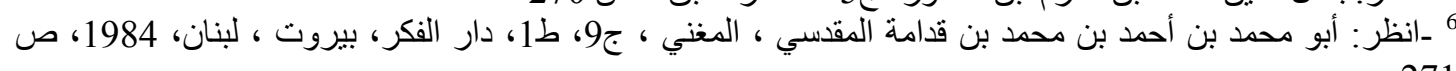

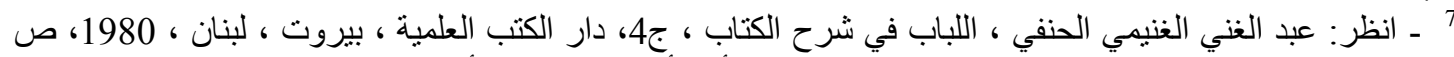

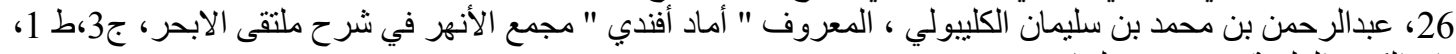

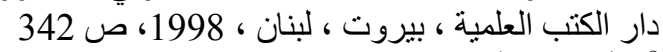

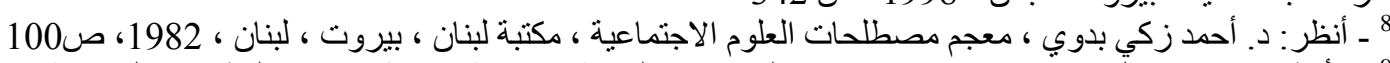

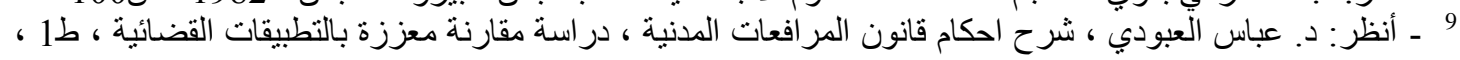

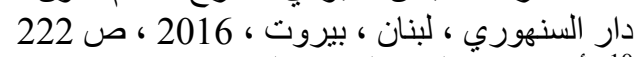

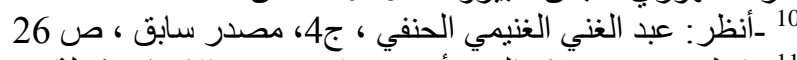

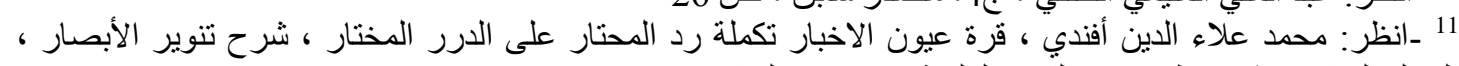

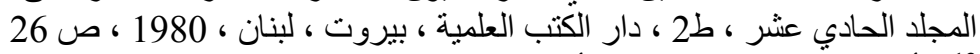

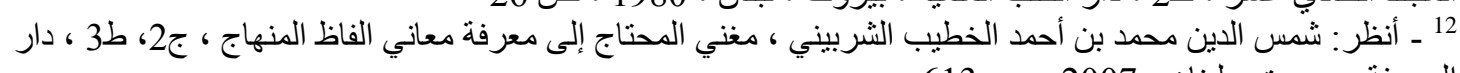

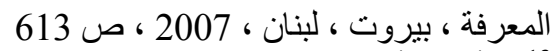
13 ـ أنظر : أبو عبداله محمد بن عبدان عالله الخرشي ، شرح الخرشي على مختصر قليل ، ج7 ، دار صادر ، بيروت ، لبنان ، 


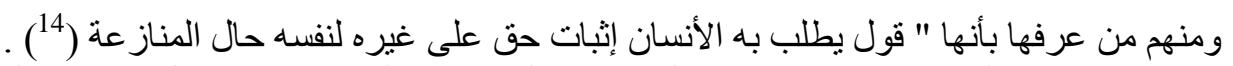

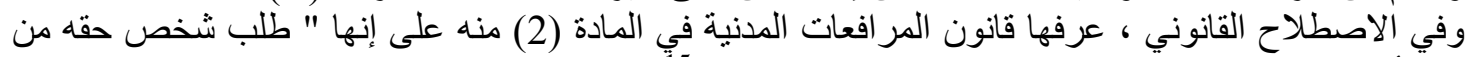

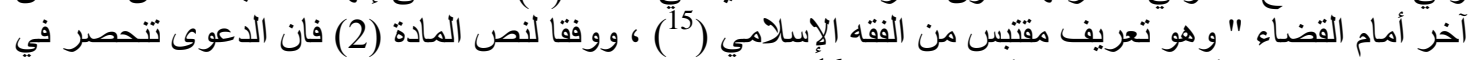

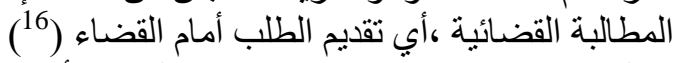

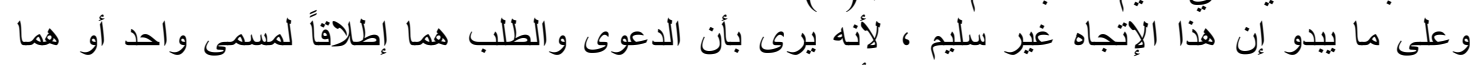

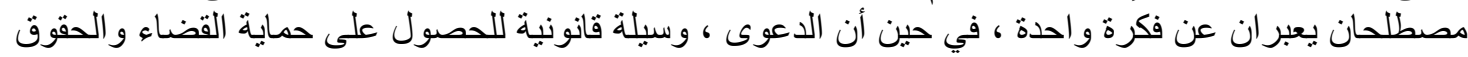

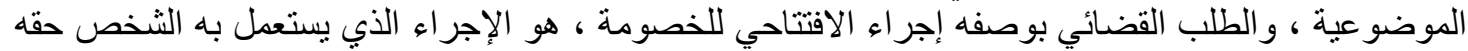
في رفع الدعوى .

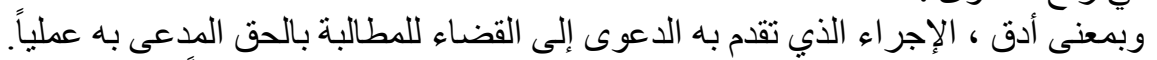

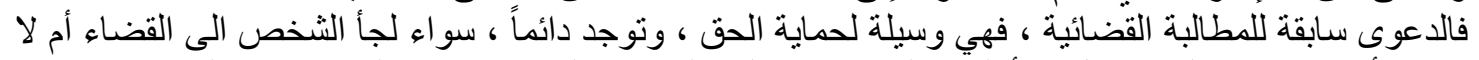

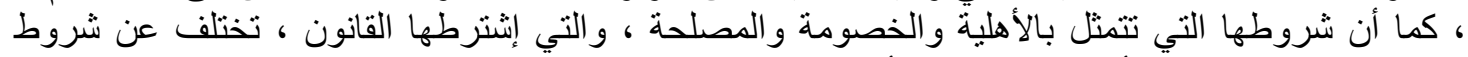

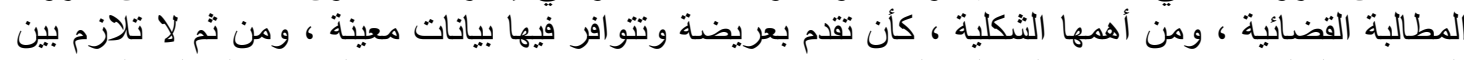

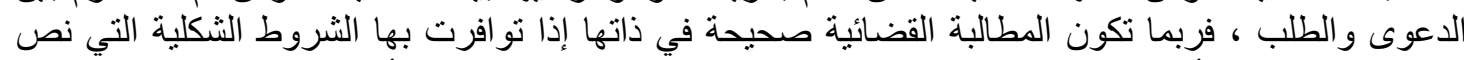

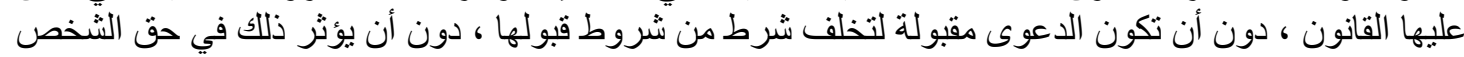

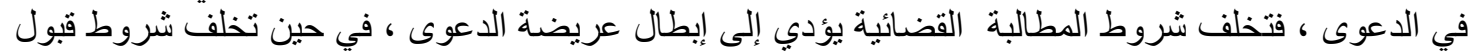

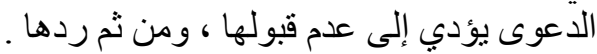

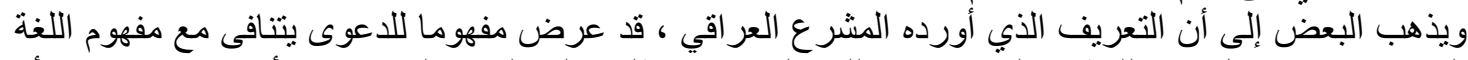

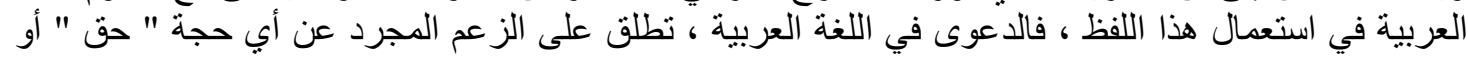

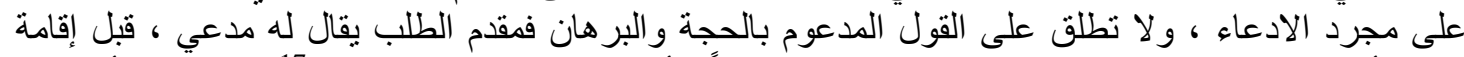

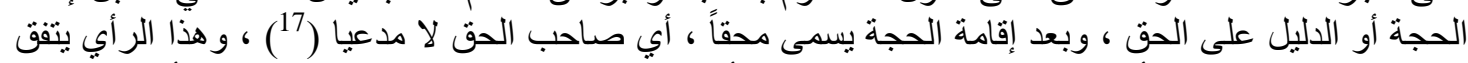

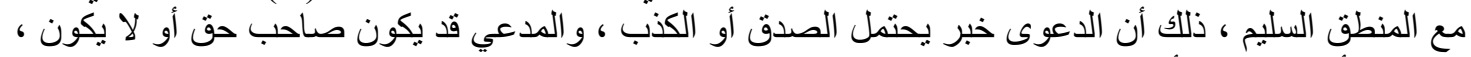

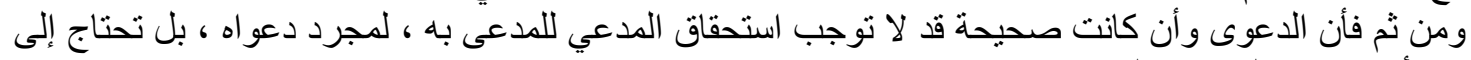

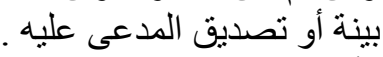

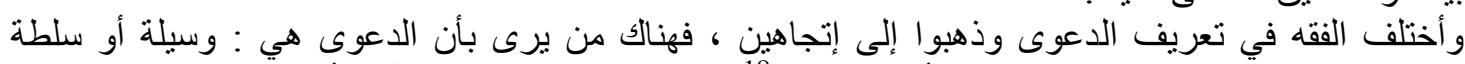

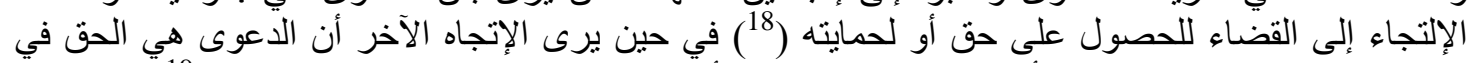

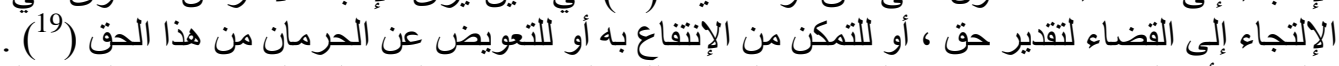

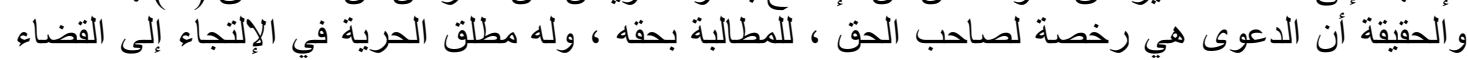

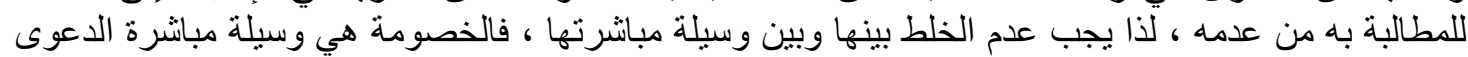

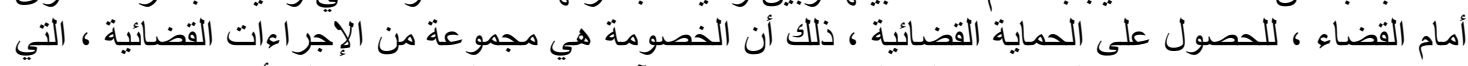

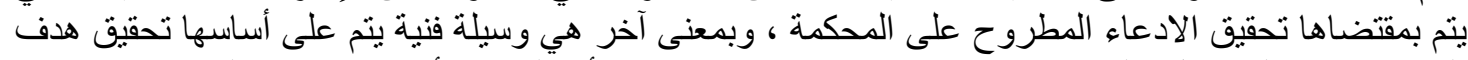

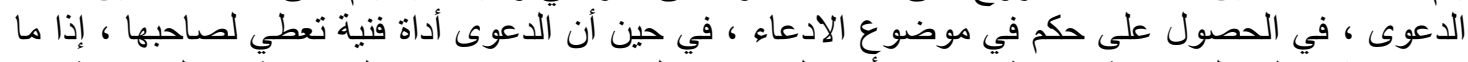

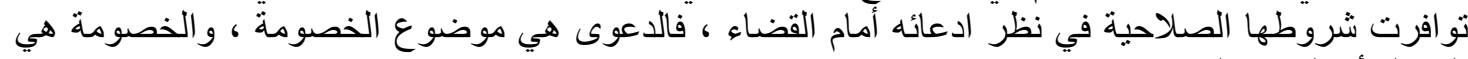
الوسيلة أو الو عاء الذي يحتويها الهئ.

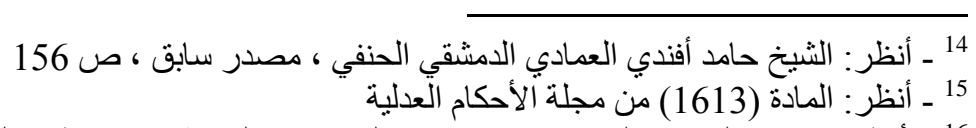

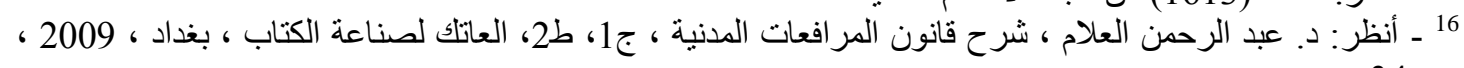
34 ص 34 17 ـ أنظر: د. اجياد ثامر الدليمي ، إبطال عريضة الدعوى للإهمال بالواجبات الإجرائية ، ط1، بيت الحكمة ، بغداد ،

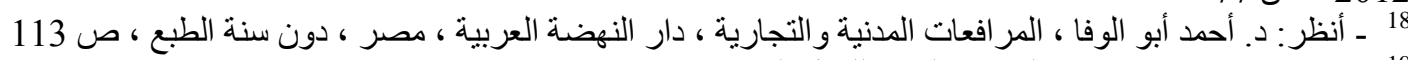

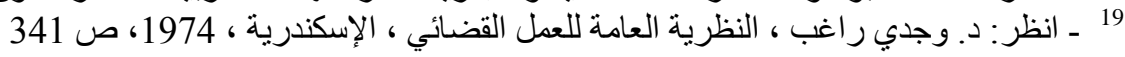




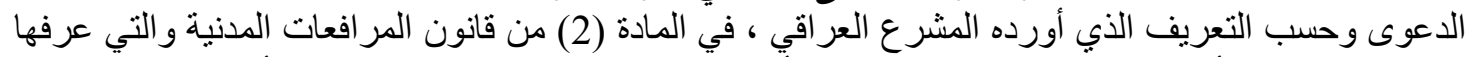

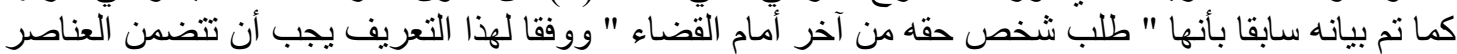
الآتية :

1 - 1طلب تحريري ، فلا يجوز أن يكون الطلب شفاهاً .

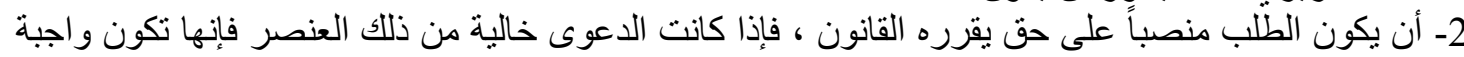

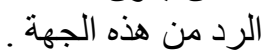

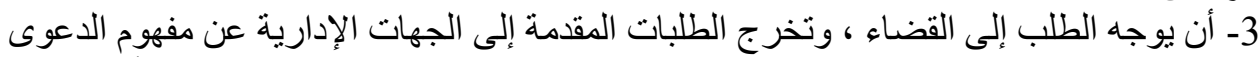

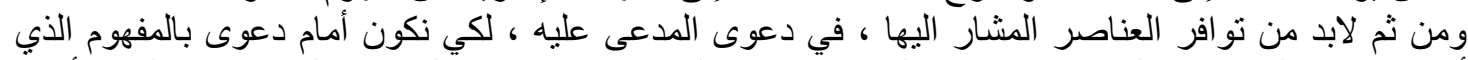

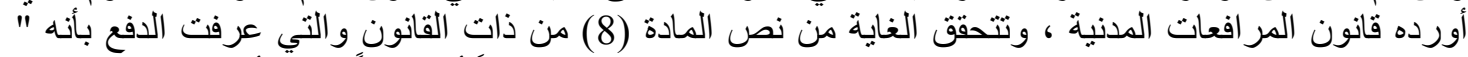

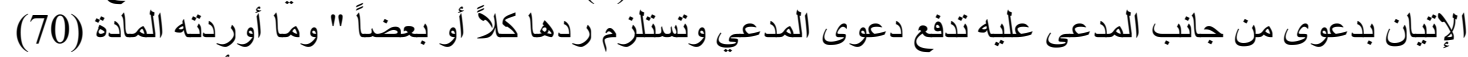

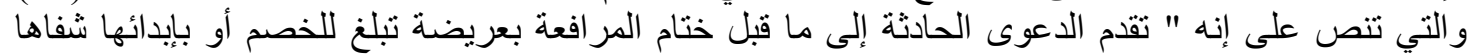

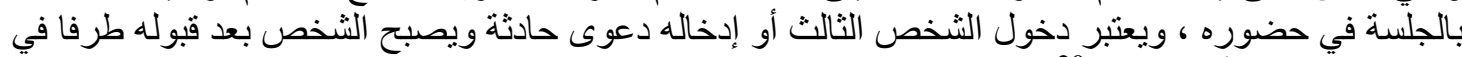

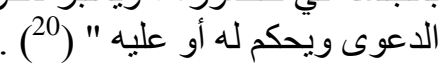

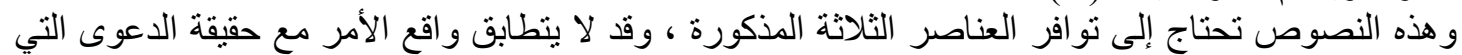

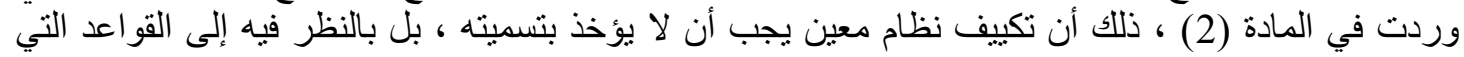

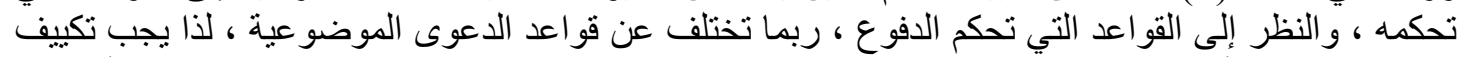

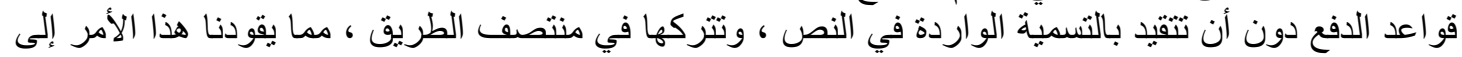

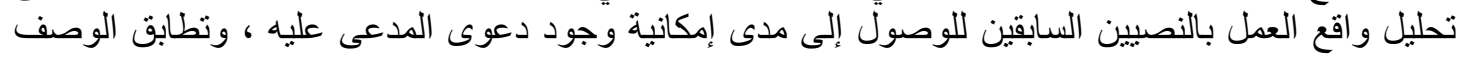

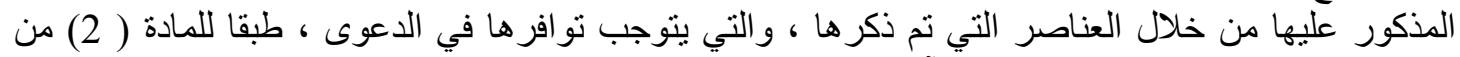

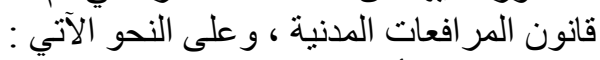

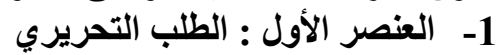

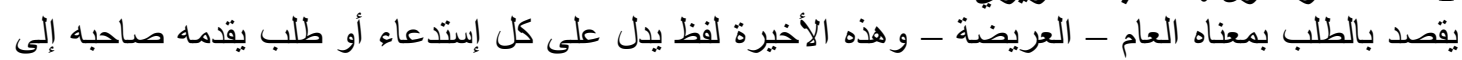

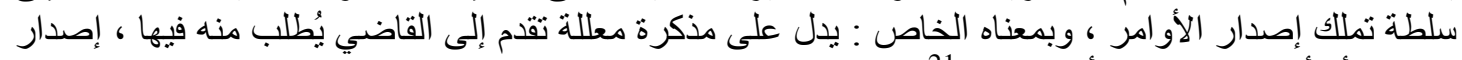

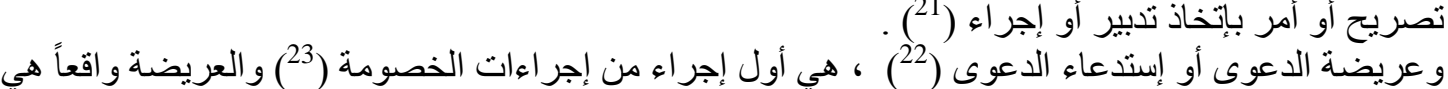

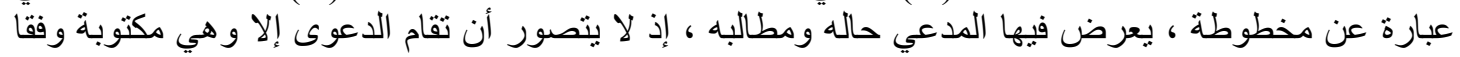

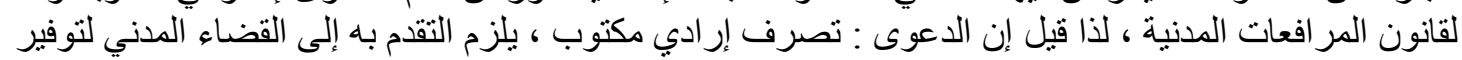

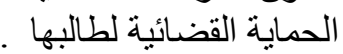

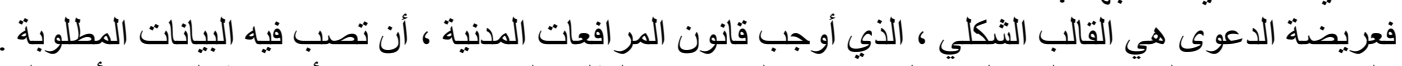

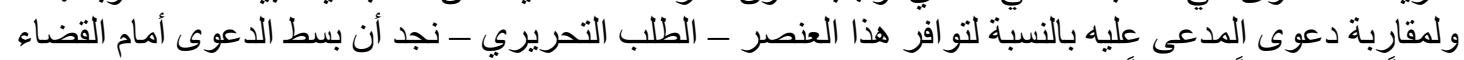

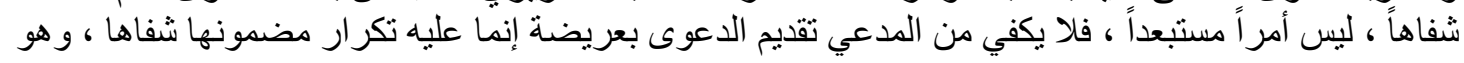

20

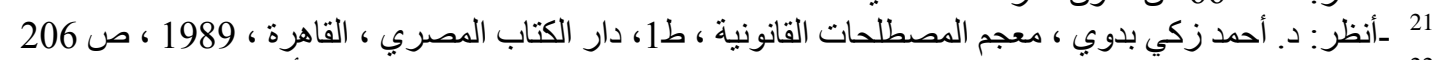

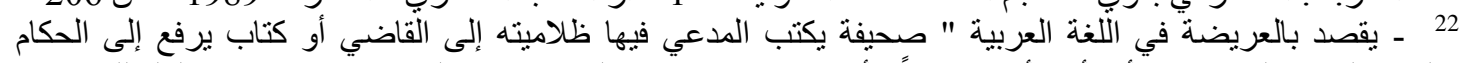

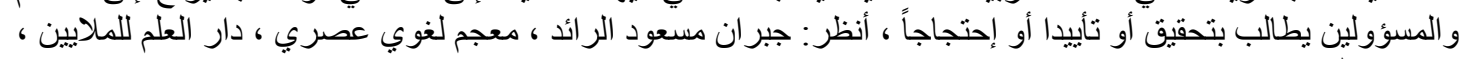

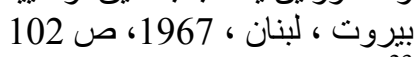

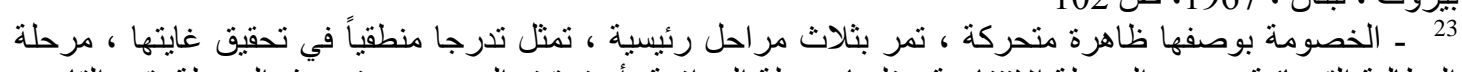

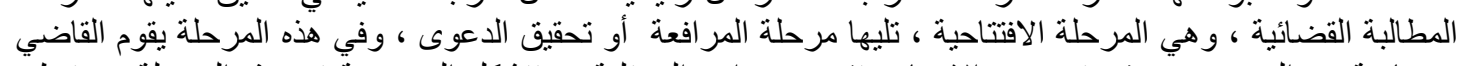

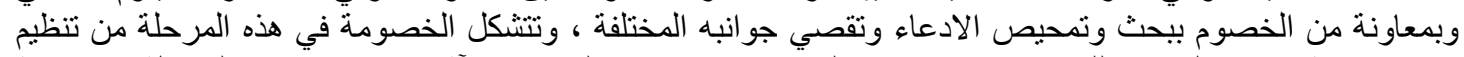

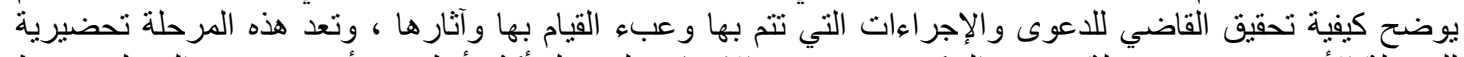

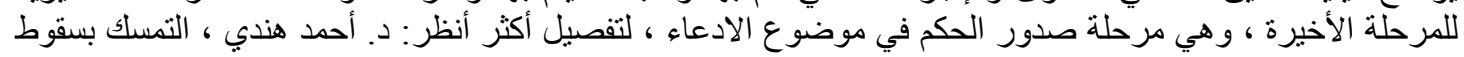
الخصومة ، دار النهضة العربية ، القاهرة ، 1991، ص 14 


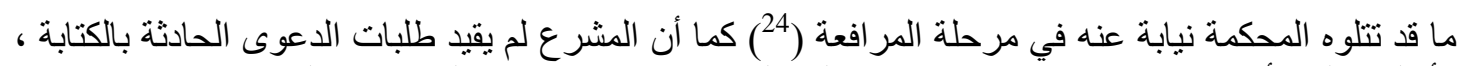

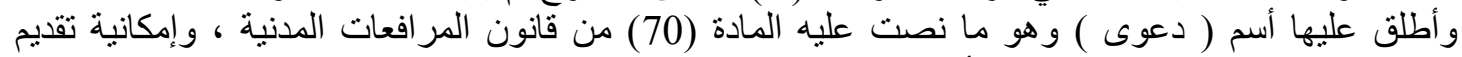

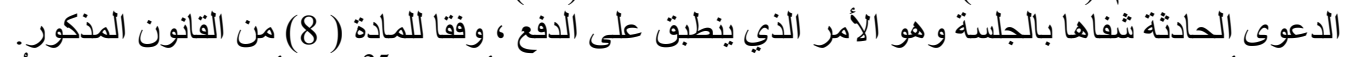

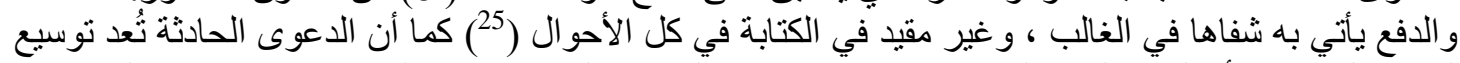

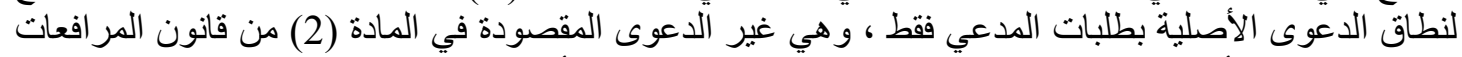

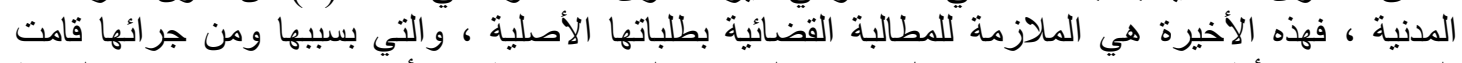

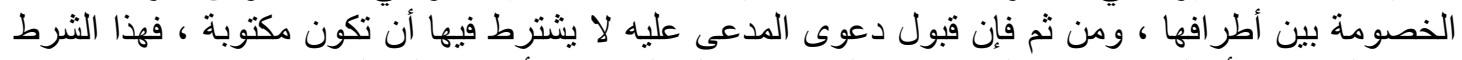

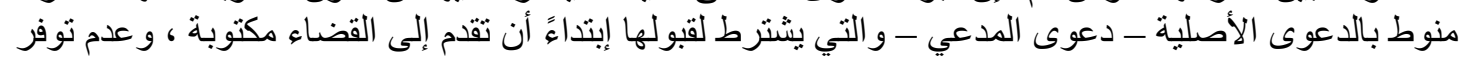

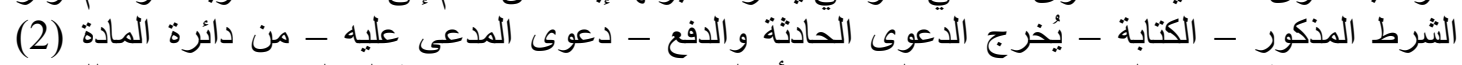

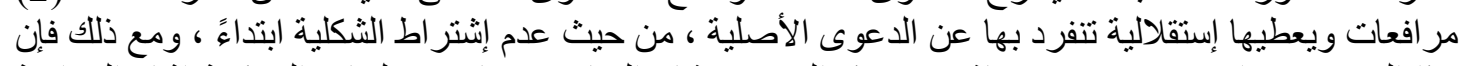

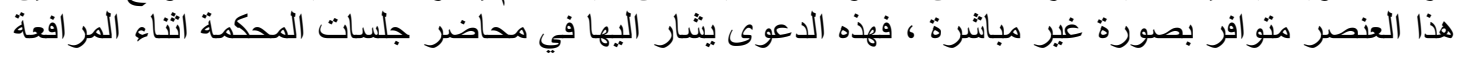

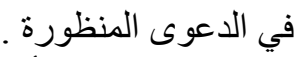

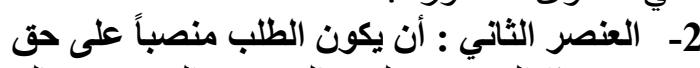

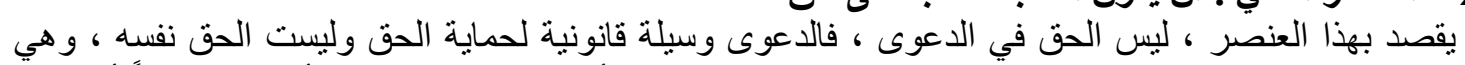

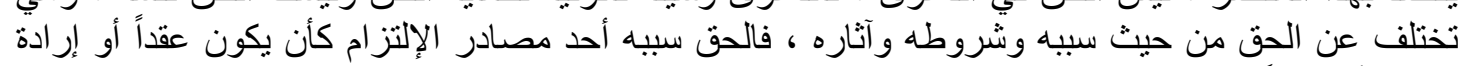

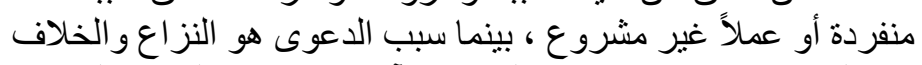

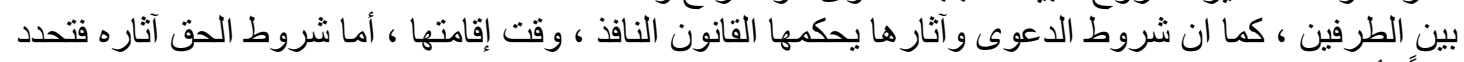

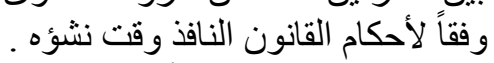

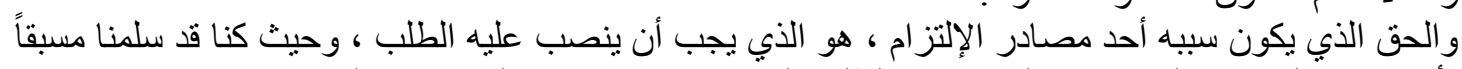

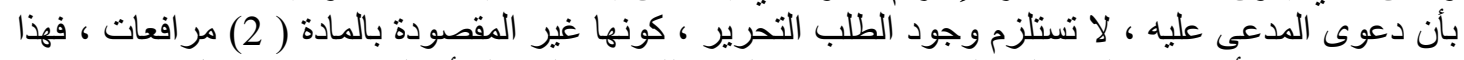

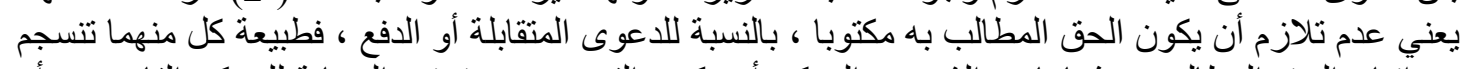

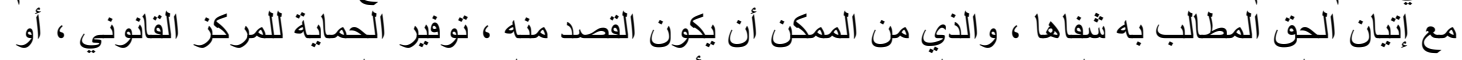

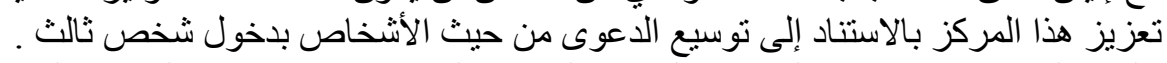

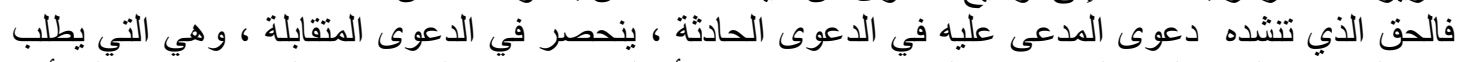

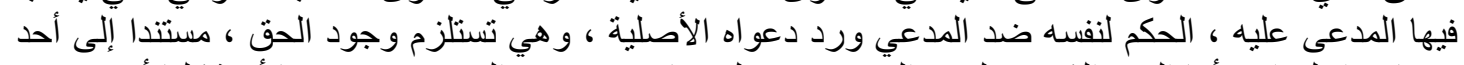

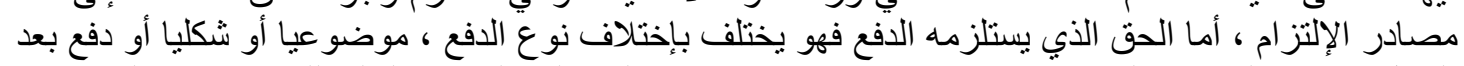

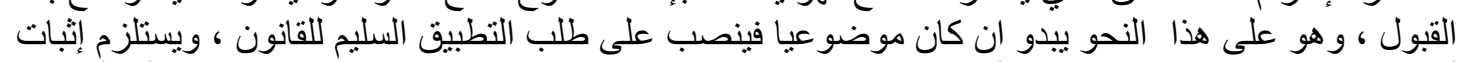

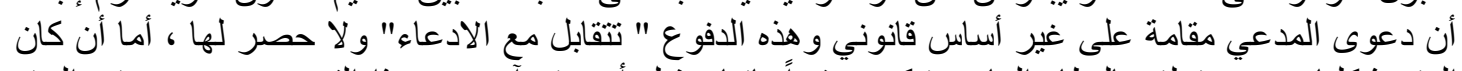

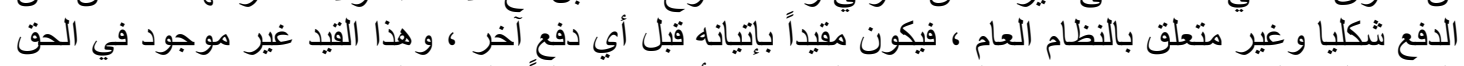

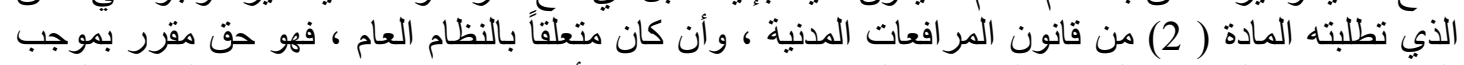

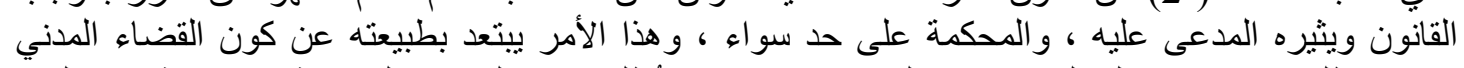

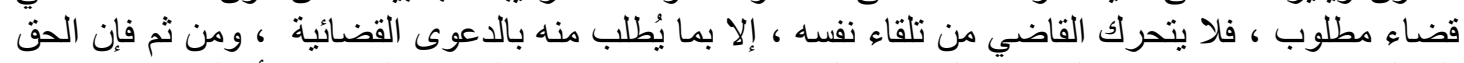

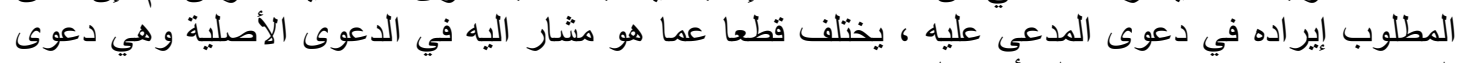

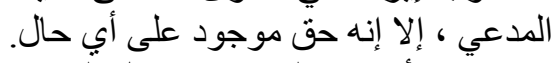

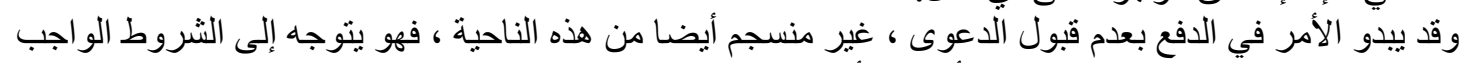

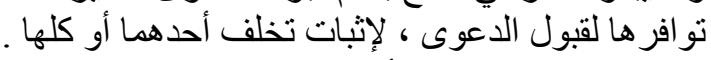

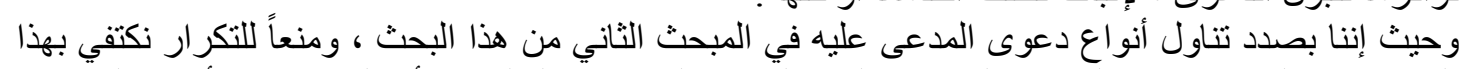

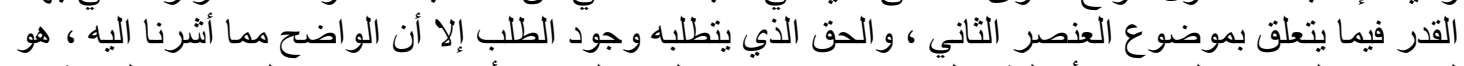

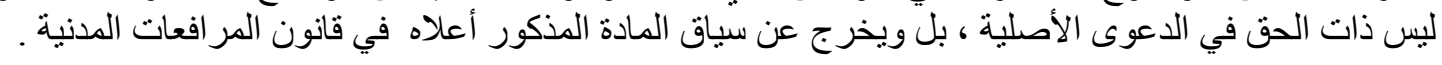

24 ـ تجدر الإنشارة إلى إن الو اقع العملي في المحكمة ، بأن تنلو المحكمة نيابة عن المدعي ما يلي : كرر الدعي ( وكيل

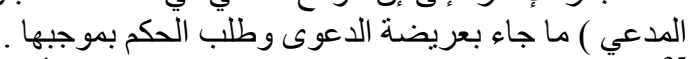

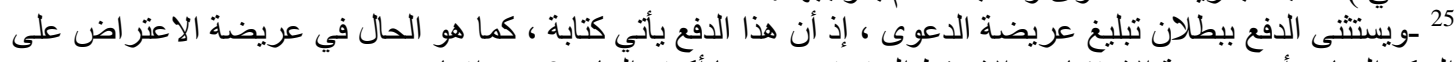

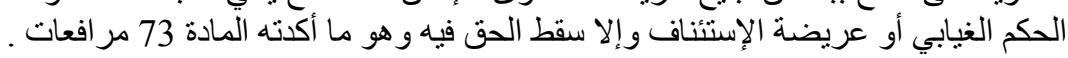




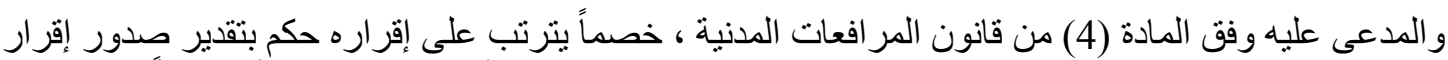

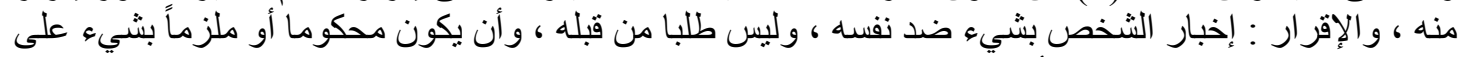

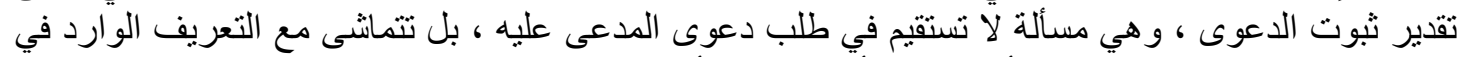

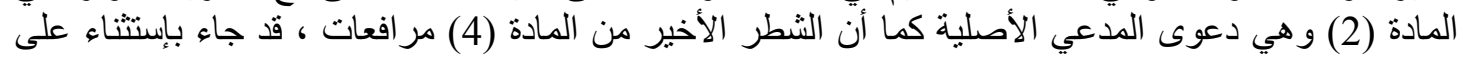

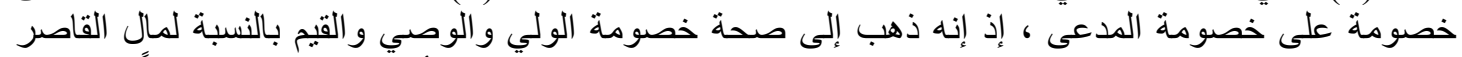

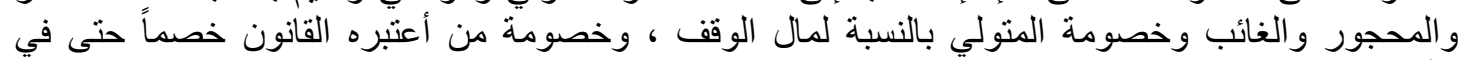

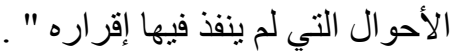

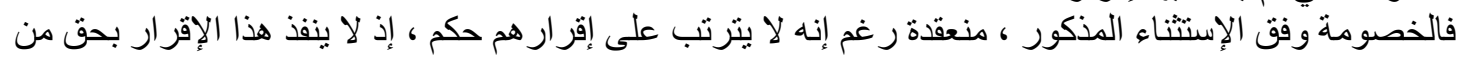

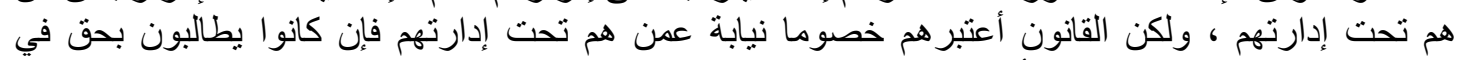

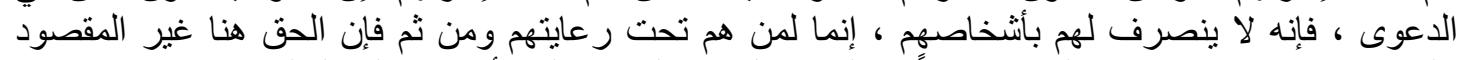

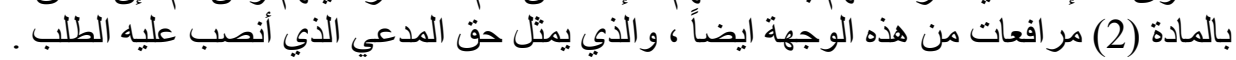

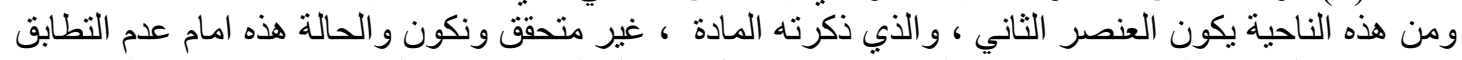

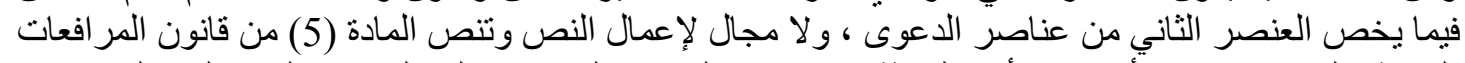

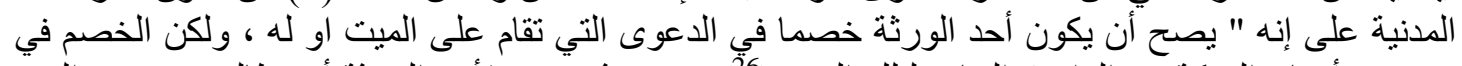

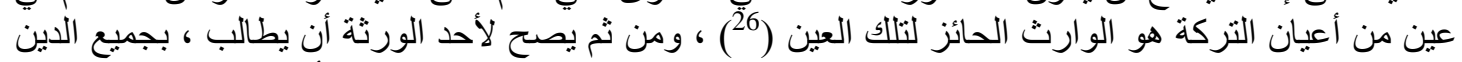

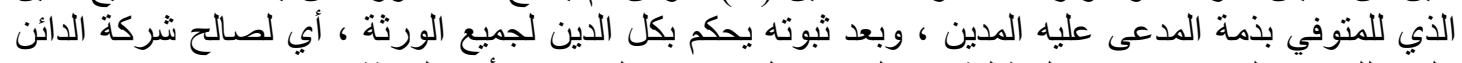

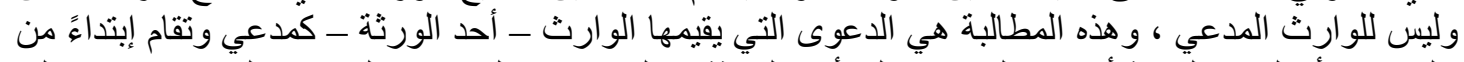

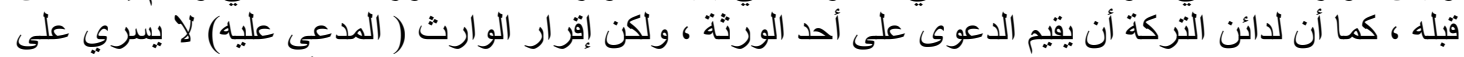

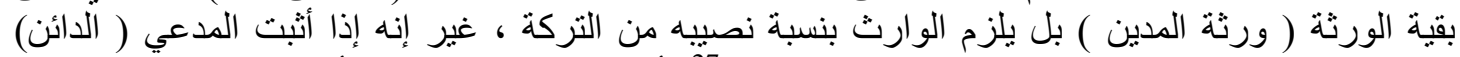

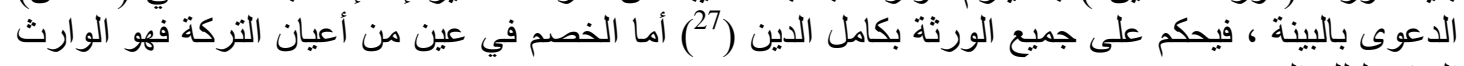

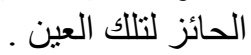

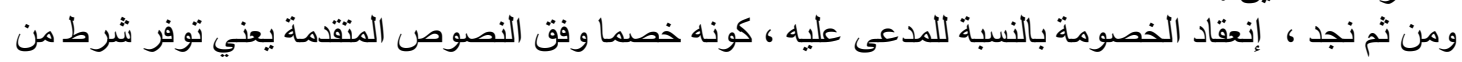

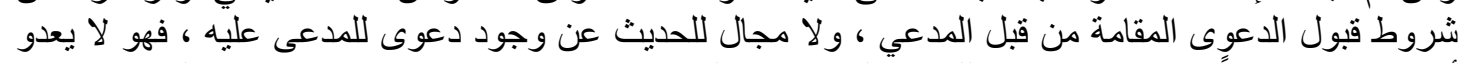

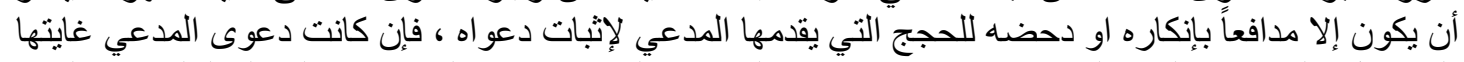

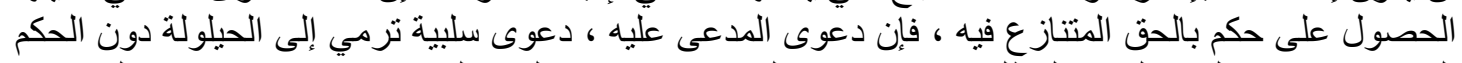

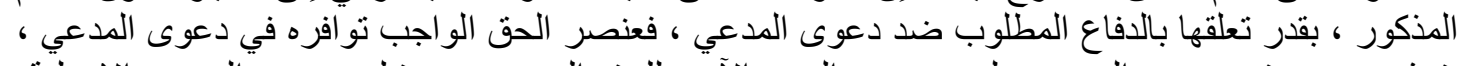

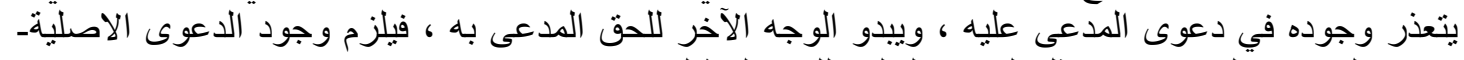

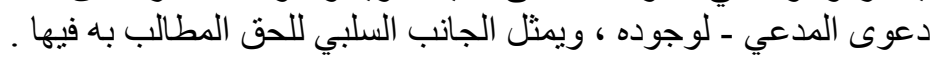

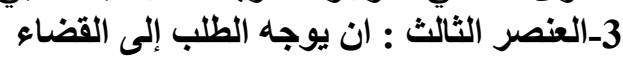

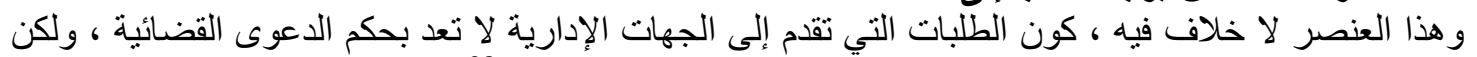

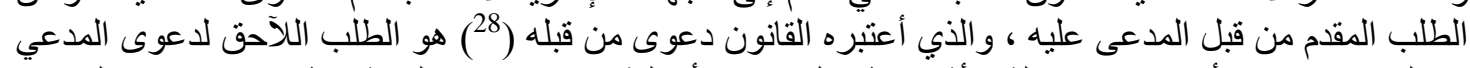

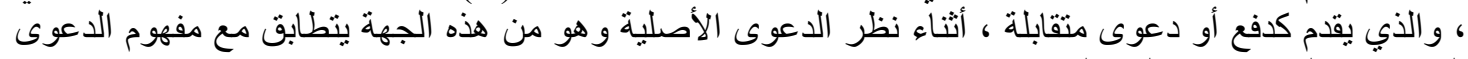

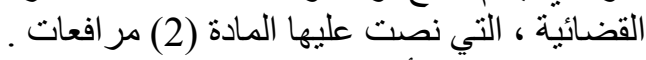

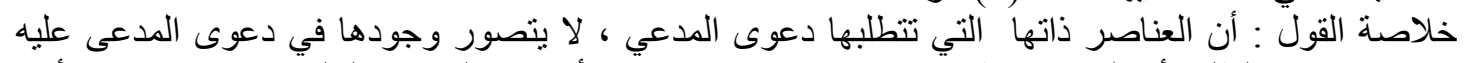

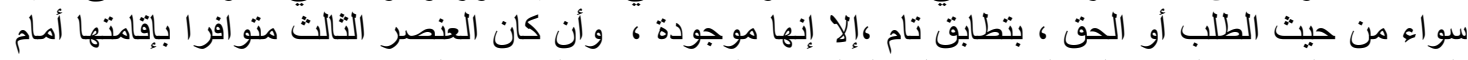

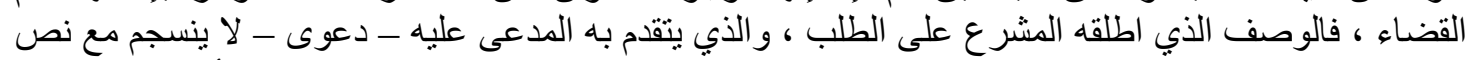

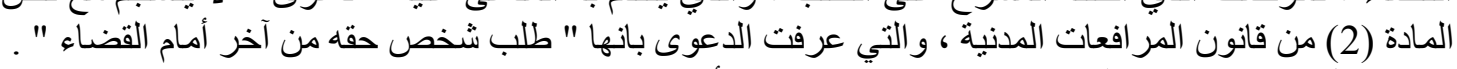

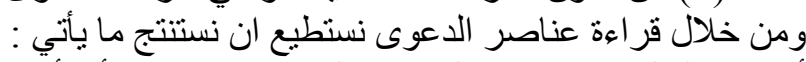

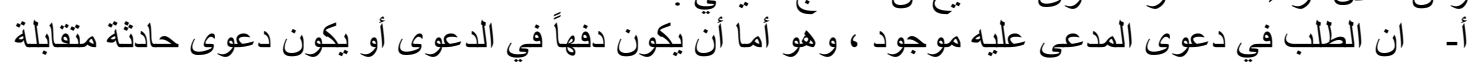

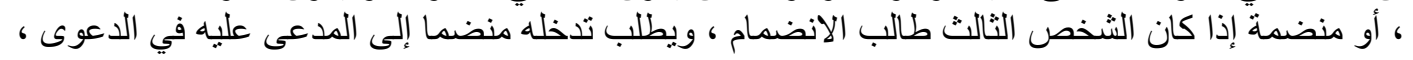

26 ـ هذه المادة منقولة حرفيا من المادة 2642 من من مجلة الأحكام العدلية

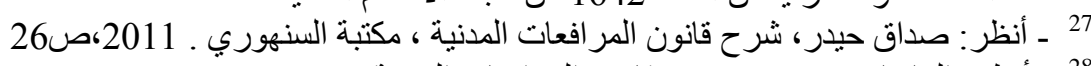
28 ـ أنظر : المادتان (8) و (70) من قانون المر افعات المدنية 


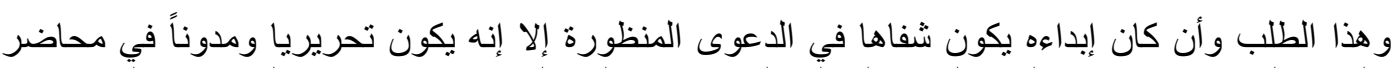

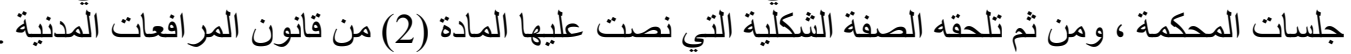

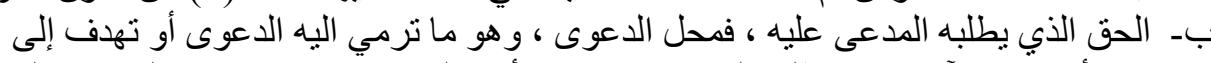

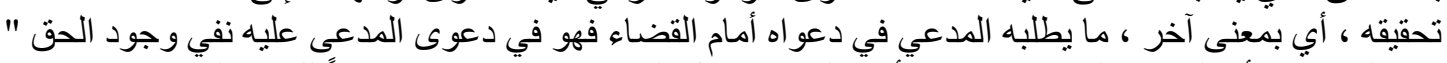

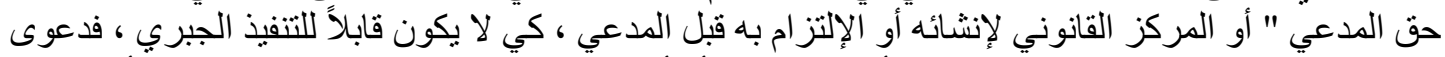

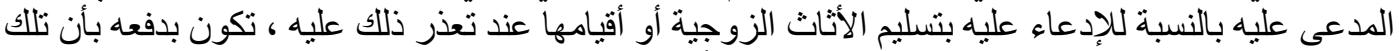

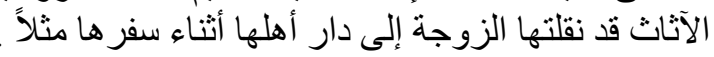

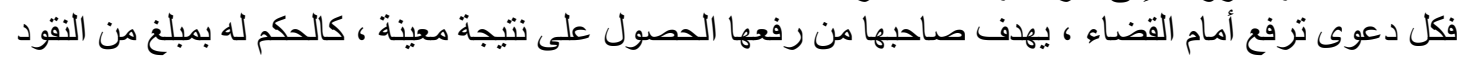

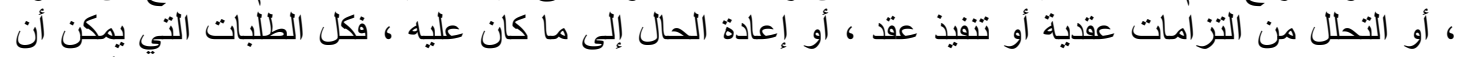

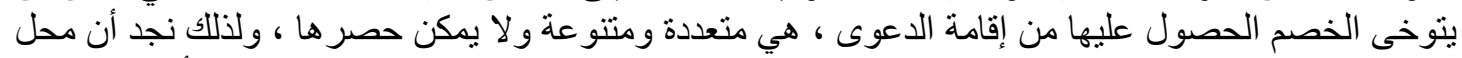

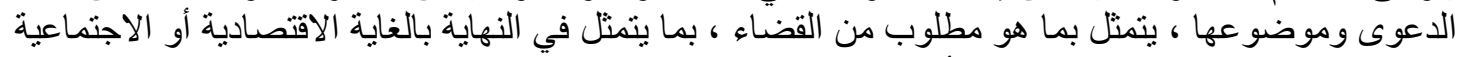

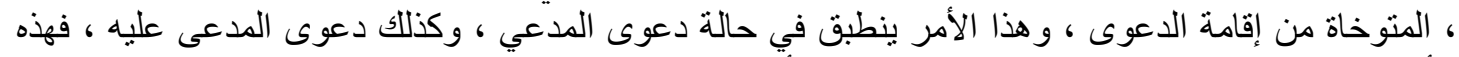

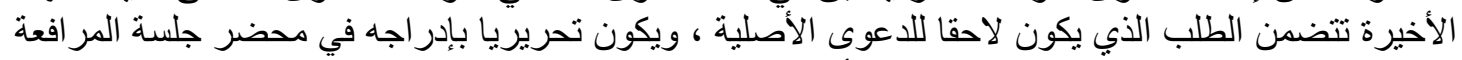

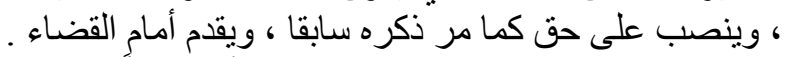

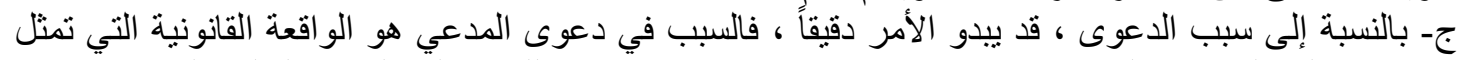

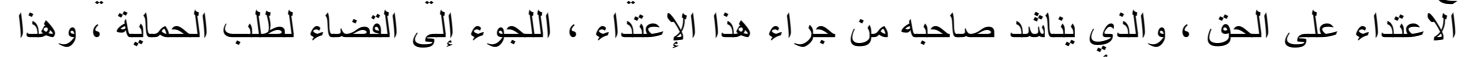

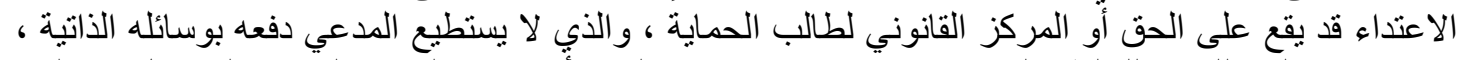

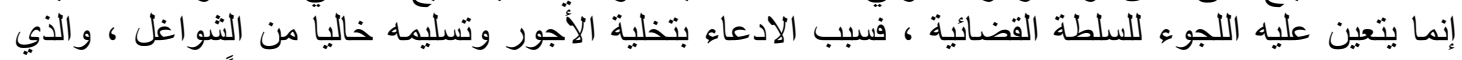

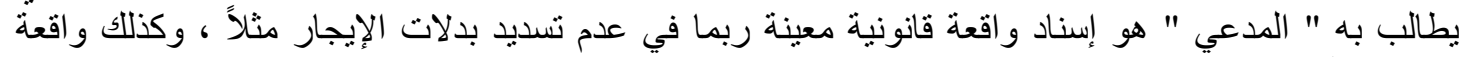

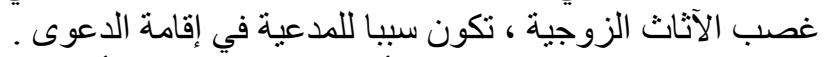

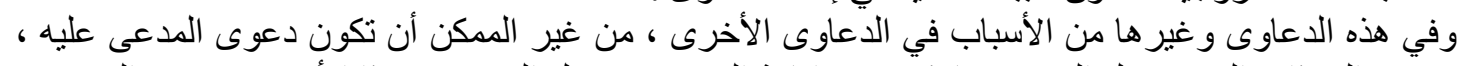

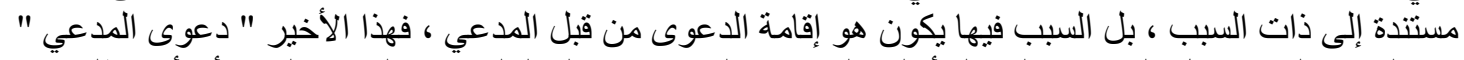

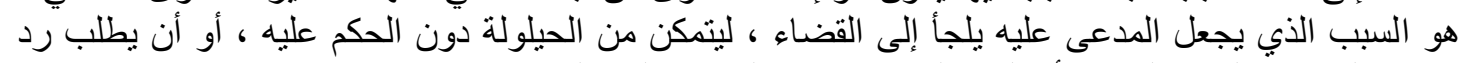

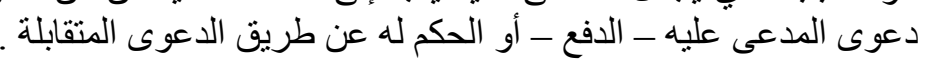

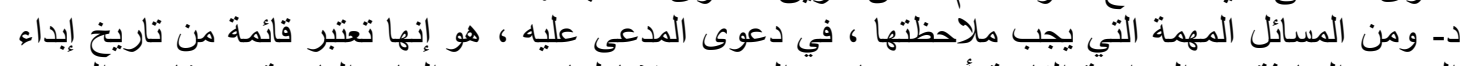

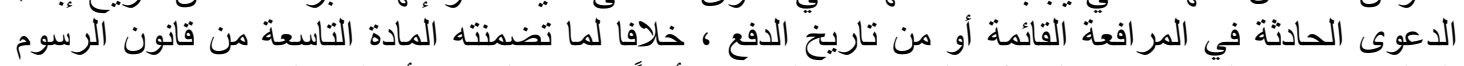

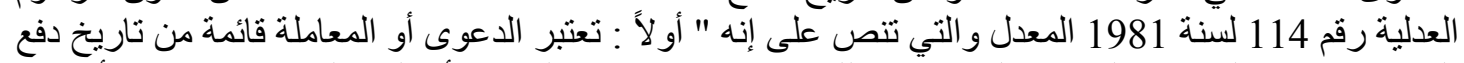

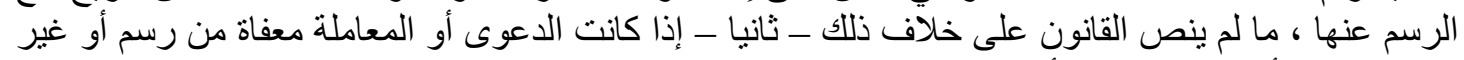

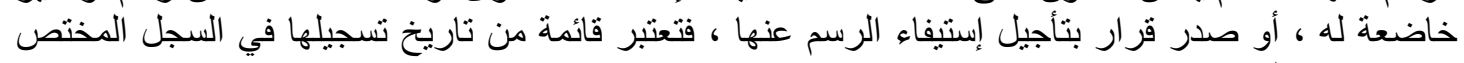
وختمها بختم المحكمة.

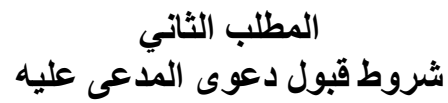

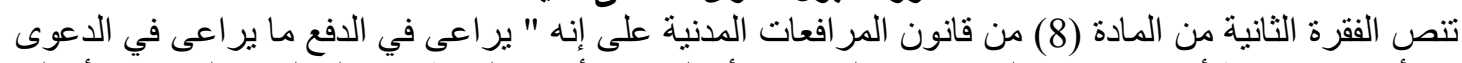

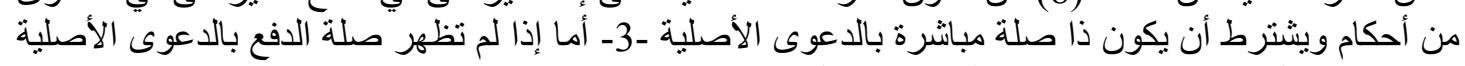

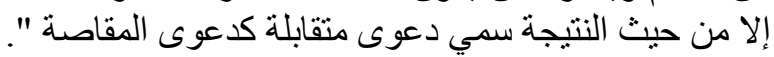

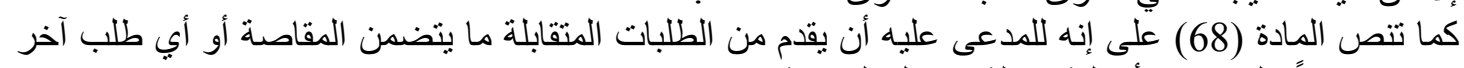

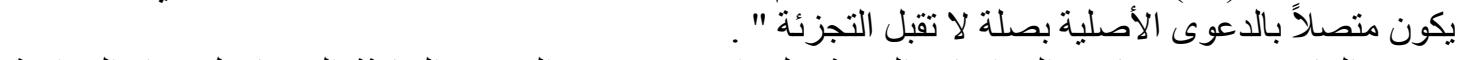

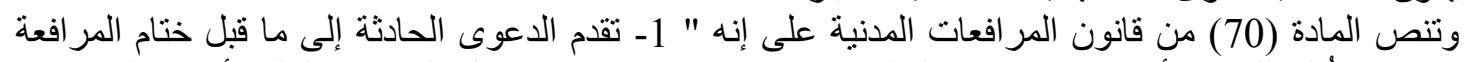

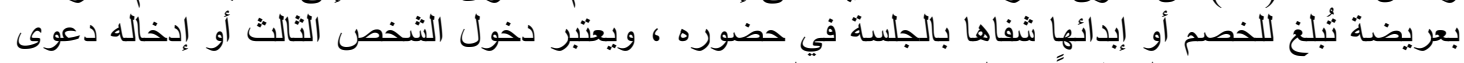

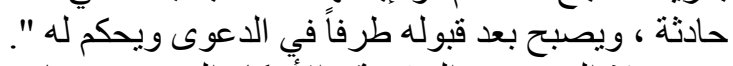

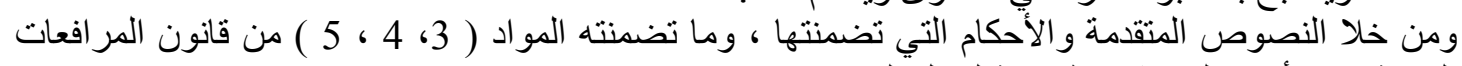

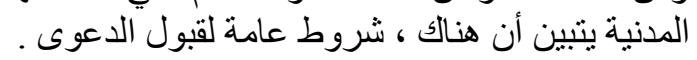

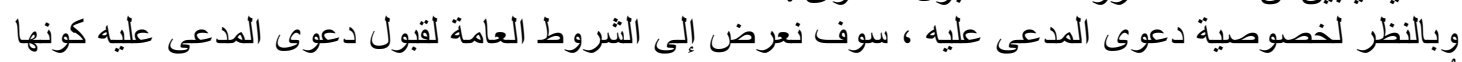

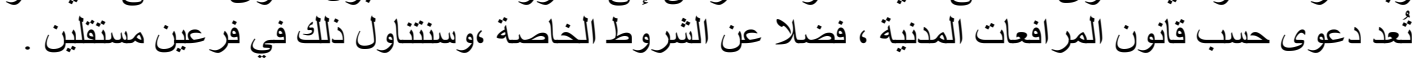




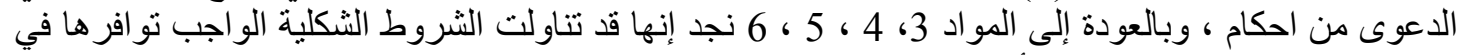

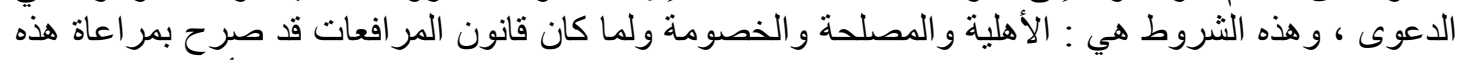

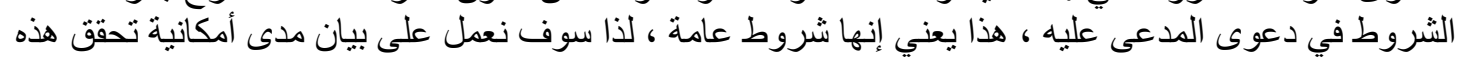

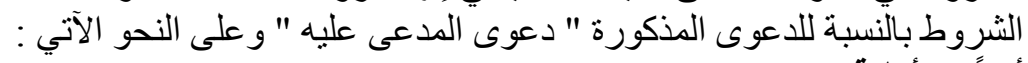

أولاً : الأهلية المبنة

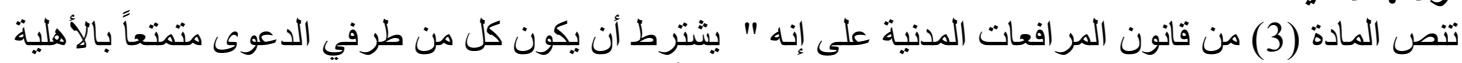

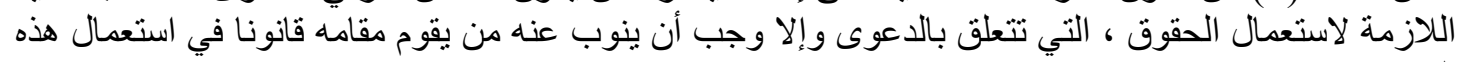

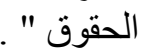

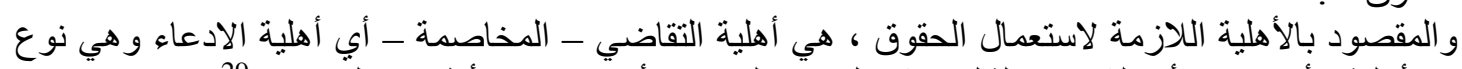

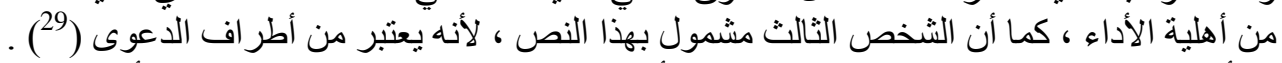

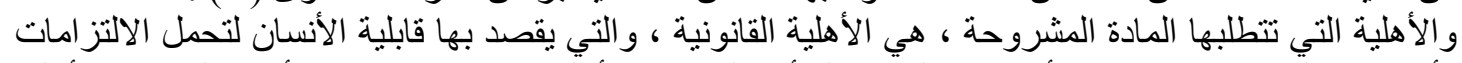

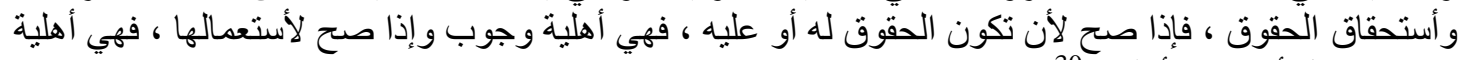

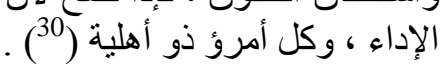

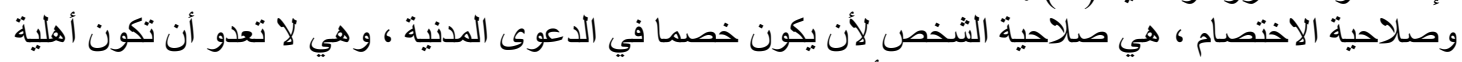

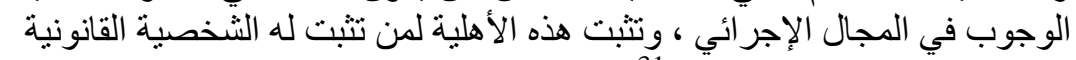

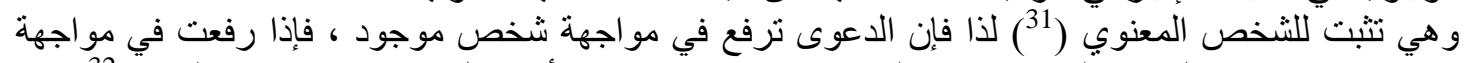

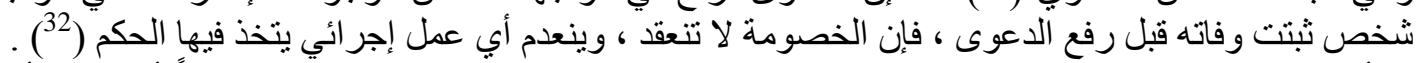

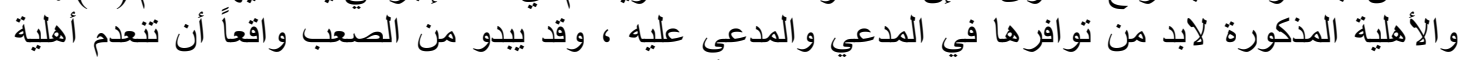

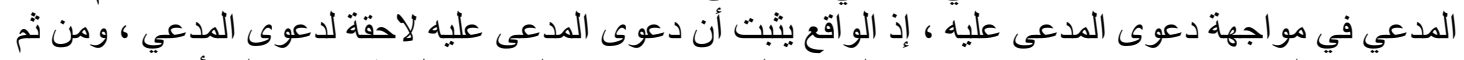

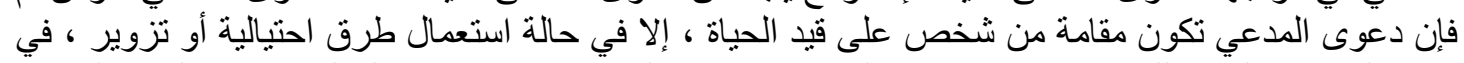

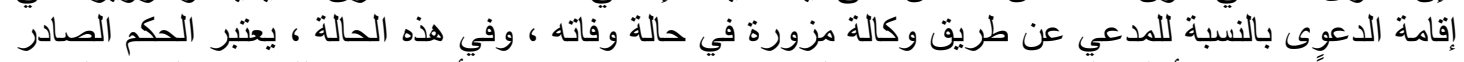

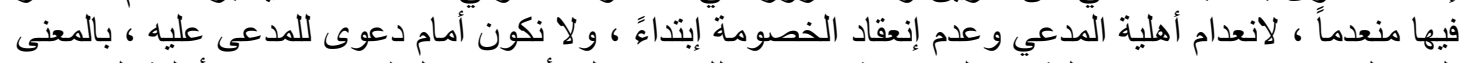

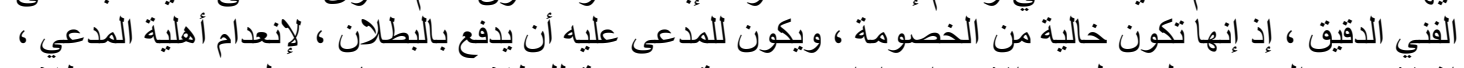

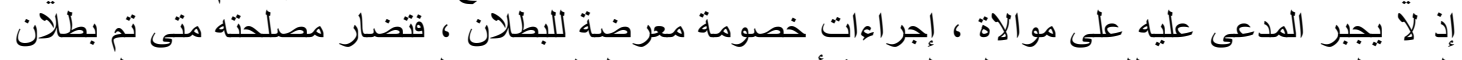

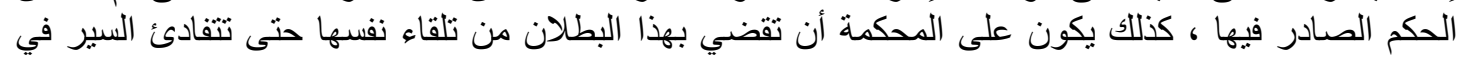

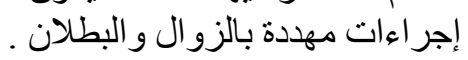

29 ــأنظر: المواد (111-93) من القانون المدني والمواد (27-39) من قانون رعاية القاصرين رقم 78 لسنة 1980 التي

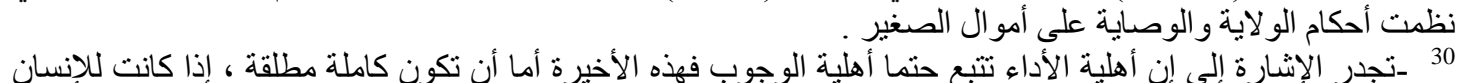

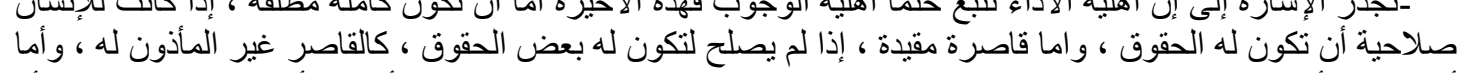

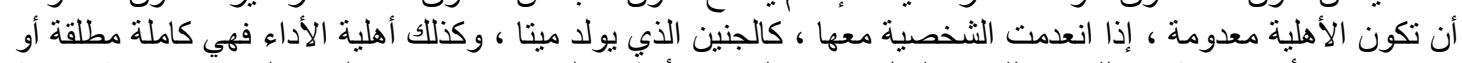

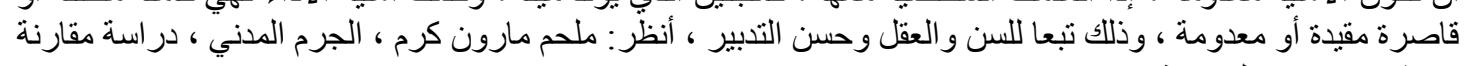

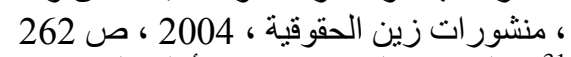

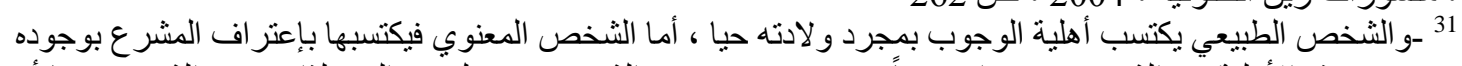

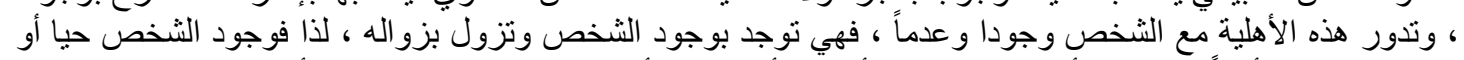

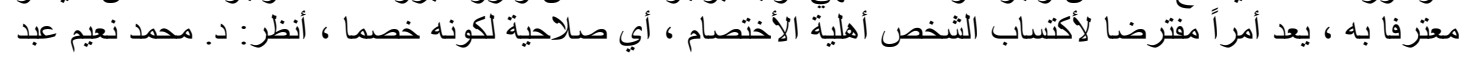

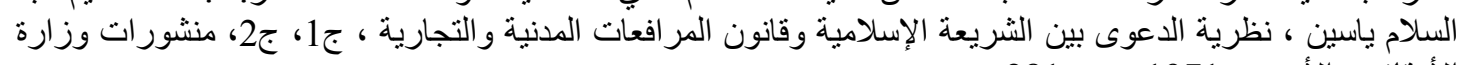

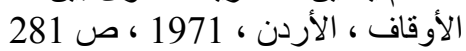

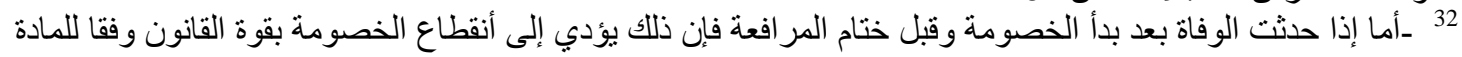
84 من قانون المر افعات المدنية . 
والحقيقة أن الثخص لكي يكون طرفاً في خصومة ، ينبخي أن تتحقق فيه أهلية الإختصام ، وهي صلاحنية

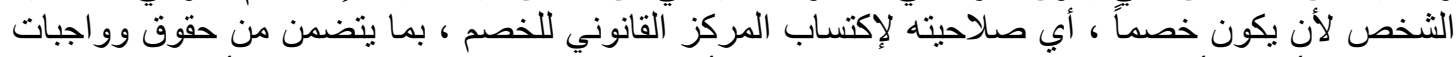

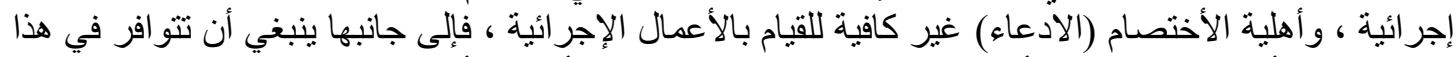

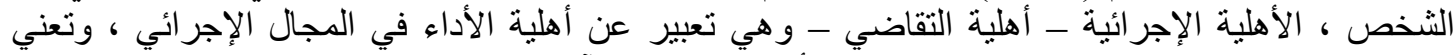

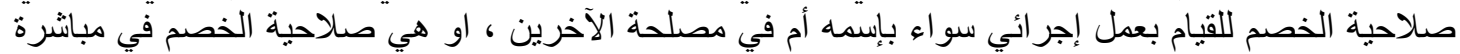

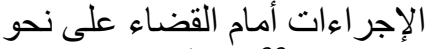

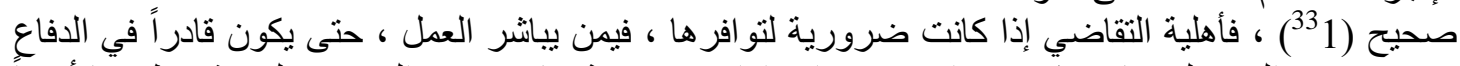

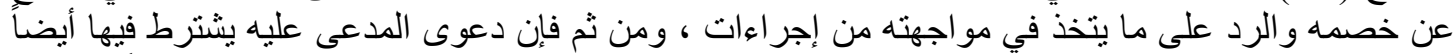

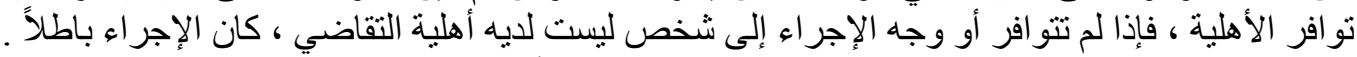

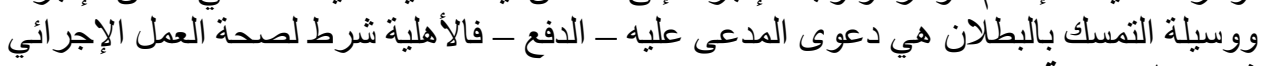

ثنانيا : الخصومة

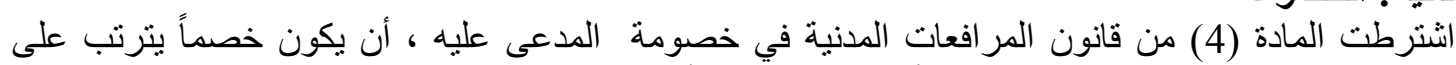

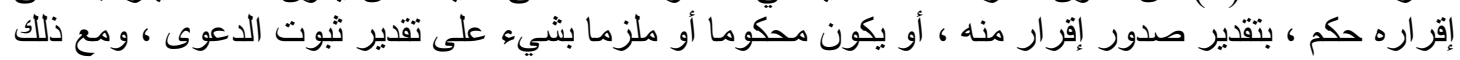

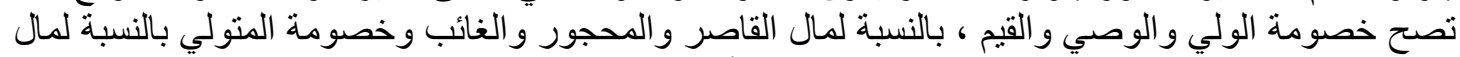

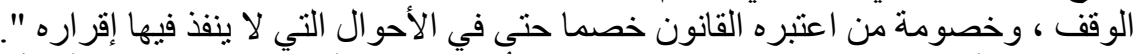

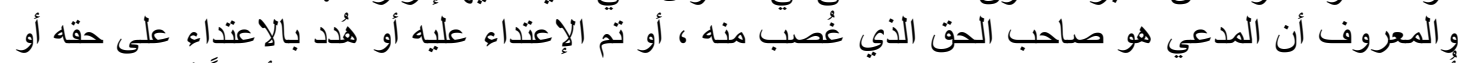

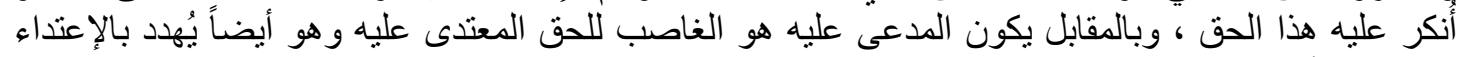

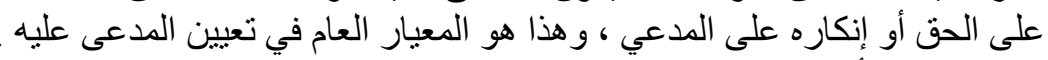

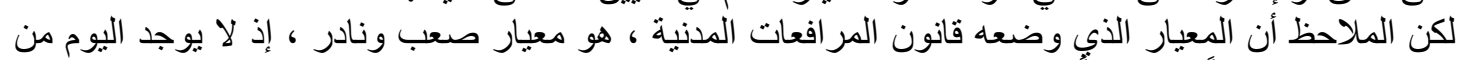

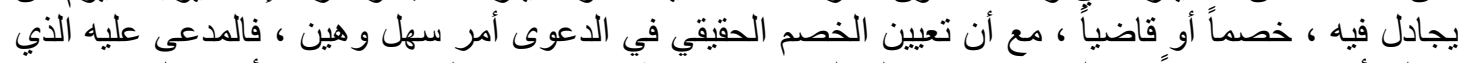

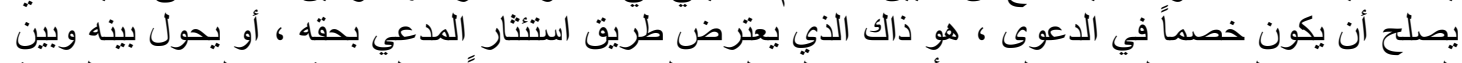

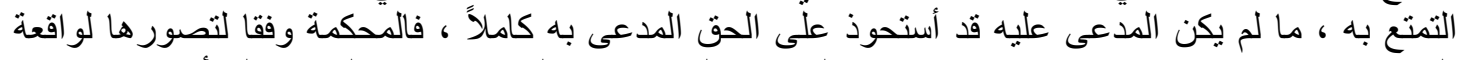

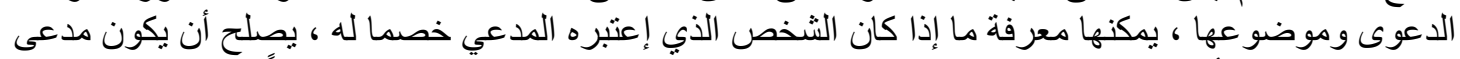

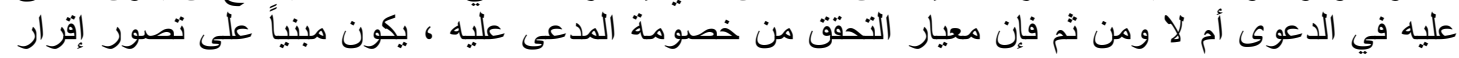
المدعى عليه

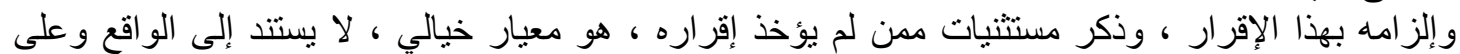

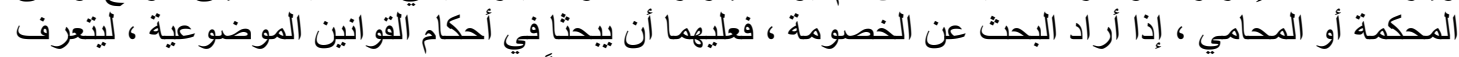

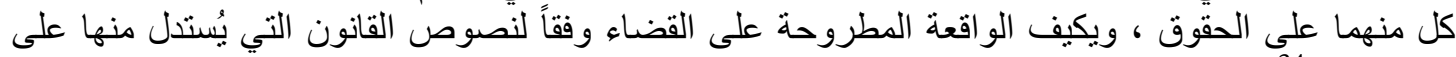

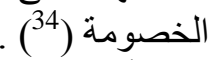

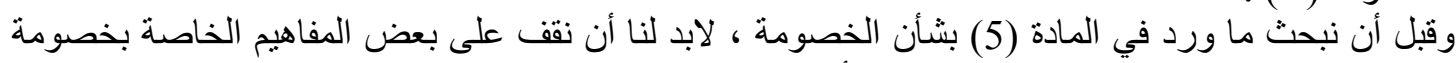

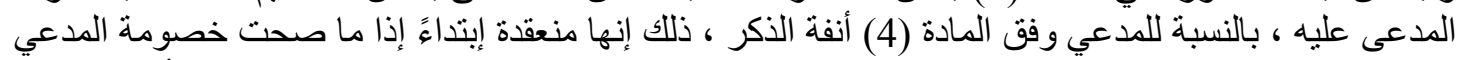

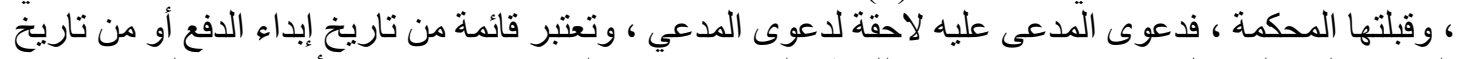

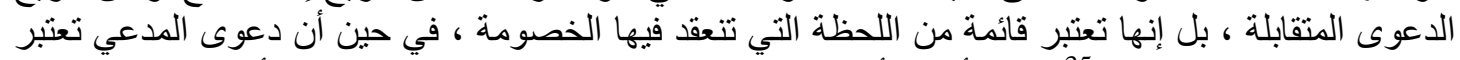

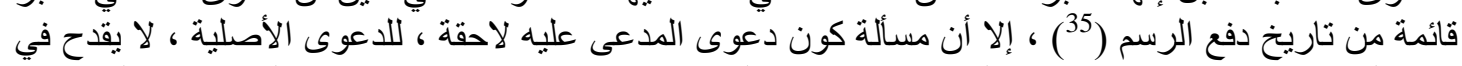

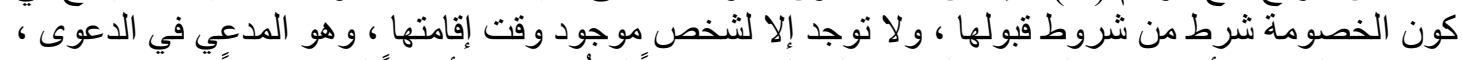

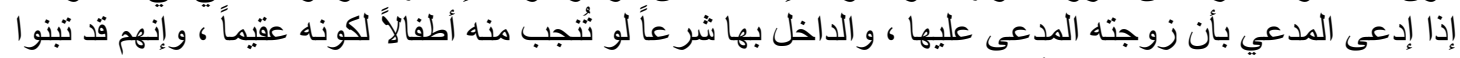

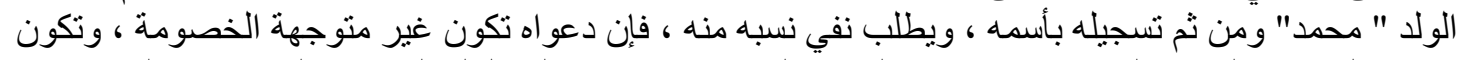

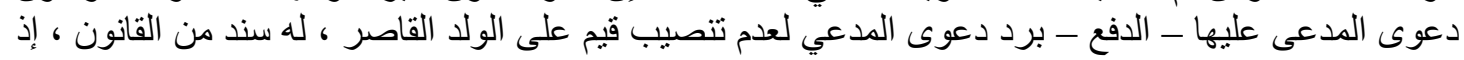

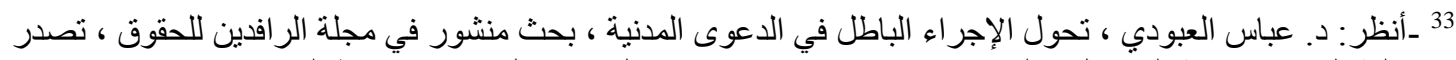

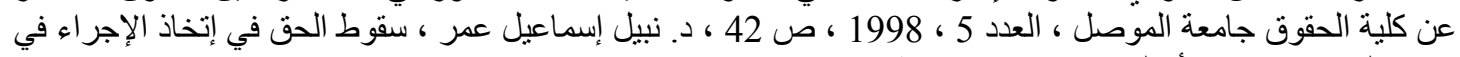

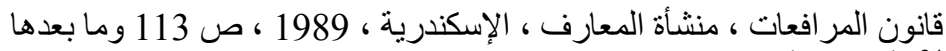

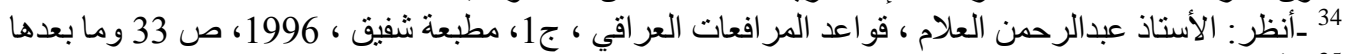

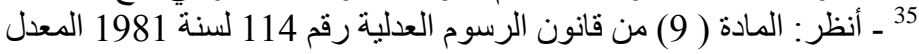


لابد من نو افر الخصومة في المدعي في دعوى المدعى عليه ، كما هو الحال في تو افر ها في المدعى الدئ عليه ابتداءً

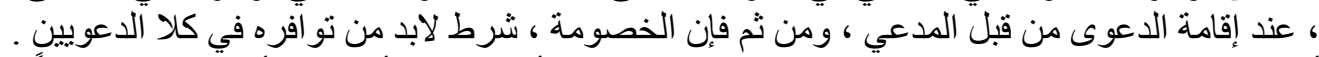

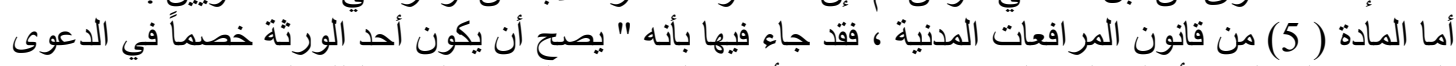

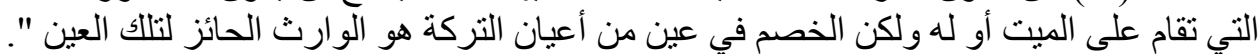

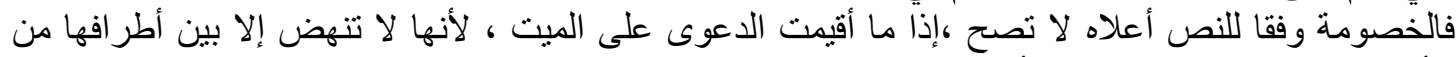

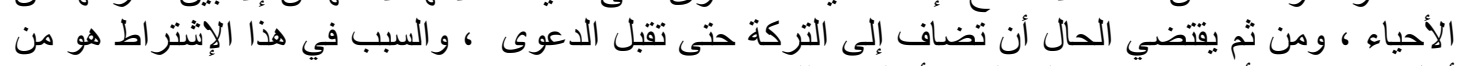

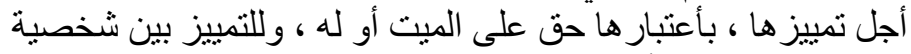

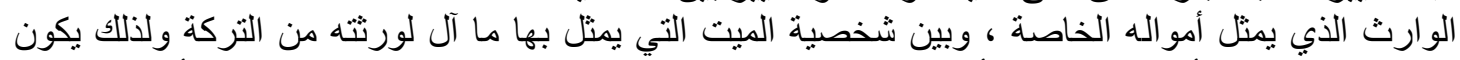

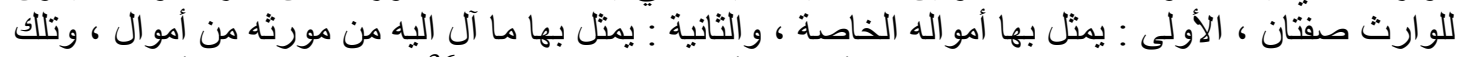

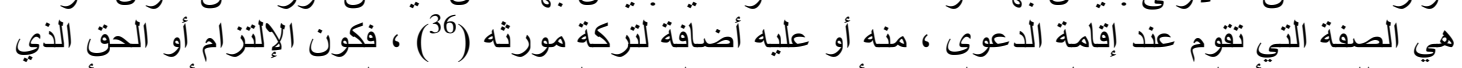

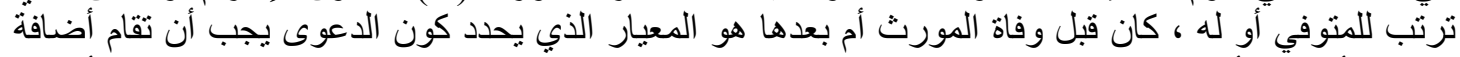

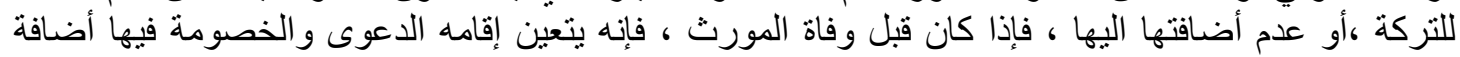

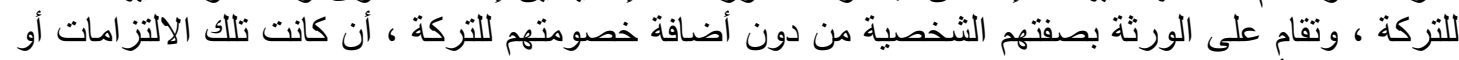

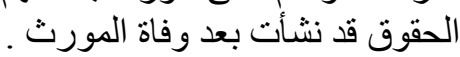

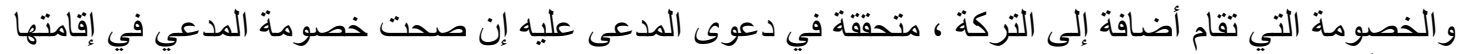

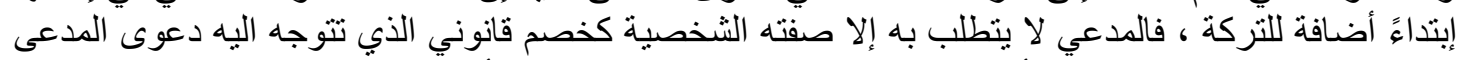

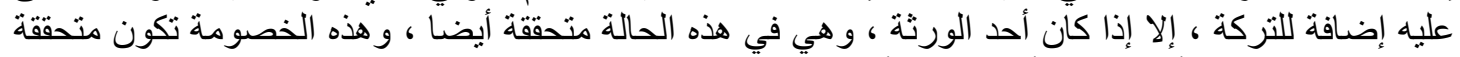

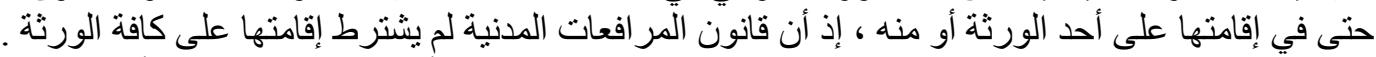

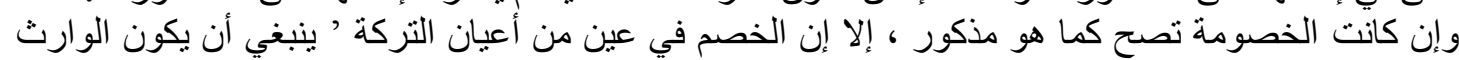

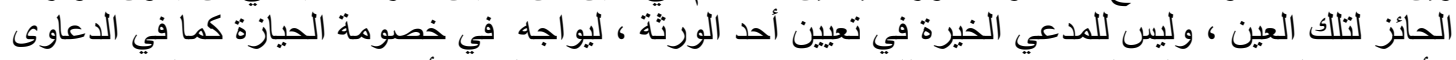

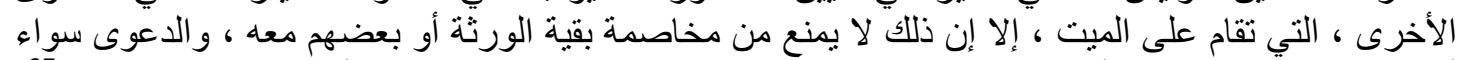

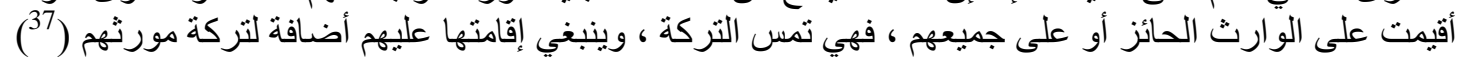

ونعتقد كون الخصم في عين من أعيان التركة ، ينبغي أن يكون الو ارث الحائز وفقا للنص المتقدام لا ينسجم القول

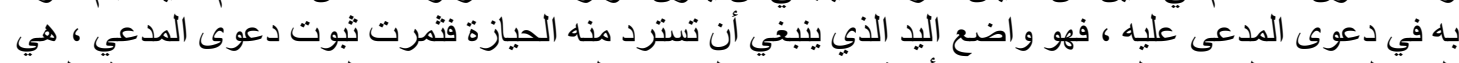

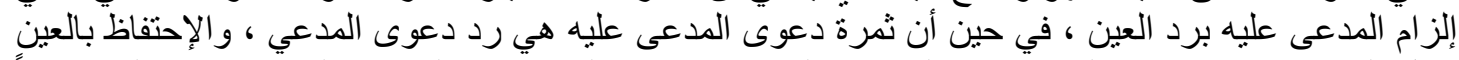

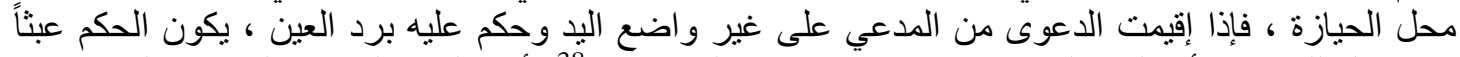

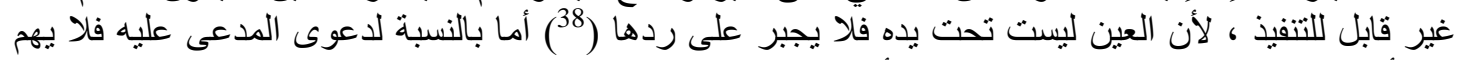

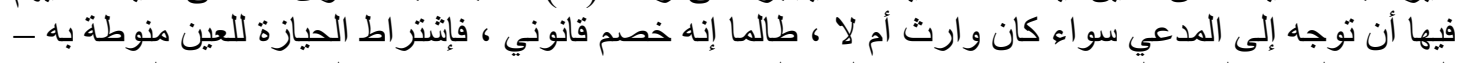

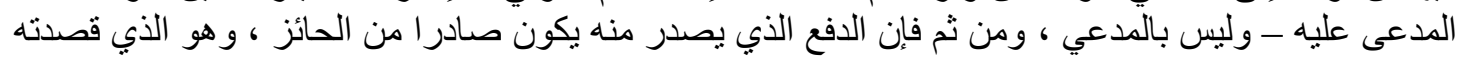

36 ـأن أضافة الدعوى على الورثة بدين المنوفي إلى تركته ، يمنع ملاحقة أمو الهم الثخصبة فالحكم الذي يصدر فيها

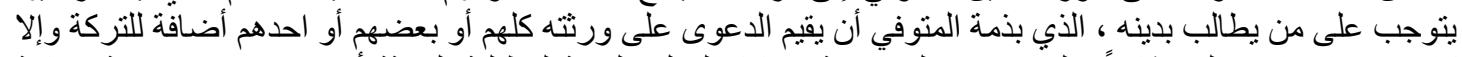

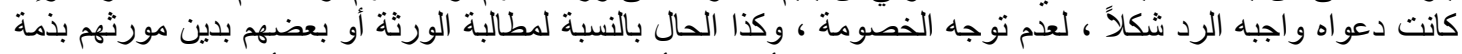

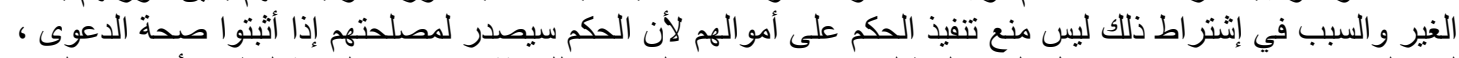

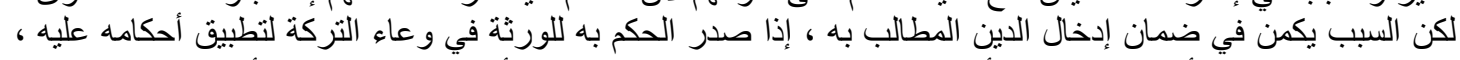

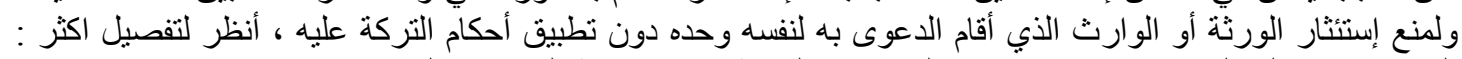

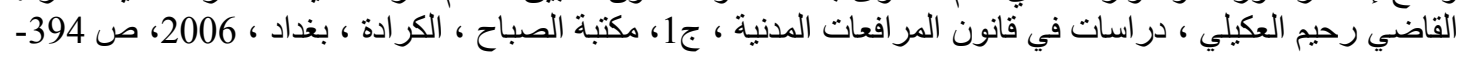

37 ـ انظر: د. عباس العبودي، شرح ، مصدر سابق ، ص 285، 28 د. د. نبيل إسماعيل عمر ، الدفع بعدم القبول ونظامه

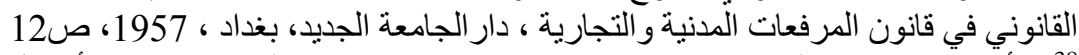

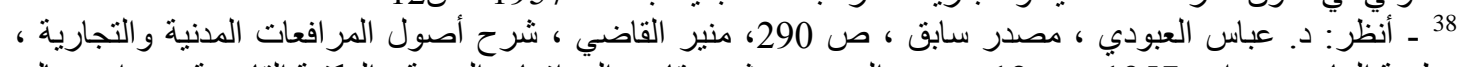

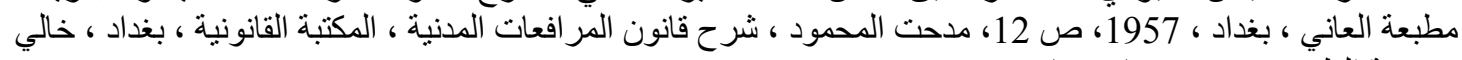

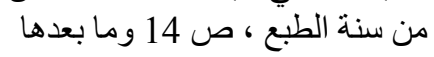


المادة (5) في شطر ها الأخير ، ومن ثم تصح خصومته ، ويتحقق شرط الخصومة من هذه الوجهة أيضا ، وهو

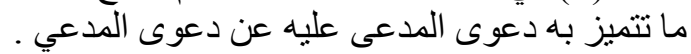

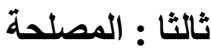

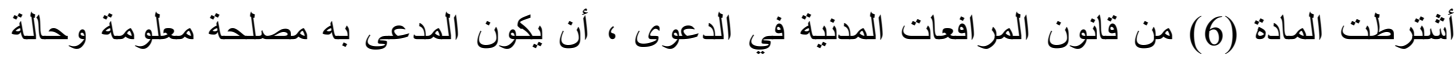

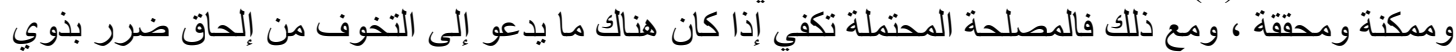

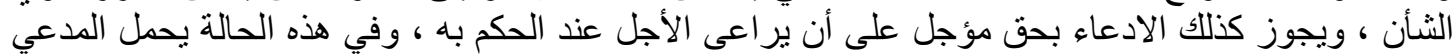

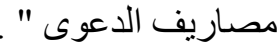
وبشأن هذا الثرط يتجه الفقه ، إلى أنه الثرط الرئيسي بل و الوحيد لقبول الدعوى ، وقد حددت المادة المشار اليها

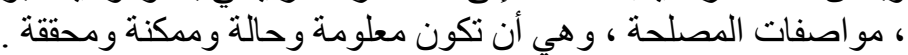

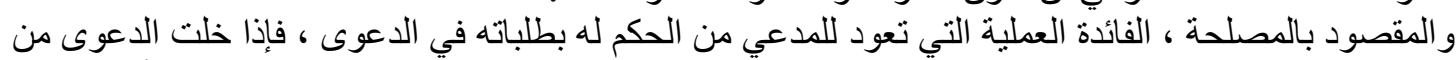

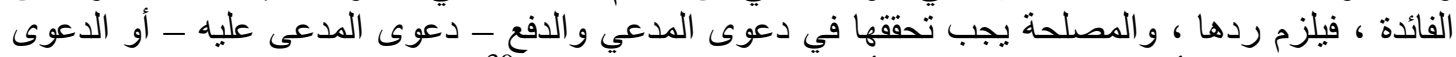

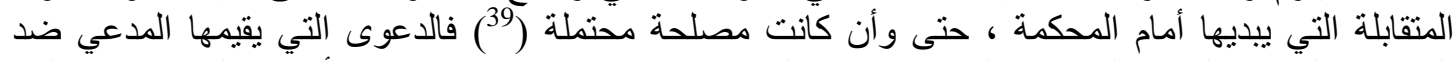

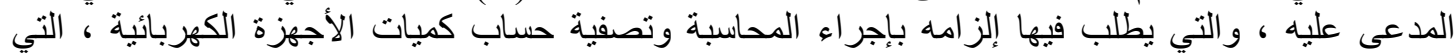

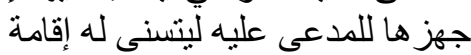

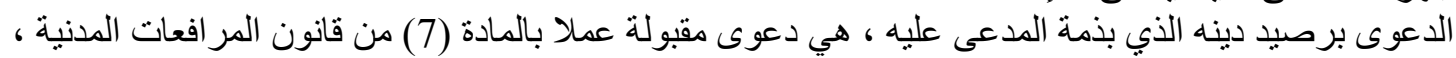

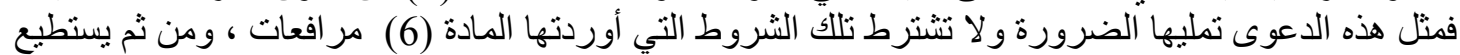

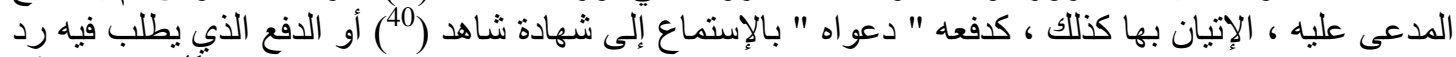

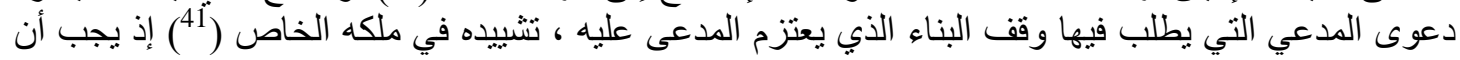

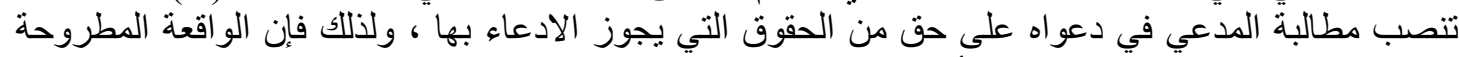

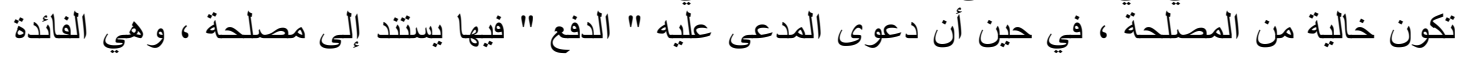

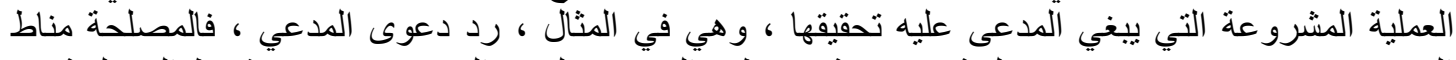

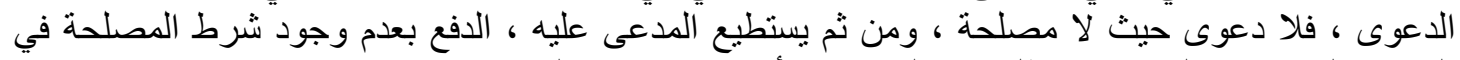

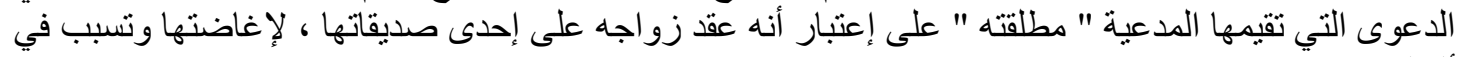

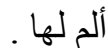

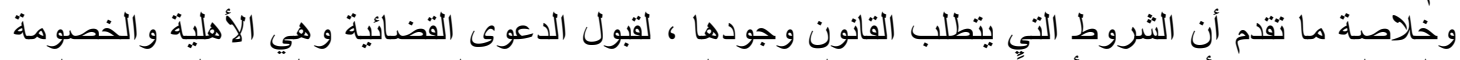

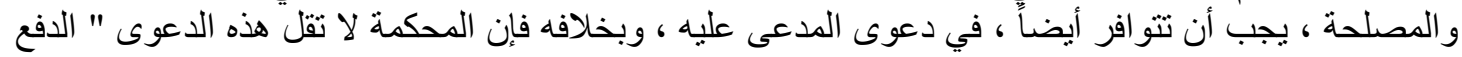

الفرع الثاني

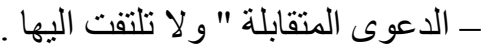

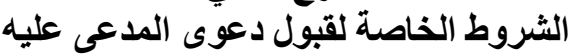

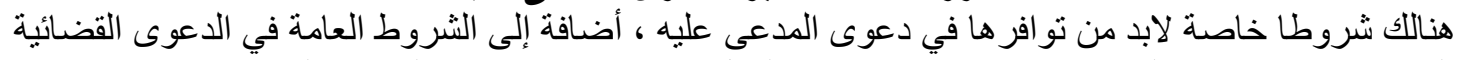

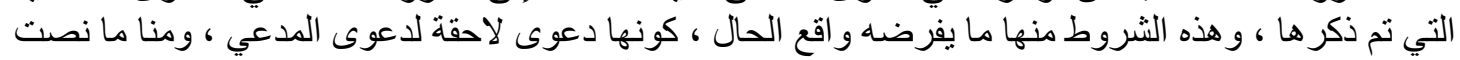

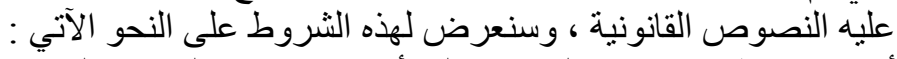

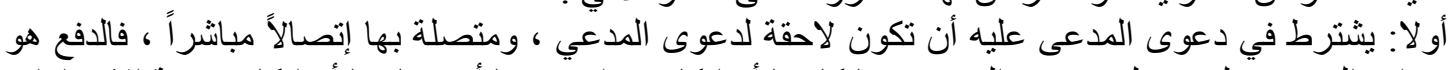

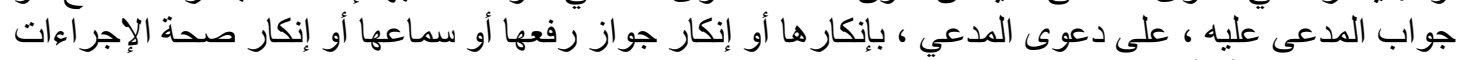

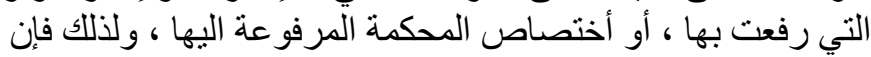

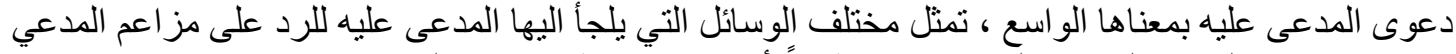

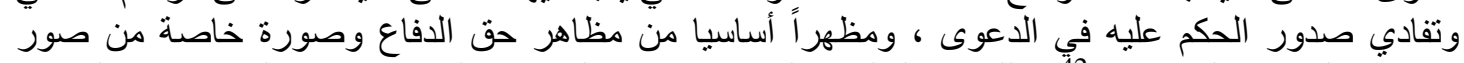

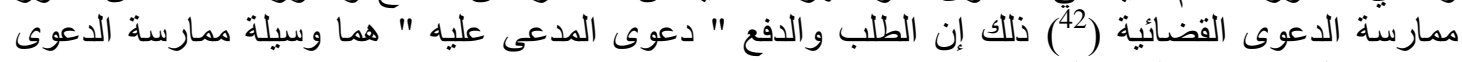

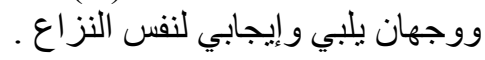




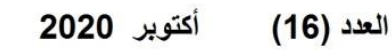

Volume (16) October 2020

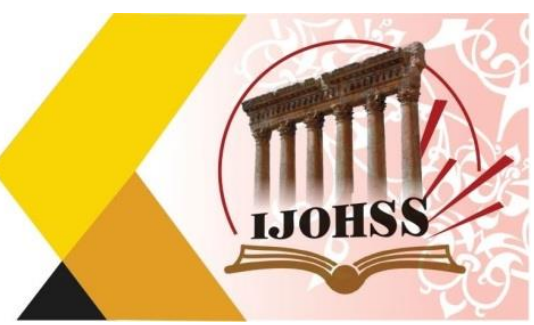

ثانيا : يشترط في دعوى المدعى عليه ، أن تكون لها صلة بالدعوى الأصلية من حيث النتيجة إذا لم تتو افر لها لها

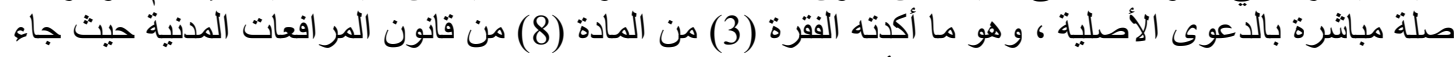

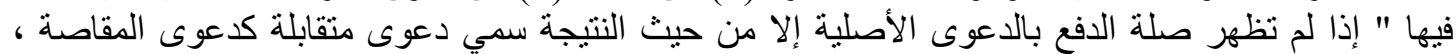

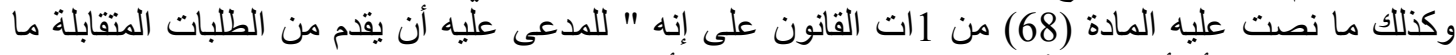

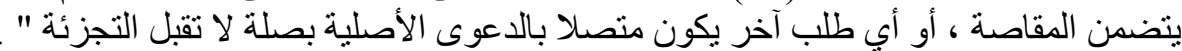

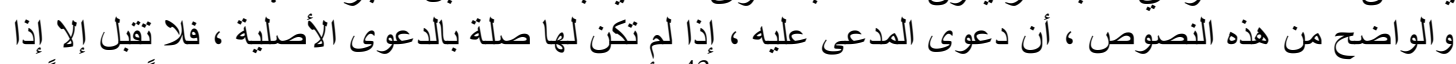

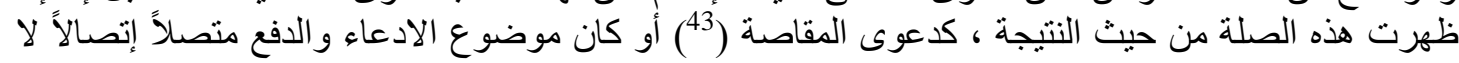

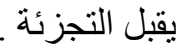
و لابد من تو افر الثروطة العامة والخاصة ، لنكون أمام دعوى للمدعى عليه ، حسب النصوص التي أوردها قانون

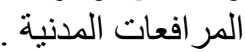

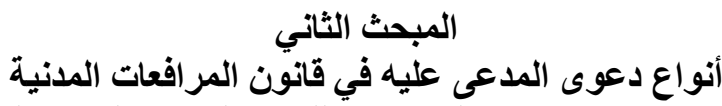

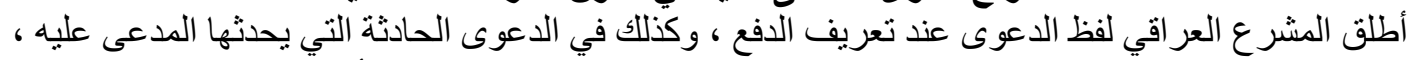

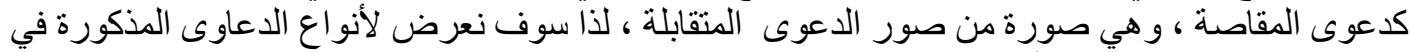

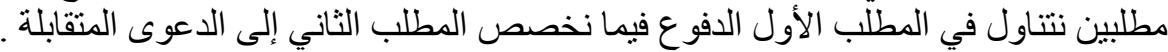

$$
\text { المطلب الأول }
$$

$$
\text { الافوع الأوع }
$$

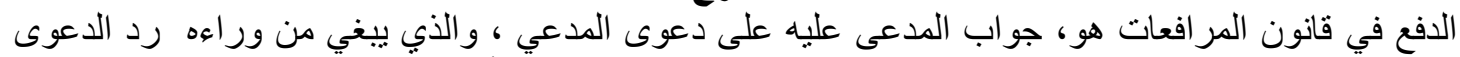

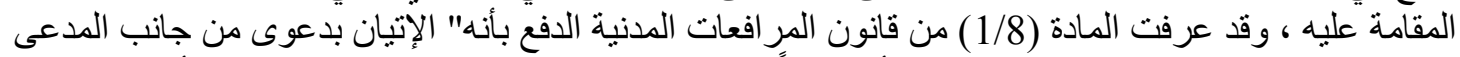

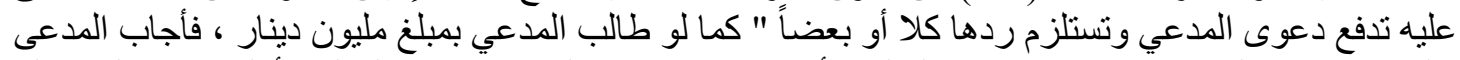

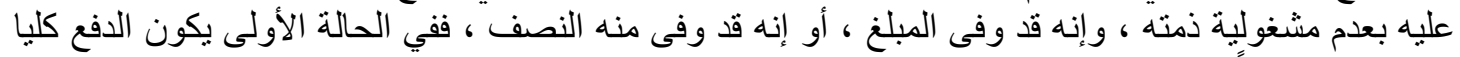
وفي الثانية جزئياً.

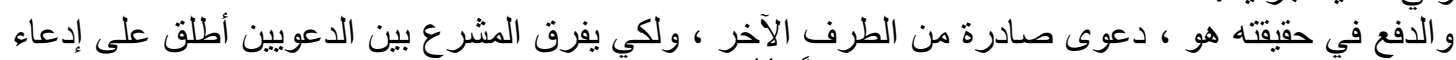

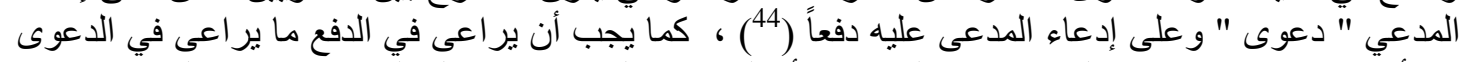

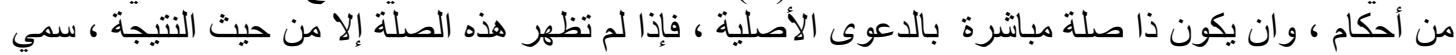

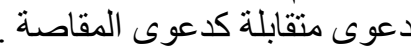

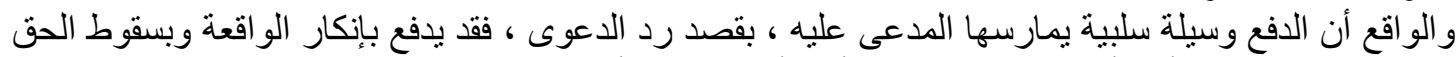

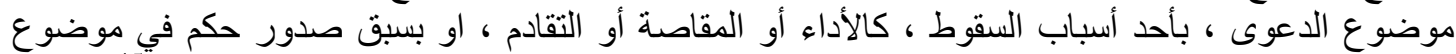

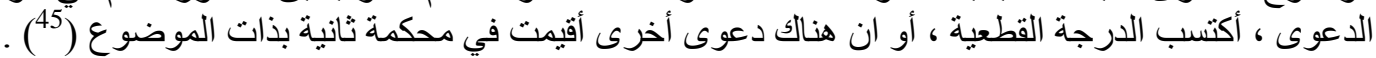

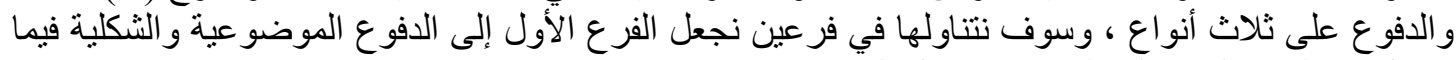

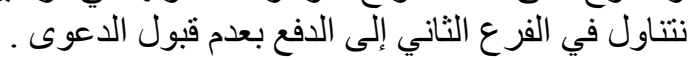

43 ـ أنظر : المادة ( 408) من القانون المدني

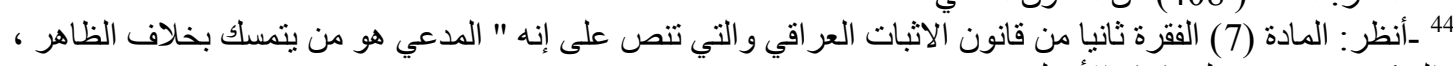

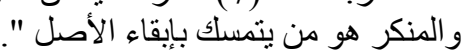

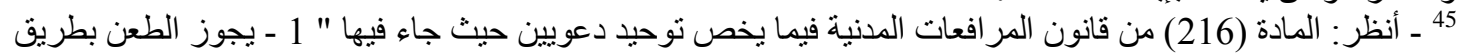

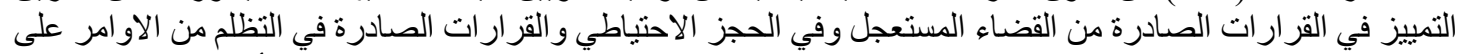

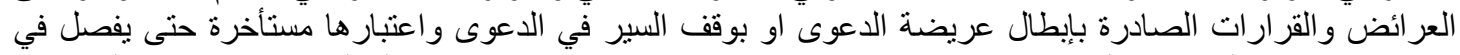

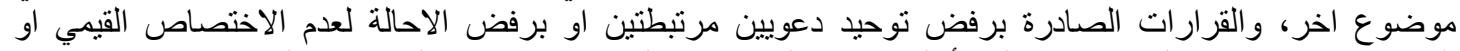

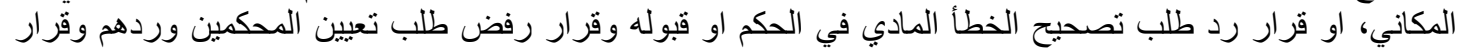

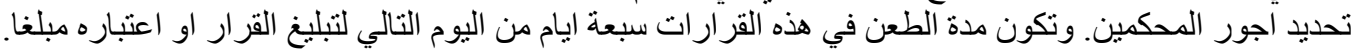




\author{
العدد (16) أكتوبر 2020 \\ Volume (16) October 2020
}

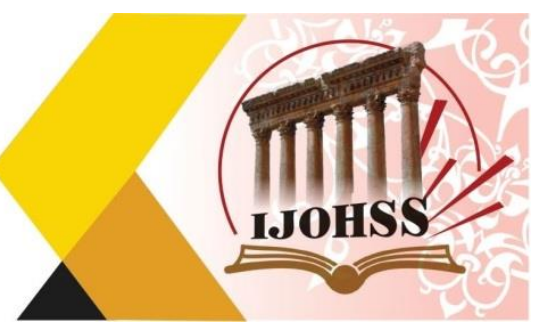

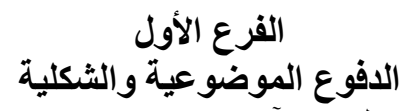

سنعرض لكل منهما في فقرة مستقلة و على النحو الآتي :

أولا : الدفوع الموضوعية إنوية

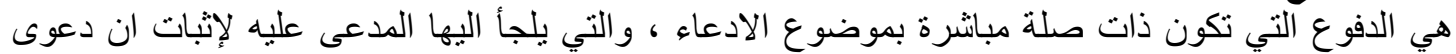

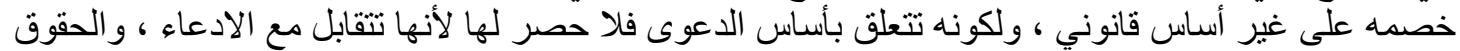

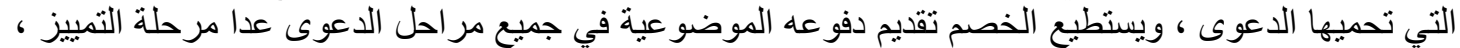

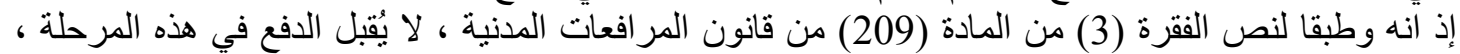

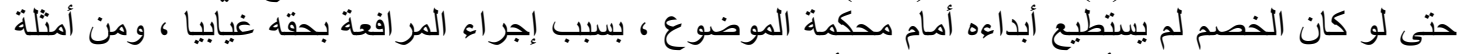

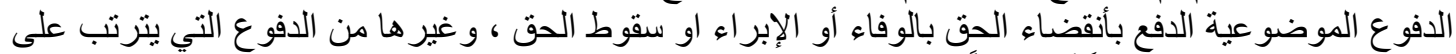

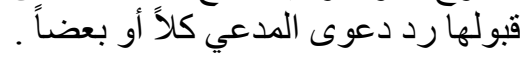

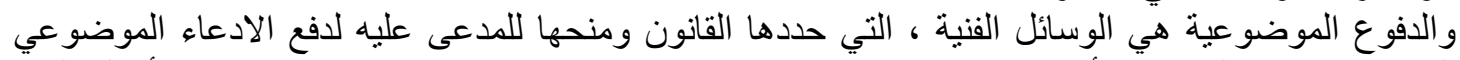

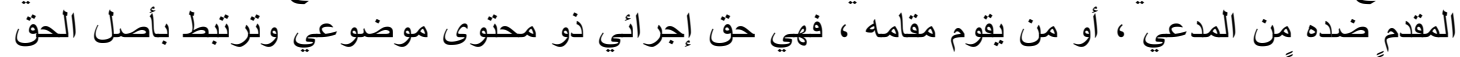

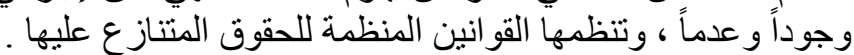

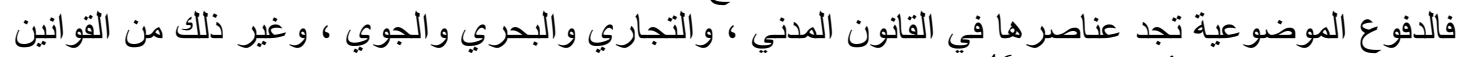

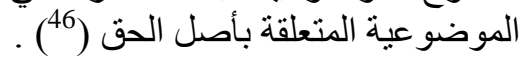

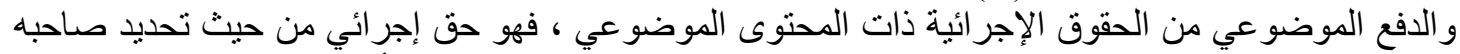

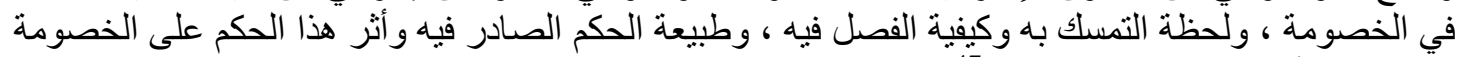

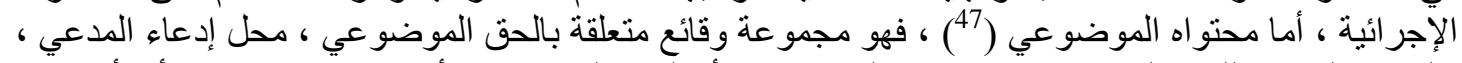

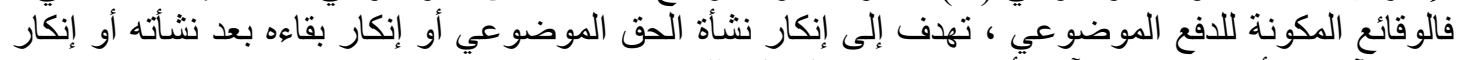

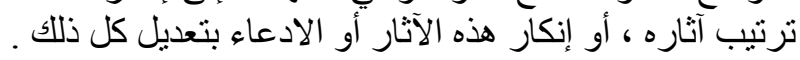

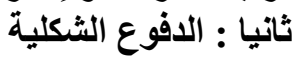

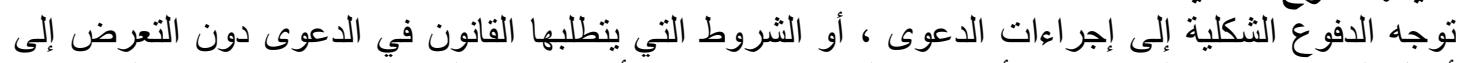

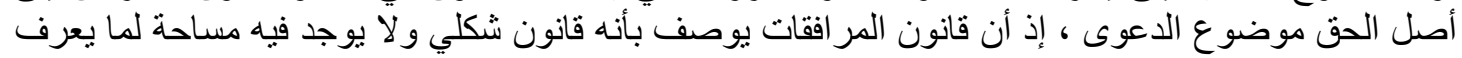

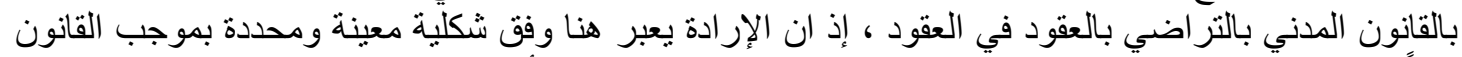

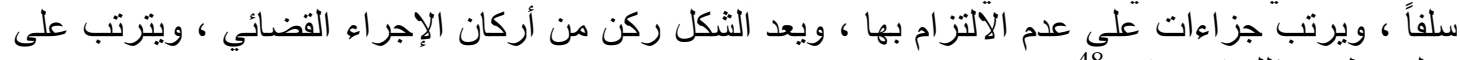
تخلفه بطلان ذللك الإجر اء (لاء (48) و القصد من الدفوع الثكلية هو رد الثئ الدعوى ، دون دخول المحكمة في موضوعها ، فالمدعى عليه يطلب دفع

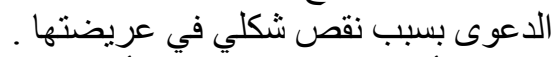

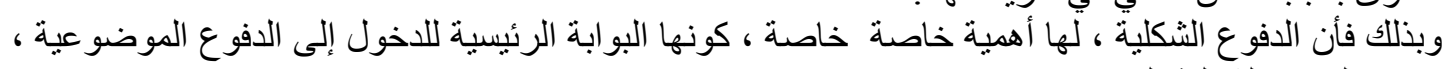
وتنقسم الدفوع الثكلية إلى قسمين :

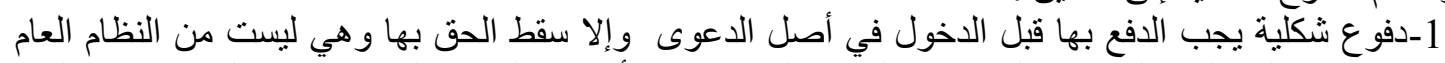

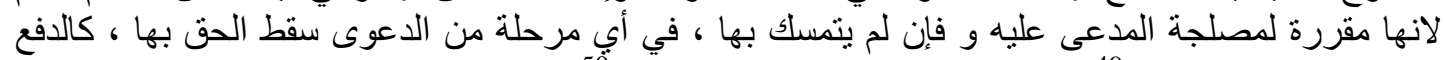

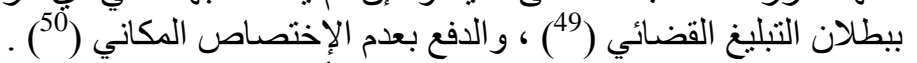

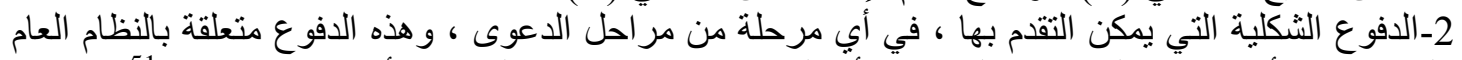

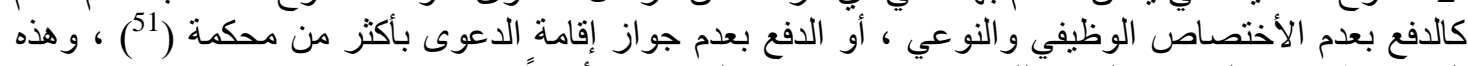
الدفوع يطعن بها المدعى عليه ، وللمحكمة أن تثير ها من تلقاء نفسها أيضاً

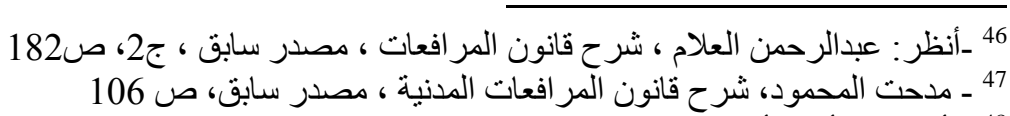

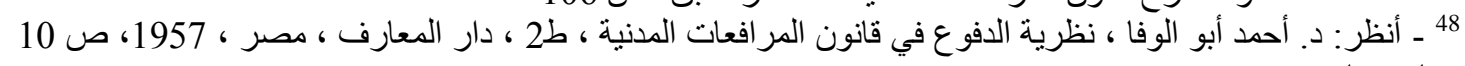
وما بعدها

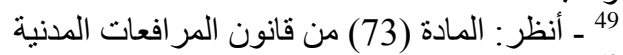
50 51 ـ أنظر : المادة (76) من قانون المر افعات المرن المدنية المدنية 


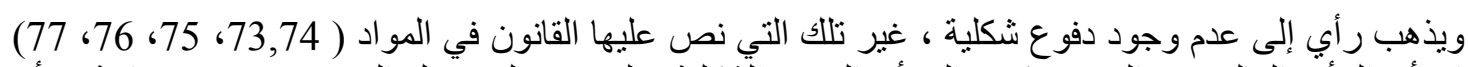

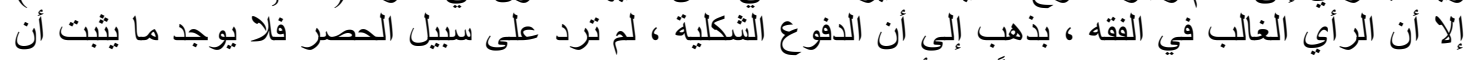

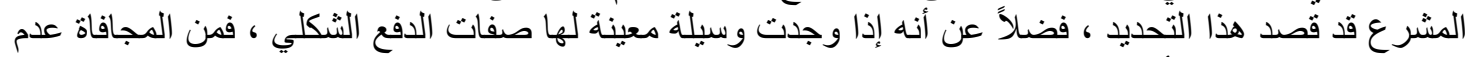

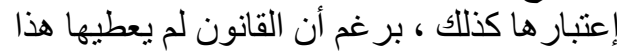

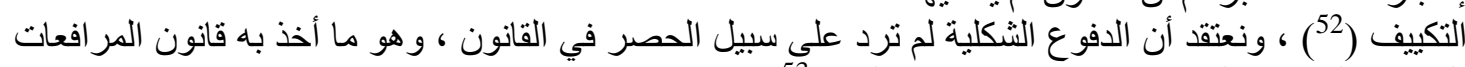

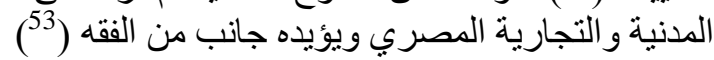

\section{الفرع الثاني (الثي

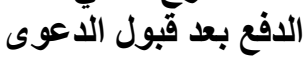

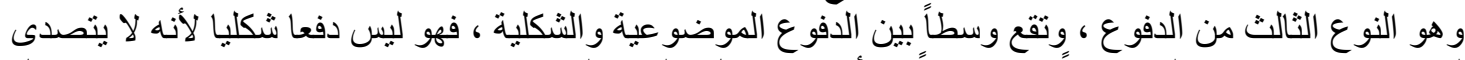

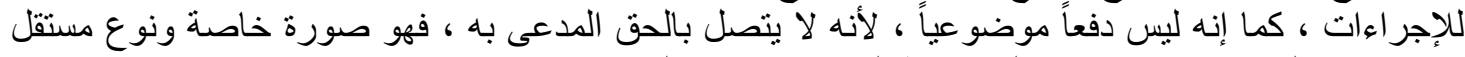

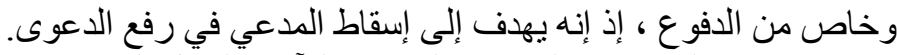

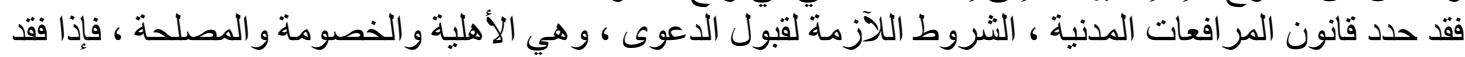

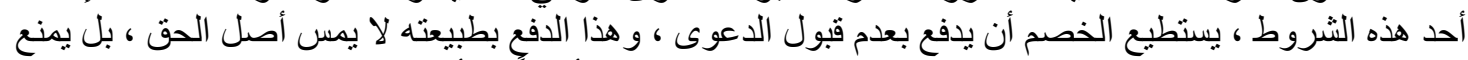

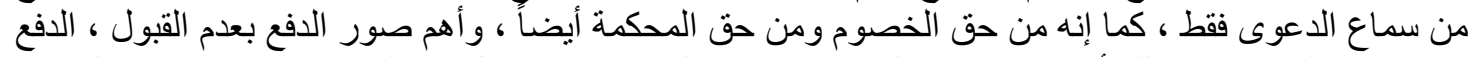

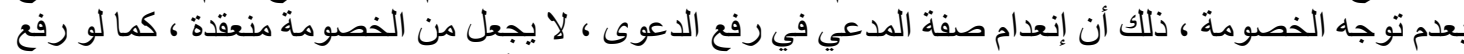

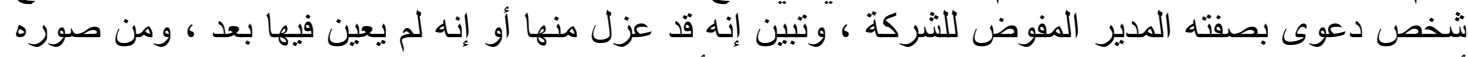

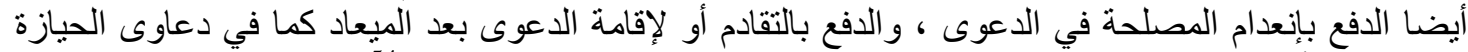

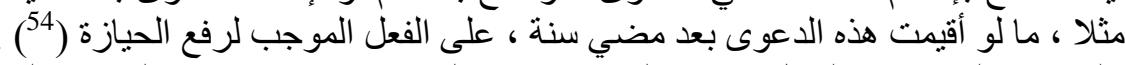

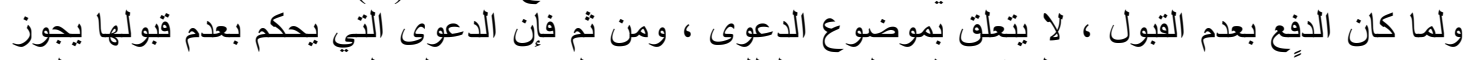

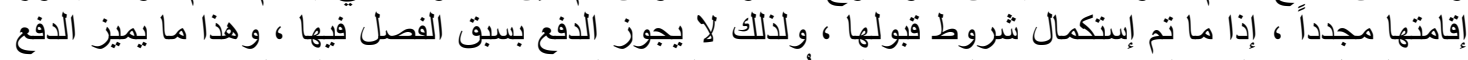

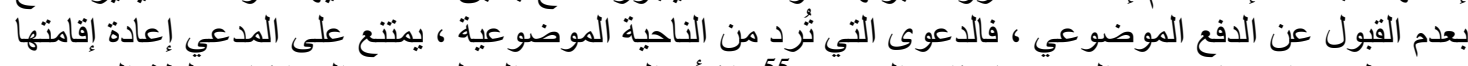

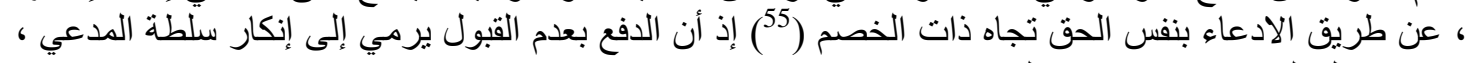

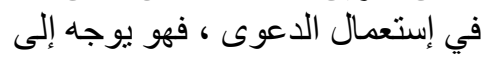

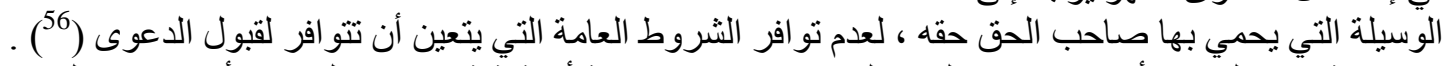

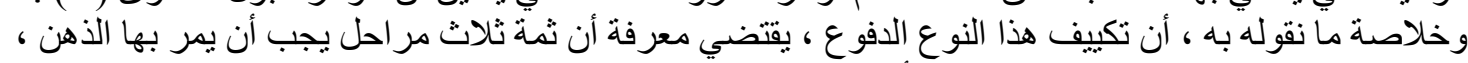

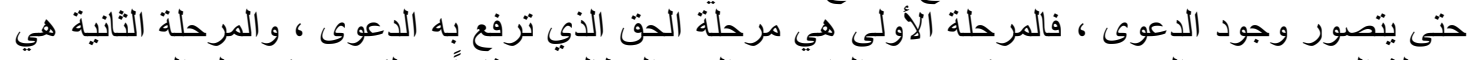

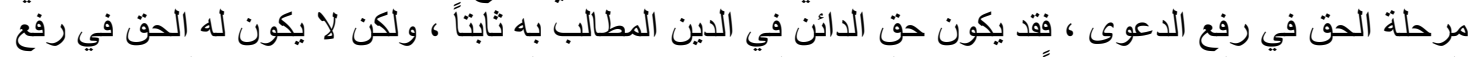

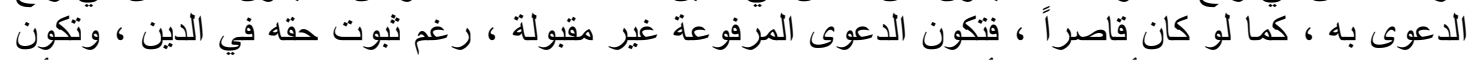

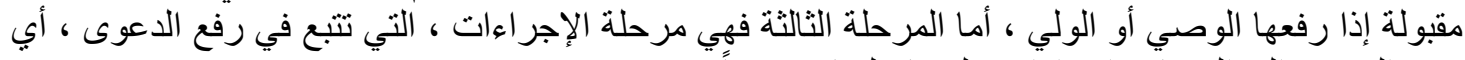

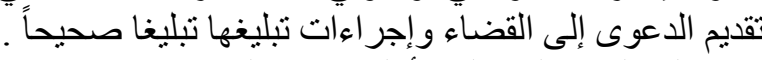

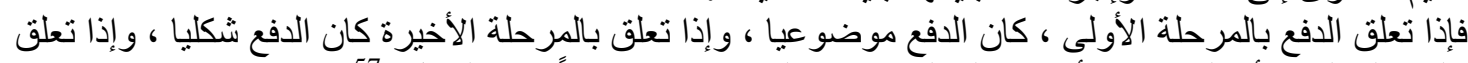

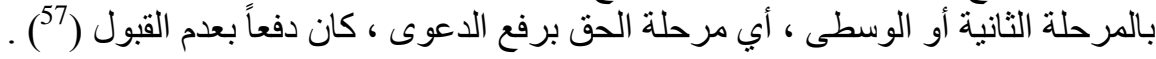

1984 ـ أنظر: د. سعيد مبارك ، و الدكتور آدم وهيب النداوي ، المر افعات الدندية ، وزارة التعليم العالي و البحث العلمي،

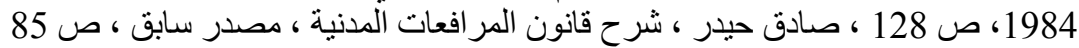

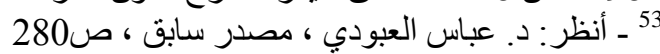

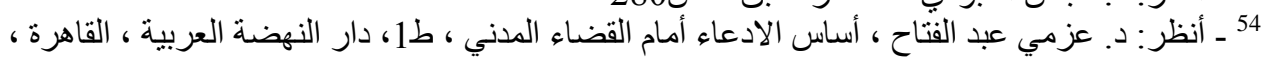

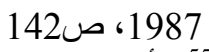

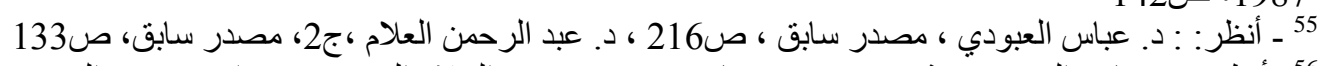

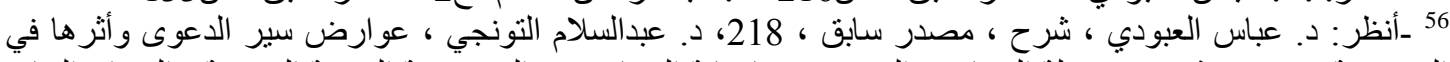

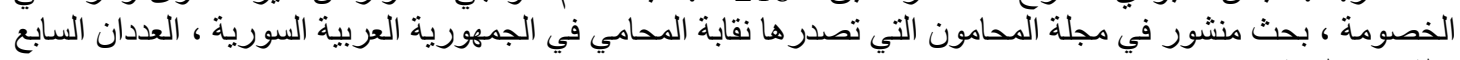

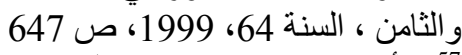

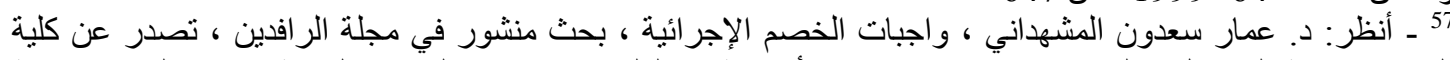

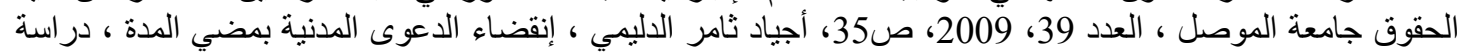

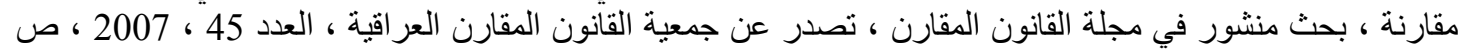




\section{الاعوى المتقابلئة}

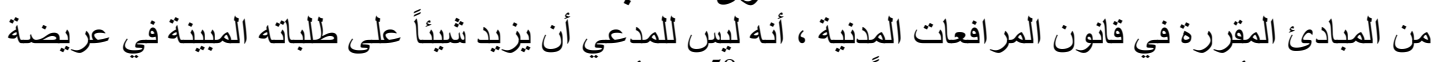

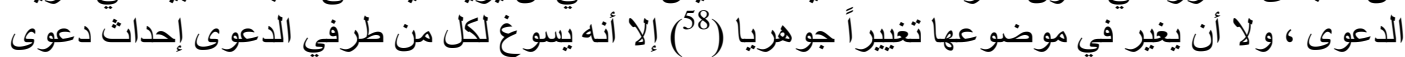

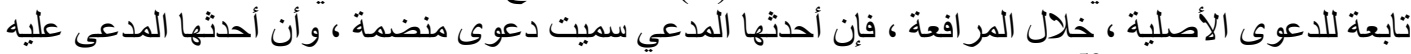

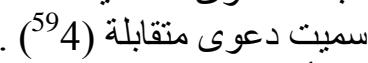

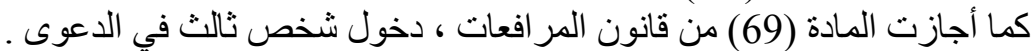

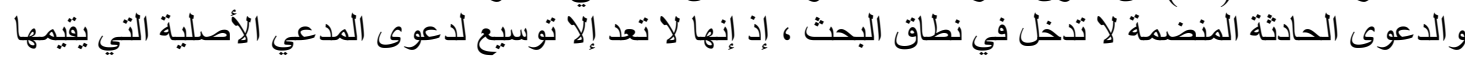

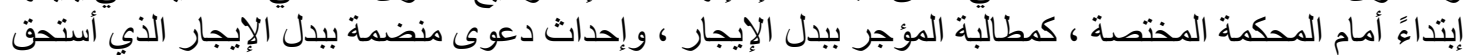

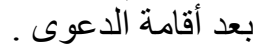

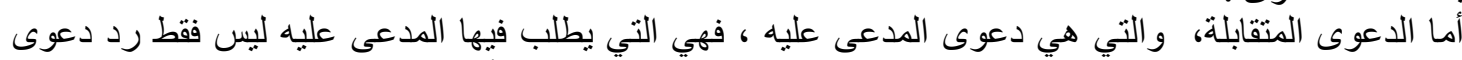

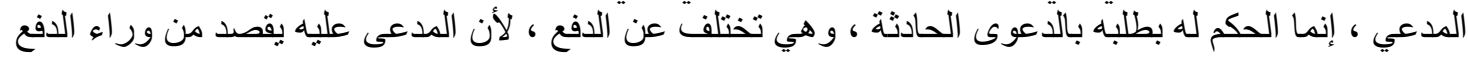

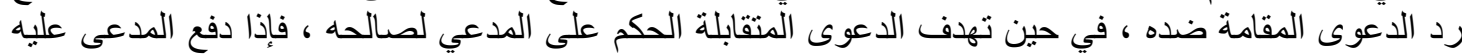

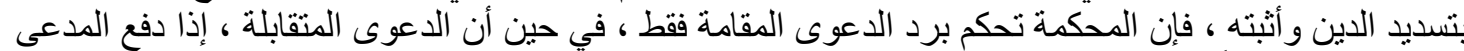

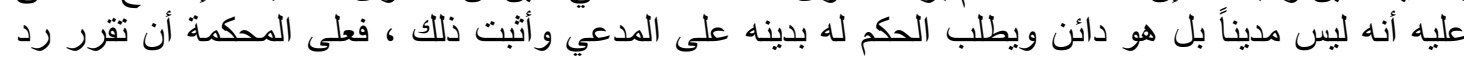

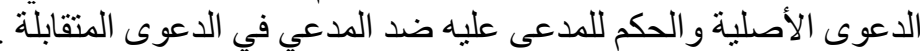

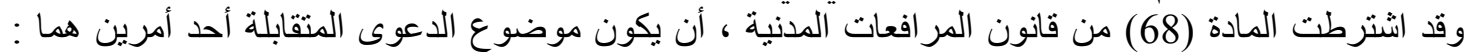

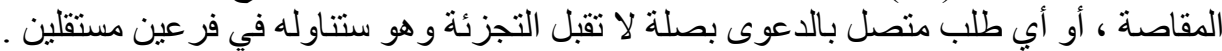

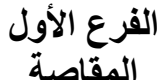

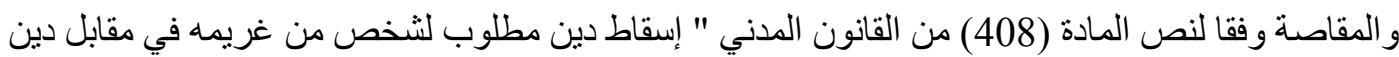

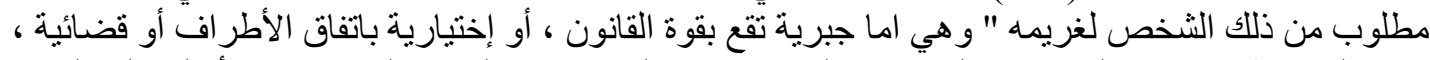

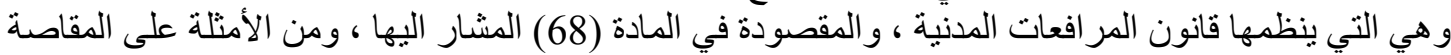

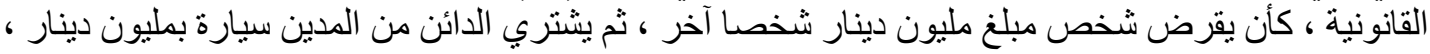

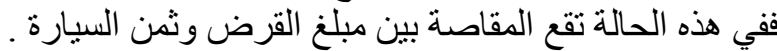

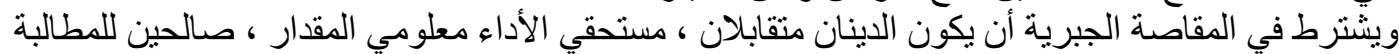

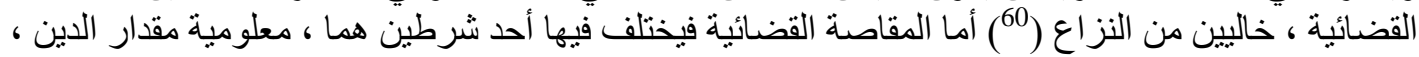

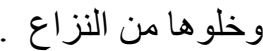

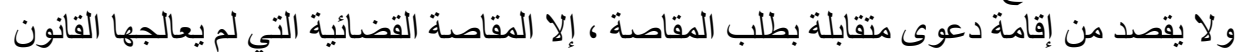

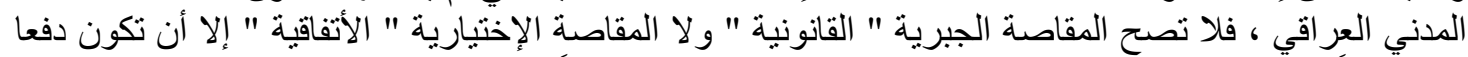

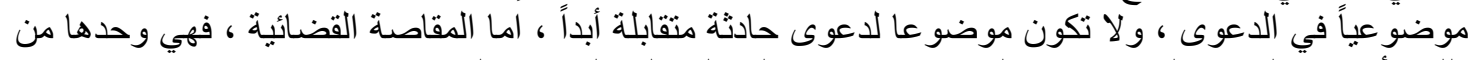

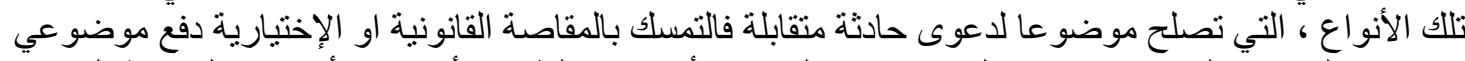

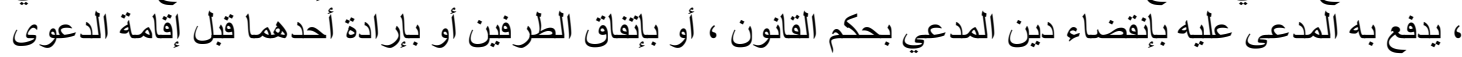

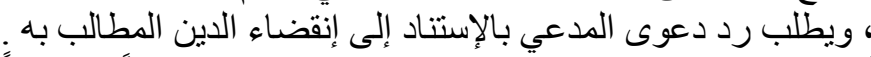

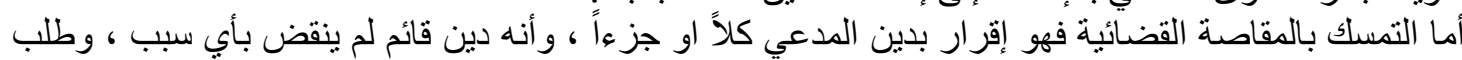

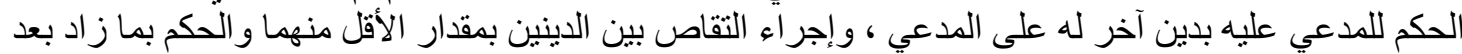

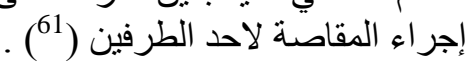

54، د. إبر اهيم أمين النفياوي ، مسؤولية الخصم عن الإجراءات ، أطروحة دكتور اه ، مقدمة إلى كلية الحقوق جامعة عين

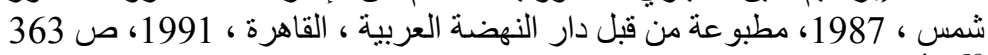

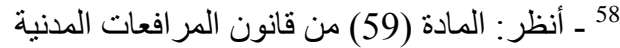

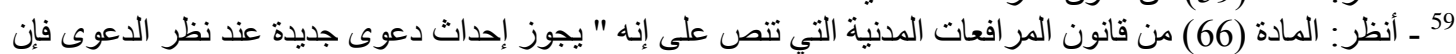

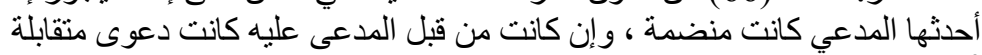

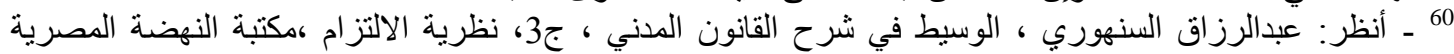




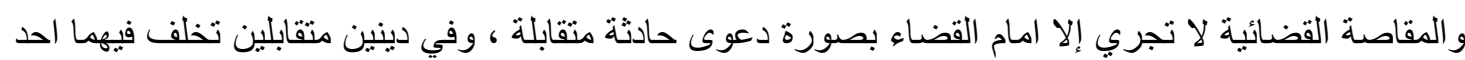

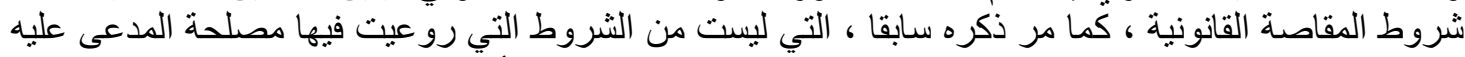

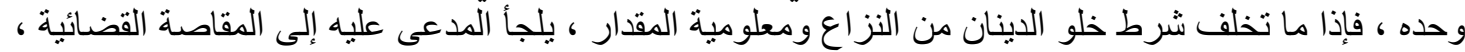

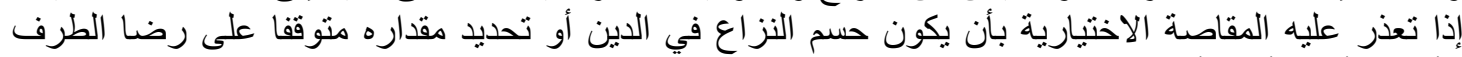

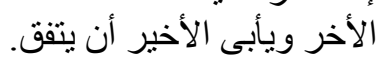

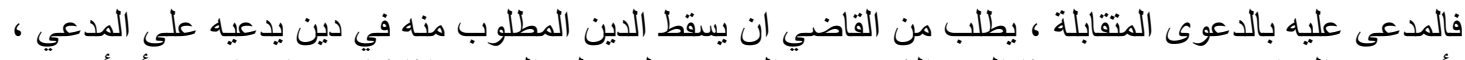

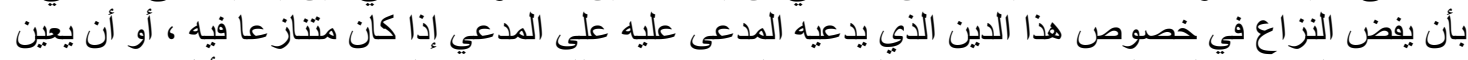

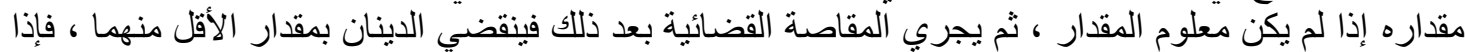

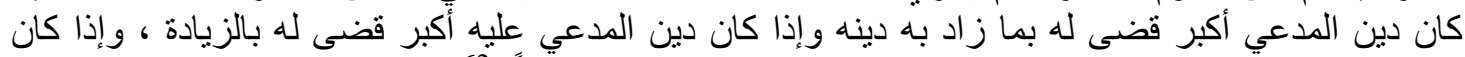

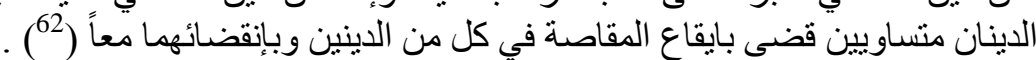

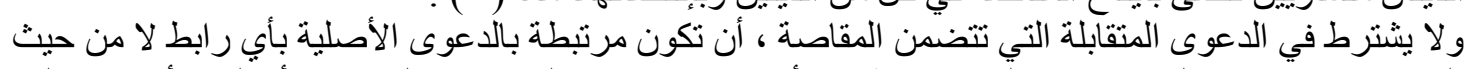

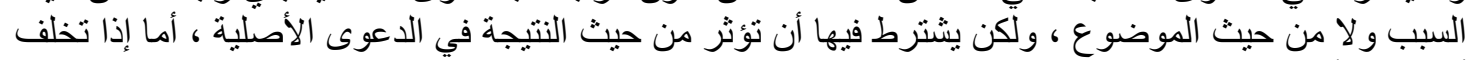

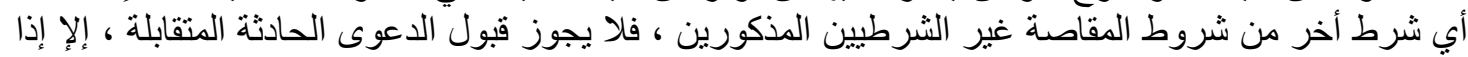

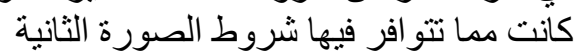

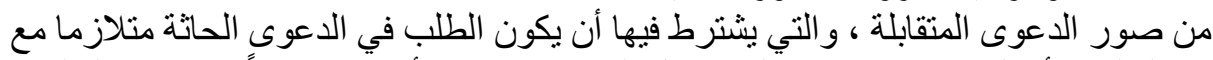

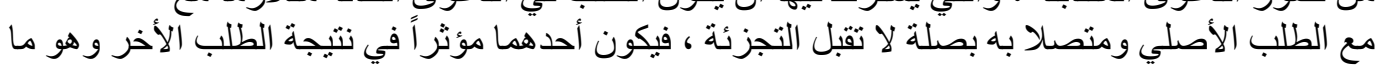

\section{الاعوى المتقابلة في غُير الثقاني} سنعرض اليه في الفرع الثناني .

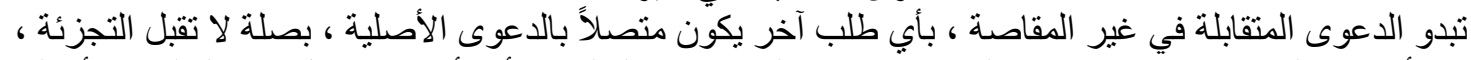

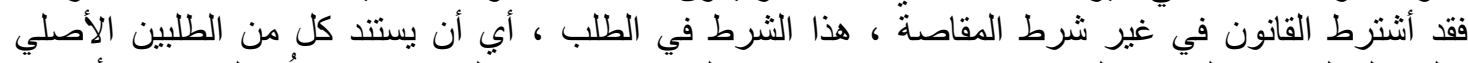

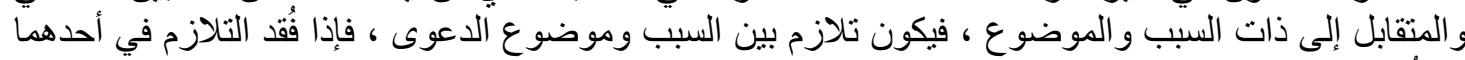

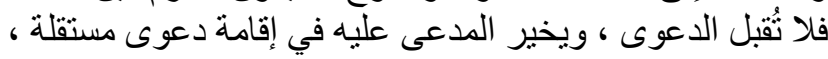

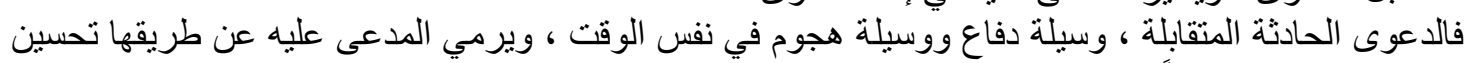

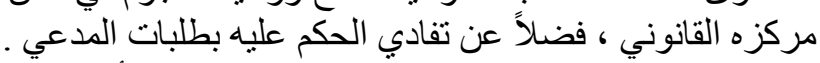

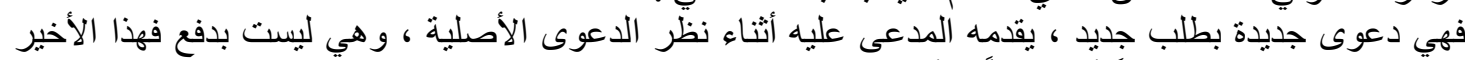

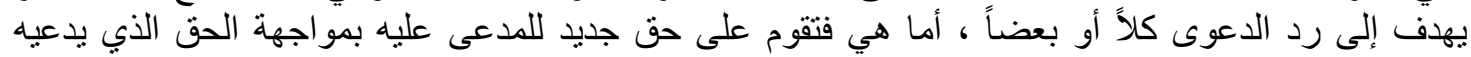

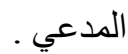

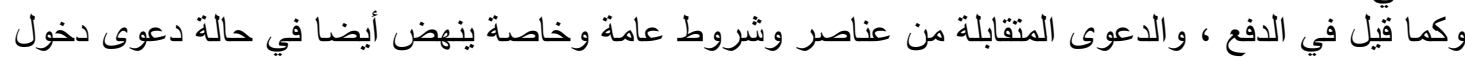

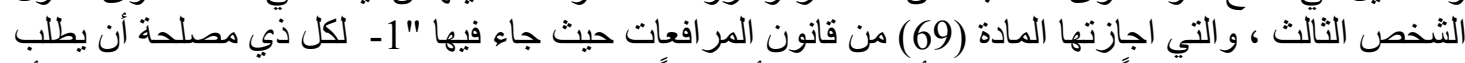

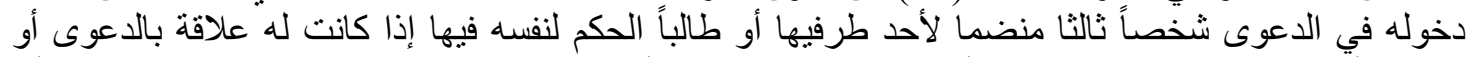

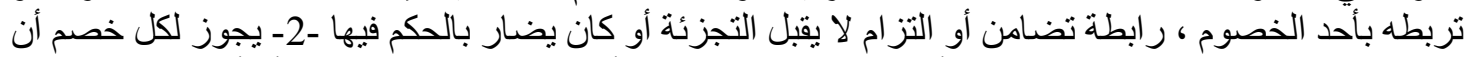

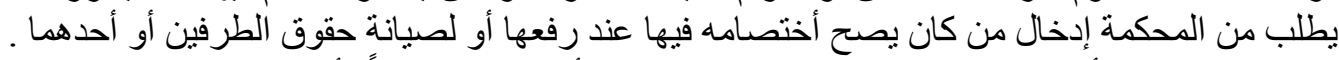

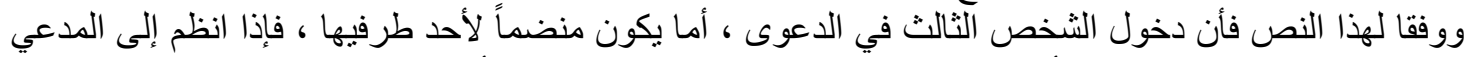

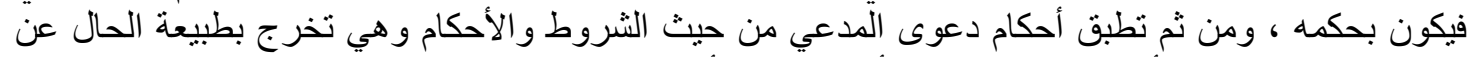

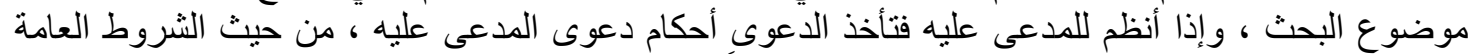

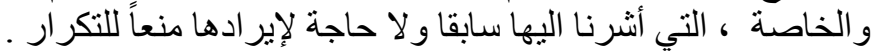

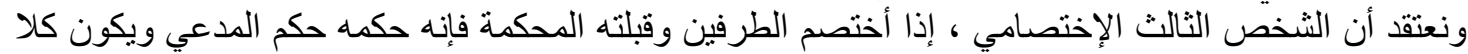

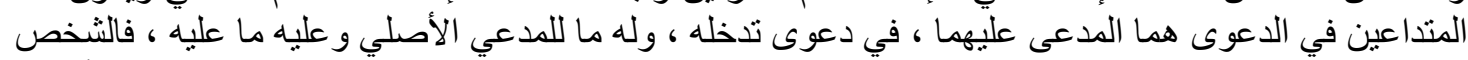

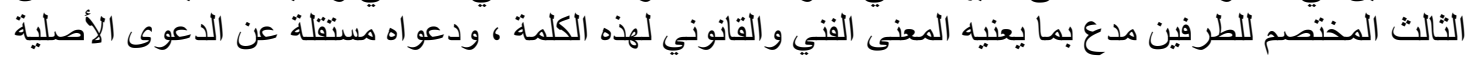

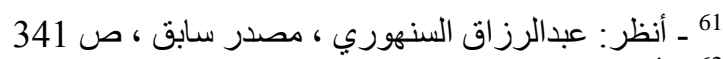
62 ـ ـ أنظر : القاضي رحيم حسن العكيلي ، دراسات في قانون المر افعات المدنية ، ج1، ط1، مكتبة الصباح ، 2006، ص 


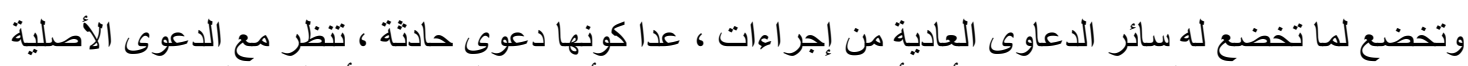

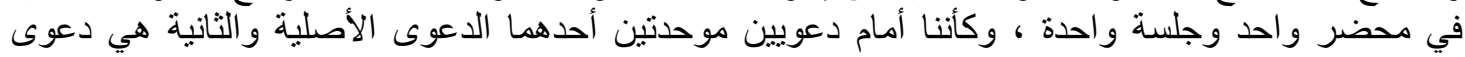

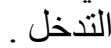

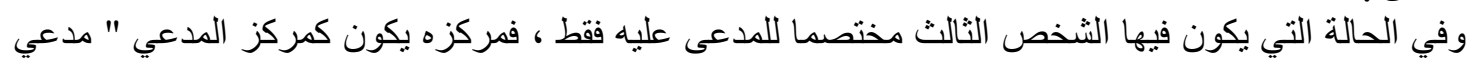

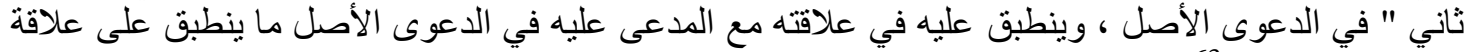

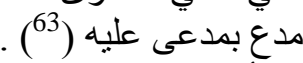

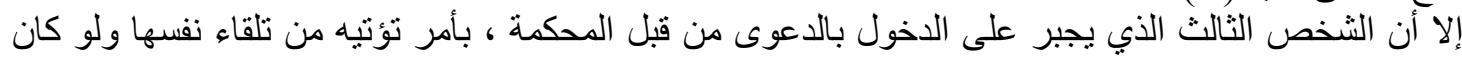

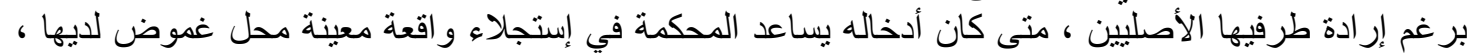

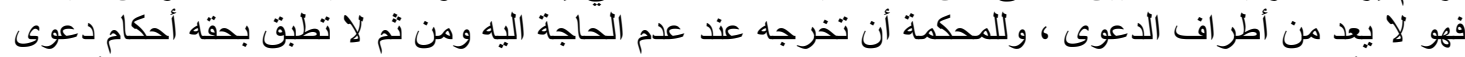

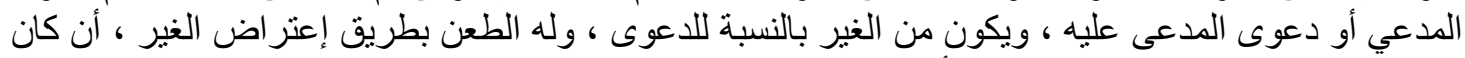

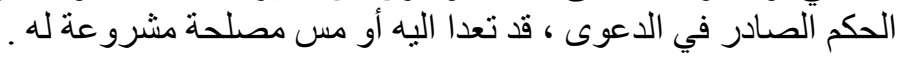

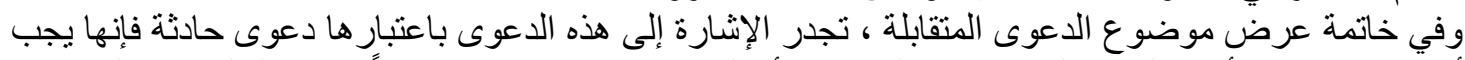

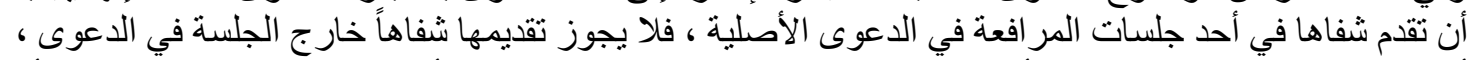

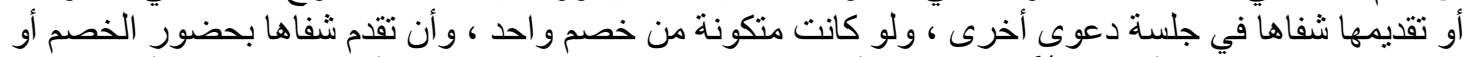

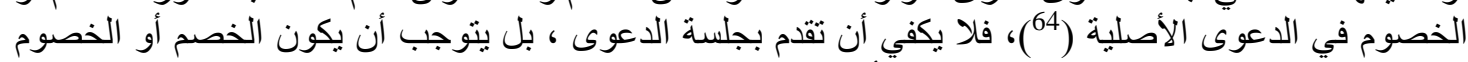

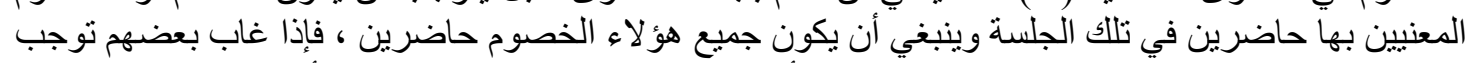

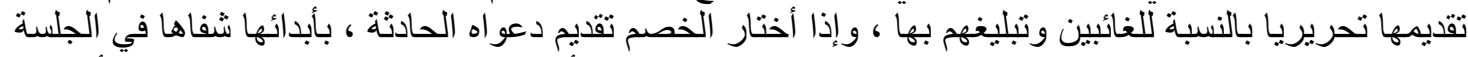

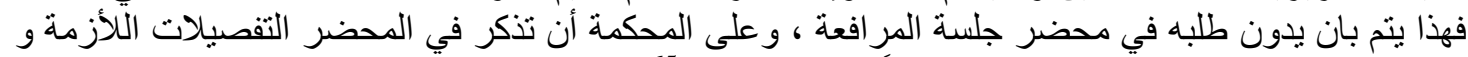

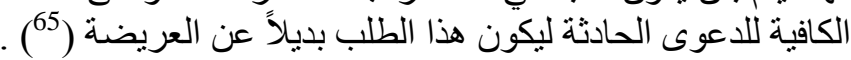

الخاتمة

بعد ان فر غنا من بحث موضو ع دعوى المدعى عليه ، لم يتبقى لنا الا كلمات أخيرة نخصصها للخاتمة لتوضيح

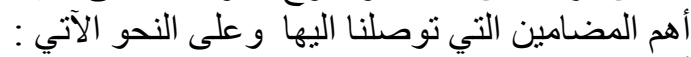

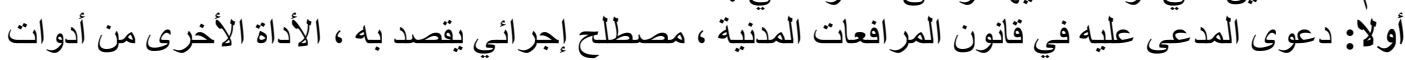

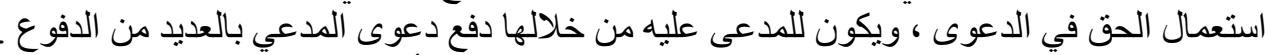

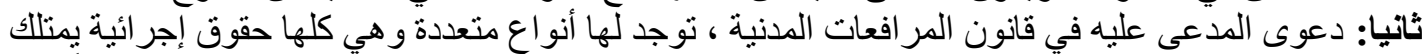

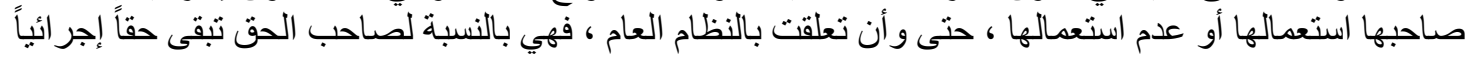

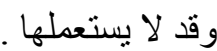

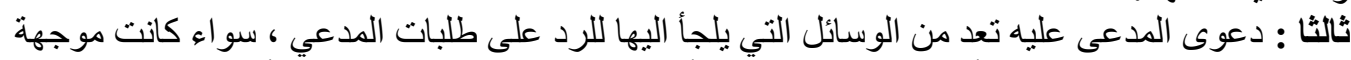

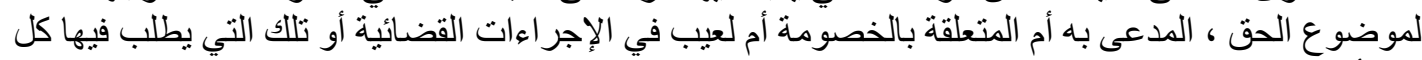

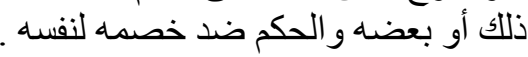

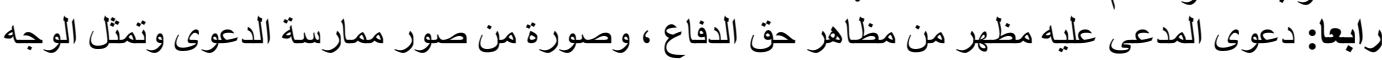

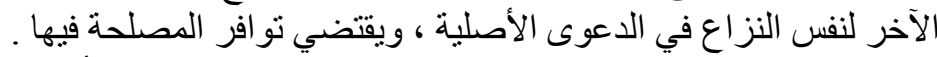

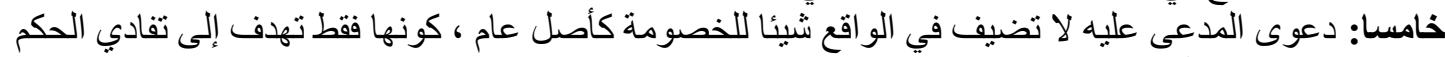

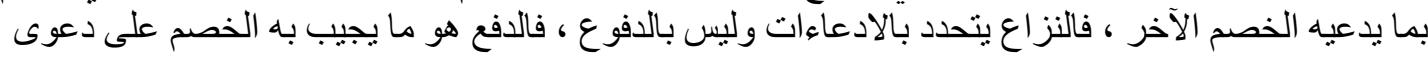

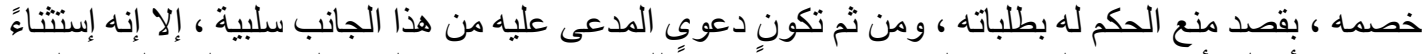

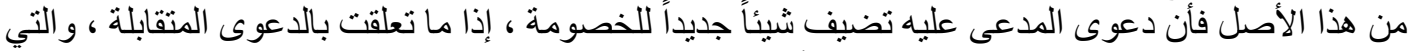

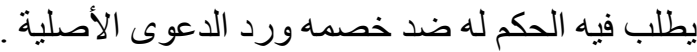

$$
\begin{aligned}
& 63 \text { ـ أنظر : ضياء شيث خطاب ، شرح قانون المر افعات المدنية و التجارية العر اقي ، مصدر سابق ، ص } 67 \text { ، عبدالرحمن }
\end{aligned}
$$

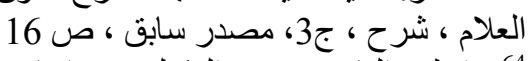

$$
\begin{aligned}
& 64
\end{aligned}
$$

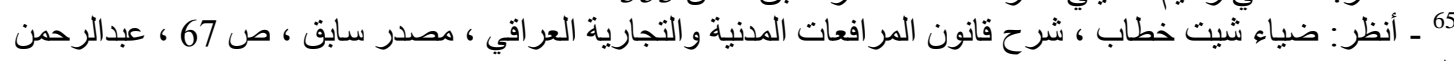

$$
\begin{aligned}
& \text { العلام ، شرح ، ج3، مصدر سابق ، ص } 16
\end{aligned}
$$


العدد (16) ( 2020 (أكتوبر 2020

Volume (16) October 2020

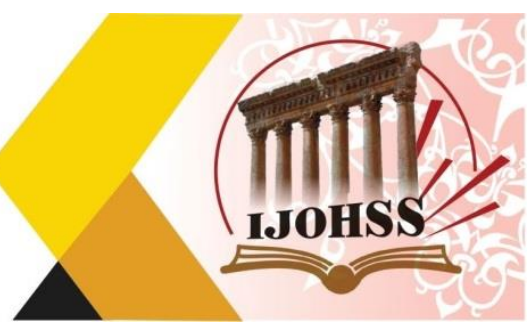

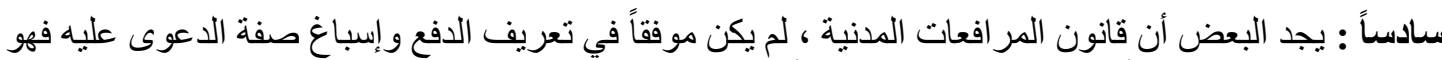

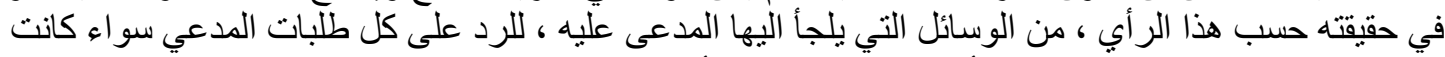

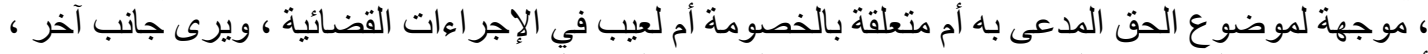

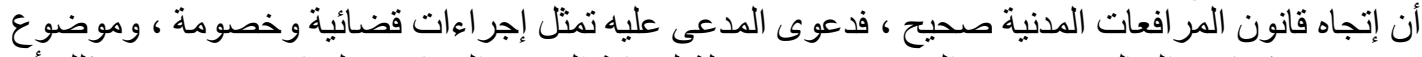

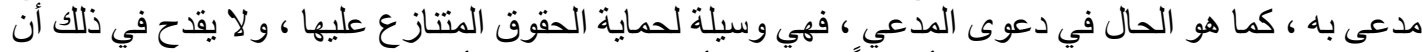

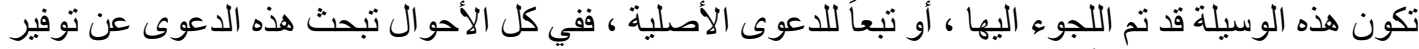

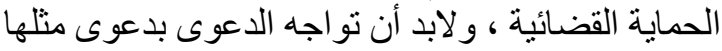

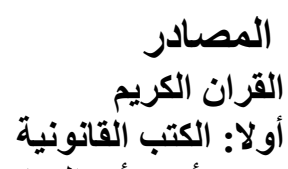

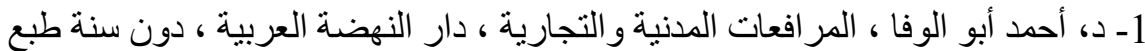

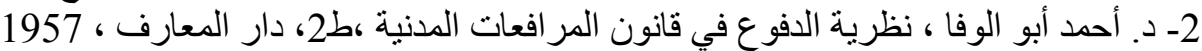

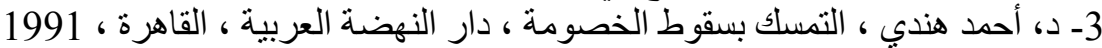

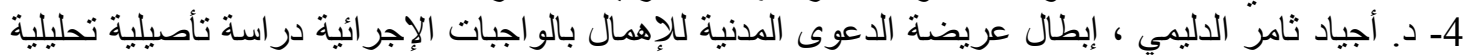

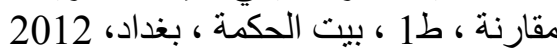

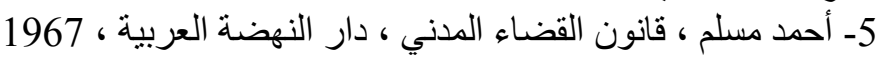

6- القاضي رحيم حسن العكيلي ، دراسات في قانون المر افعات المدنية ، ج1، ط1، مكتبة الصباح ، 2006، ص

7- د. سعيد مبارك و الدكتور آدم و هيب النداوي ، المرافعات المدنية ، وزارة التعليم العالي والبحث العلمي ،

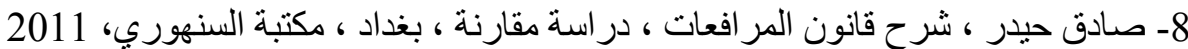

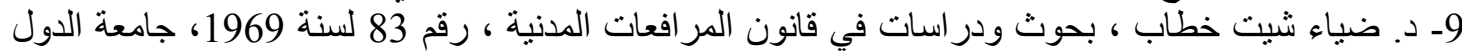
العربية ، القاهرة ، 1970

10-عبدالرزاق السنهوري ، الوسيط في شرح القانون المدني ، ج3، نظرية الالتزام ،مكتبة النهضة المصرية 1958

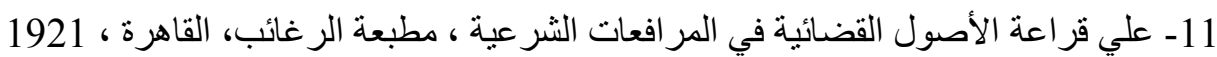

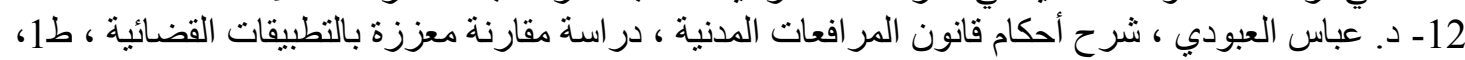

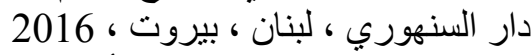

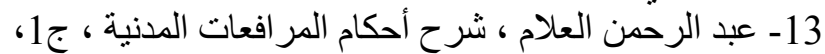

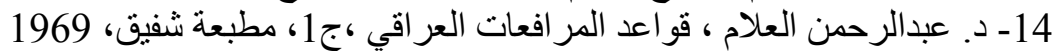

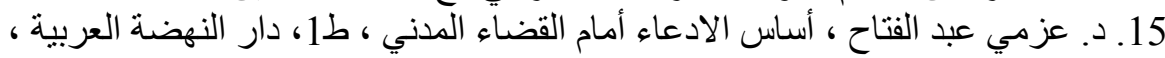

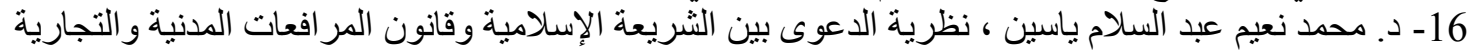

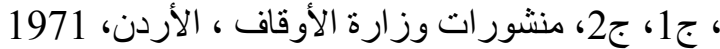

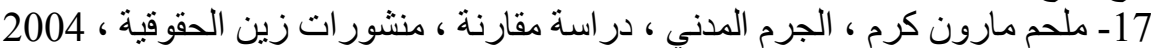

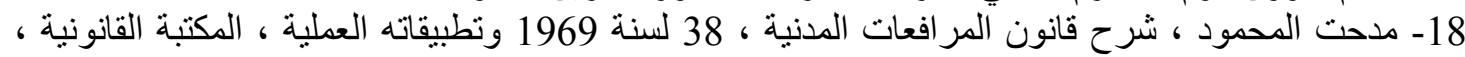

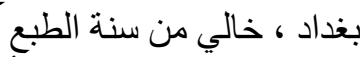

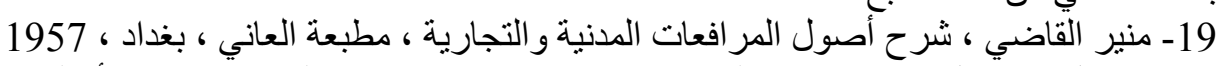
20- د. نبيل إسماعيل عمر ، سقوط الحق في إتخاذ الاجر اء في قانون المر افعات ، منثأة المعارف ، الإسكندرية ،

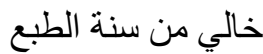
21- د. نبيل إسماعيل عمر ، الدفع بعدم القبول ونظامه القانوني في قانون المر افعات المدنية و التجارية ، دار

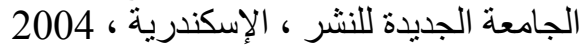

22- د. وجدي ر اغب، النظرية العامة للعمل القضائي ، الإسكندرية ، مصر ، 1974 
العدد (16) أكتوبر 2020

Volume (16) October 2020

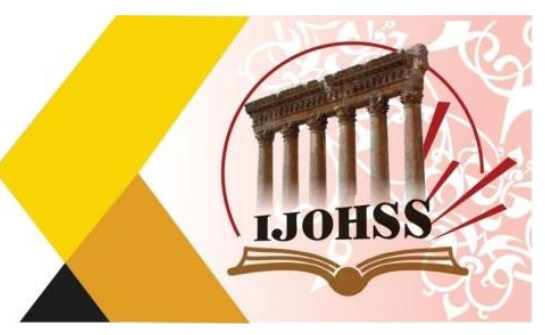

ثانيا : كتب الفقه والحديث

1أُبو الفضل جمال الدين محمد مكرم ابن منظور الافريقي المصري ، لسان العرب ، ج5،ط6،دار صادر ،

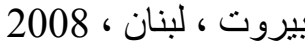

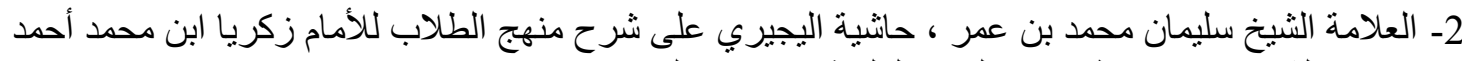
الانصاري الثافعي ، ج4، ط1، دار الكتب العلمية ، بيروت، لبنان البنان ،

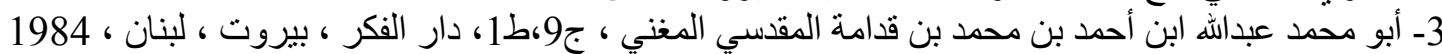

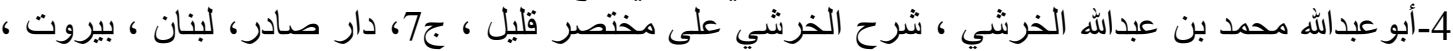

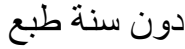

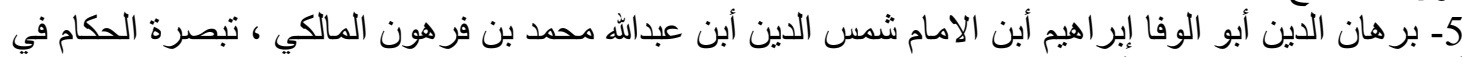

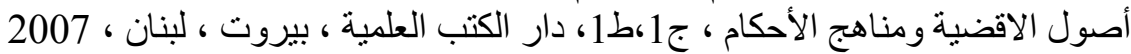

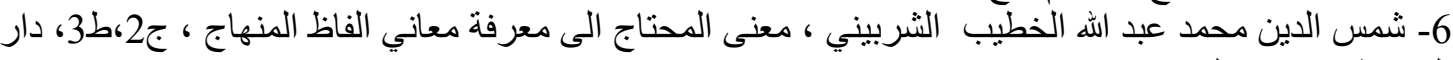

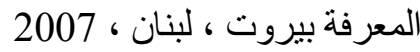

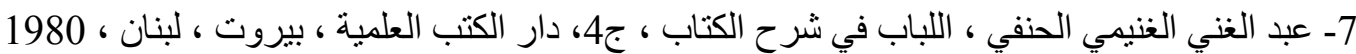

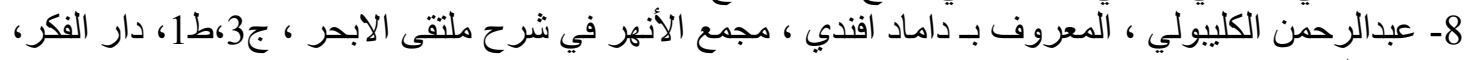
بيروت، لبنان،

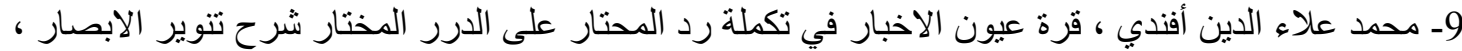

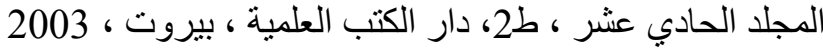

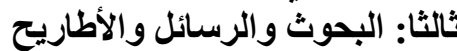

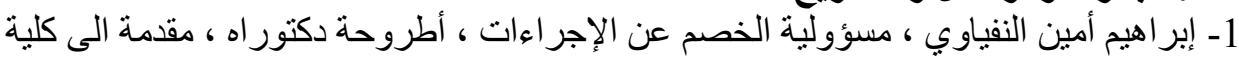

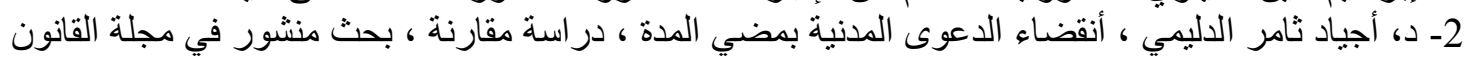

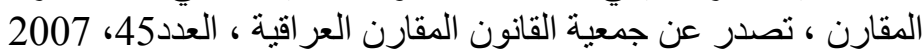

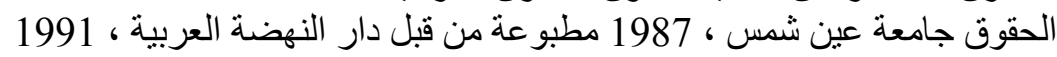

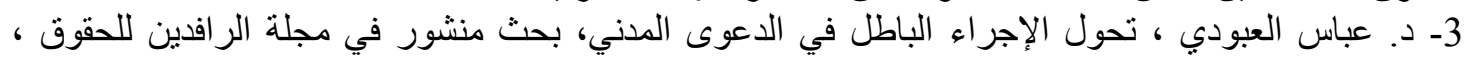
تصدر عن كلية الحقوق في جامعة الموصل ، ، العدد 5 ، 1998

4-د. عمار سعدون المشهداني ، واجبات الخصم الإجرائية ، بحث منشور في مجلة الر افدين ، تصدر عن كلية

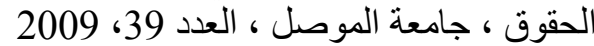

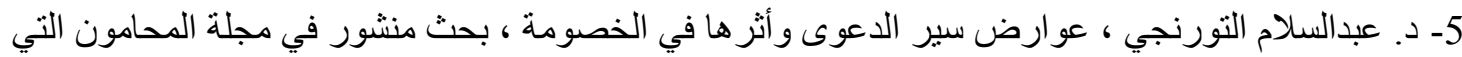
تصدر ها نقابة المحامين في الجمهورية العربية السورية ، العوبية العددان السابع و الثامن ، السنة 64 ، 1999 رابعا : المعاجم اللغوية والتقانونية المدية

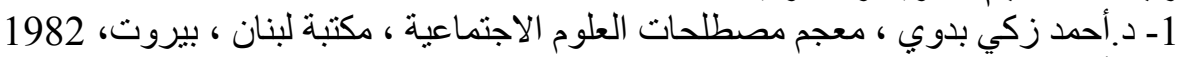

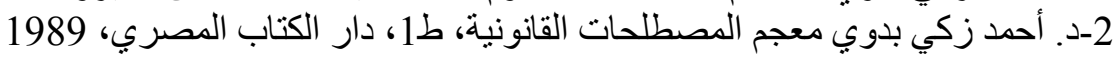

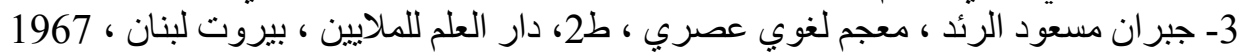

خامسا: القوانين

1-قانون المر افعات المدنية رقم 83 لسنة 1969

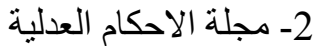
3-فانون الرسوم العدلية رقم 114 لسنة العالية 4-القانون المدني العر اقي رقم 40 لسنة 1951 


\section{المجلة اللحولية اللملوم الآنسانية والإمتماعية}

International Journal of Humanities and Social Sciences

website:www.ijohss.com Emailseditor@ijohss.com

ISSN: $2415-4822$

العدد (16) أكتوبر 2020

Volume (16) October 2020

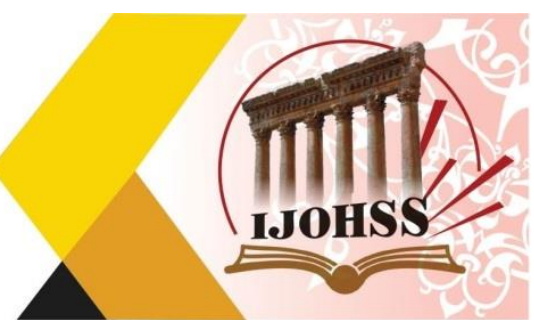

\section{References}

\section{First: Law books}

1- Dr. Ahmad Abu Al-Wafa, Civil and Commercial Pleadings, Dar Al-Nahda AlArabiya, without a year of printing

2- Dr. Ahmad Abu Al-Wafa, The Theory of Defenses in the Civil Procedure Law, 2nd Edition, Dar Al-Maarif, 1957

3- Dr. Ahmed Hindi, Adherence to the Fall of the Opposition, Dar Al-Nahda AlArabiya, Cairo, 1991

4- Dr. Ajyad Thamer Al-Dulaimi, Annulment of the Civil Case Petition for Negligence of Procedural Duties, Comparative Analysis and Originality Study, 1st Edition, House of Wisdom, Baghdad, 2012

5- Ahmed Muslim, Civil Justice Law, Arab Renaissance House, 1967

6- Judge Rahim Hassan Al-Aqili, Studies in the Civil Procedure Law, Part 1, 1st Edition, Al-Sabah Library, 2006, p. 243

7- Dr. Saeed Mubarak and Dr. Adam Wahib Al-Nadawi, Civil Procedures, Ministry of Higher Education and Scientific Research, 1984

8- Sadiq Haidar, Explanation of the Procedure Law, a comparative study, Baghdad, Al-Sanhouri Library, 2011

9- Dr. Diaa Shit Khattab, Research and Studies in the Civil Procedure Law, No. 83 of 1969, League of Arab States, Cairo, 1970

10- Abdel Razzaq Al-Sanhouri, Mediator in Explaining Civil Law, Part 3, The Theory of Commitment, The Egyptian Renaissance Library, 1958

11- Ali Karaa, Judicial Principles of Legal Pleadings, Al-Raghaib Press, Cairo, 1921

12- Dr. Abbas Al-Aboudi, Explanation of the provisions of the Civil Procedure Law, a comparative study reinforced by judicial applications, 1st Edition, Dar Al-Sanhouri, Lebanon, Beirut, 2016

13- Abd al-Rahman al-Allam, Explanation of the Rulings on Civil Procedures, Part 1,

14- Dr. Abdul Rahman Al-Allam, Iraqi Procedural Rules, C1, Shafiq Press, 1969

15. Dr. Azmi Abdel-Fattah, The Basis of the Prosecution before the Civil Court, 1st floor, Dar Al-Nahda Al-Arabiya,

16- Dr. Muhammad Na im Abd al-Salam Yassin, The Case Theory between Islamic Law and the Law of Civil and Commercial Procedures, C1, C2, Publications of the Ministry of Awqaf, Jordan, 1971

17- Melhem Maroun Karam, Civil Crime, A Comparative Study, Zain Legal Publications, 2004

18- Medhat Al-Mahmoud, Explanation of the Civil Procedure Law, 38 of 1969 and its practical applications, The Legal Library, Baghdad, free of the year of printing

19- Munir Al-Qadi, Explanation of the Origins of Civil and Commercial Pleadings, Al-Ani Press, Baghdad, 1957

20- Dr. Nabil Ismail Omar, Discontinuation of the Right to Take Action in the Law of Procedures, Maarif Establishment, Alexandria, Free of the Year of Publication 21- Dr. Nabil Ismail Omar, Advocacy of non-acceptance and its legal system in the Civil and Commercial Procedure Law, New University House for Publishing, Alexandria, 2004 


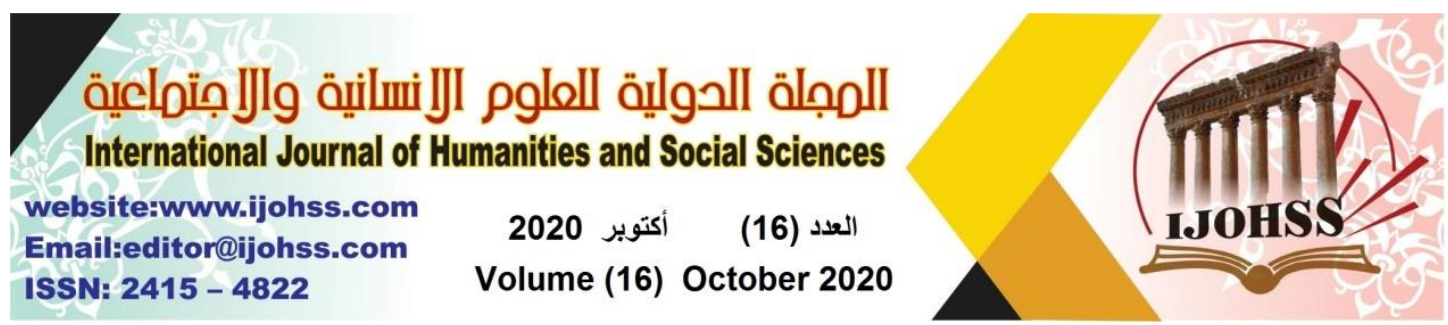

22- Dr. Wagdy Ragheb, The General Theory of Judicial Work, Alexandria, Egypt, 1974

\section{Second: Books of Fiqh and Hadith}

1- Abul-Fadl Jamal Al-Din Muhammad Makram Ibn Manzoor Al-Afriqi Al-Masry, Lisan Al-Arab, vol.5, 6th floor, Dar Sader, Beirut, Lebanon, 2008

2- The scholar Sheikh Suleiman Muhammad bin Omar, a footnote to al-Jijiri on explaining the curriculum of the students of Imam Zakaria Ibn Muhammad Ahmad alAnsari al-Shafi'i, vol. 4, First Edition, Dar al-Kutub al-Ilmiyya, Beirut, Lebanon, 2000 3- Abu Muhammad Abdullah Ibn Ahmad Ibn Muhammad Ibn Qudamah Al-Maqdisi Al-Mughni, C9, 1st floor, Dar Al-Fikr, Beirut, Lebanon, 1984

4- Abu Abdullah Muhammad ibn Abdullah al-Khurshi, Sharh al-Khurshi Ali Muqtasar Qalil, Part 7, Sader House, Lebanon, Beirut, without a year of reprint

5- Burhan al-Din Abu al-Wafa Ibrahim Ibn al-Imam Shams al-Din Ibn Abdullah Muhammad ibn Farhun al-Maliki, The Rulers Brief on the Fundamentals of the Districts and Approaches to Rulings, Part 1, First Edition, Dar al-Kutub al-Ilmiyya, Beirut, Lebanon, 2007

6- Shams Al-Din Muhammad Abdullah Al-Khatib Al-Sherbini, the meaning of the needy to know the meanings of the words Al-Minhaj, Part 2, 3rd Edition, Dar AlMaarifa Beirut, Lebanon, 2007

7- Abd Al-Ghani Al-Ghunaimi Al-Hanafi, Al-Labab Fi Sharh Al-Kitab, Part 4, Dar Al-Kotob Al-Alami, Beirut, Lebanon, 1980

8- Abd al-Rahman al-Kulaybuli, known as Damad Effendi, Al-Anhar Complex in Explaining Al-Bahr Junction, C3, 1st floor, Dar Al-Fikr, Beirut, Lebanon, 1998

9- Muhammad Ala Al-Din Effendi, Qurat Uyun Al-Akhbar in Complementing the Response of the Confused to the Mukhtar Durar, Explanation of Enlightenment AlSisar, Volume Eleven, Edition 2, Dar Al-Kutub Al-Ilmiyya, Beirut, 2003

\section{Third: Research and dissertations}

1- Ibrahim Amin Al-Nafiawi, Responsibility of the Adversary for Procedures, PhD thesis, submitted to the College

2- Dr. Ajyad Thamer Al-Dulaimi, The Civil Case Lapse By The Lapse Of Time, A Comparative Study, A Research Published In The Journal Of Comparative Law, Issued By The Iraqi Comparative Law Association, Issue 45, 2007

Law Ain Shams University, 1987 printed by the Arab Renaissance House, 1991

3- Dr. Abbas Al-Aboudi, The Invalid Procedure Transformation in the Civil Case, a research published in Al-Rafidain Journal of Law, issued by the Faculty of Law at the University of Mosul, Issue 5, 1998

1987

4-Dr. Ammar Saadoun Al-Mashhadani, The Adversary's Procedural Duties, a research published in Al-Rafidain Magazine, issued by the Faculty of Law, University of Mosul, Issue 39, 2009 


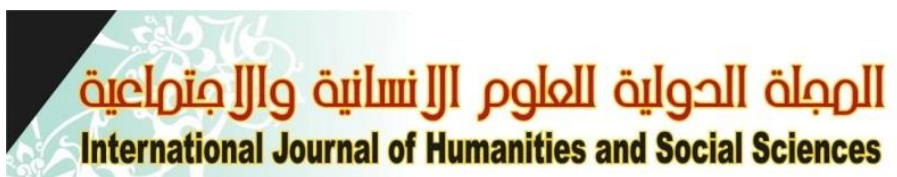
website:www.ijohss.com Email:editor@ijohss.com ISSN: $2415-\mathbf{4 8 2 2}$

$\begin{array}{cc}2020 & \text { ألعدد (16) } 2020 \\ \text { Volume (16) October } 20\end{array}$

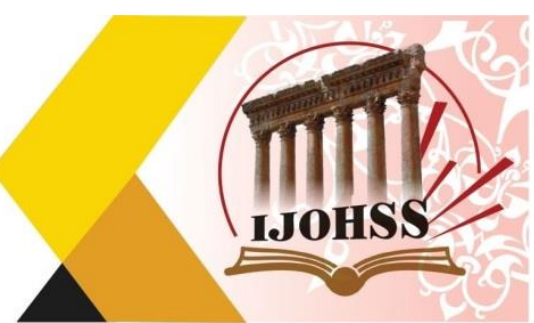

5- Dr. Abdul Salam Al-Turingi, Symptoms of the Case's Course and Their Impact on the Litigation, a research published in the Lawyers' Journal issued by the Bar Association in the Syrian Arab Republic, Issues Seven and Eight, Year 64, 1999

\section{Fourth: linguistic and legal dictionaries}

1- Dr. Ahmed Zaki Badawi, Dictionary of Social Sciences Terms, Lebanon Library, Beirut, 1982

2-D. Ahmed Zaki Badawi, Dictionary of Legal Terms, 1st Edition, The Egyptian Book House, 1989

3- Gibran Masoud Al-Raed, A Modern Linguistic Dictionary, 2nd Edition, Dar AlAlam Al-Mali'a, Beirut, Lebanon, 1967

\section{Fifth: Laws}

1- Civil Procedure Law No. 83 of 1969

2- The Journal of Judicial Rulings

3- Legal fees Law No. 114 of the year

4- Iraqi Civil Law No. 40 of 1951 